\title{
A DESCRIPTION OF GLIMPCE, 1986, LARGE OFFSET \\ SEISMIC EXPERIMENT FROM THE GREAT LAKES
}

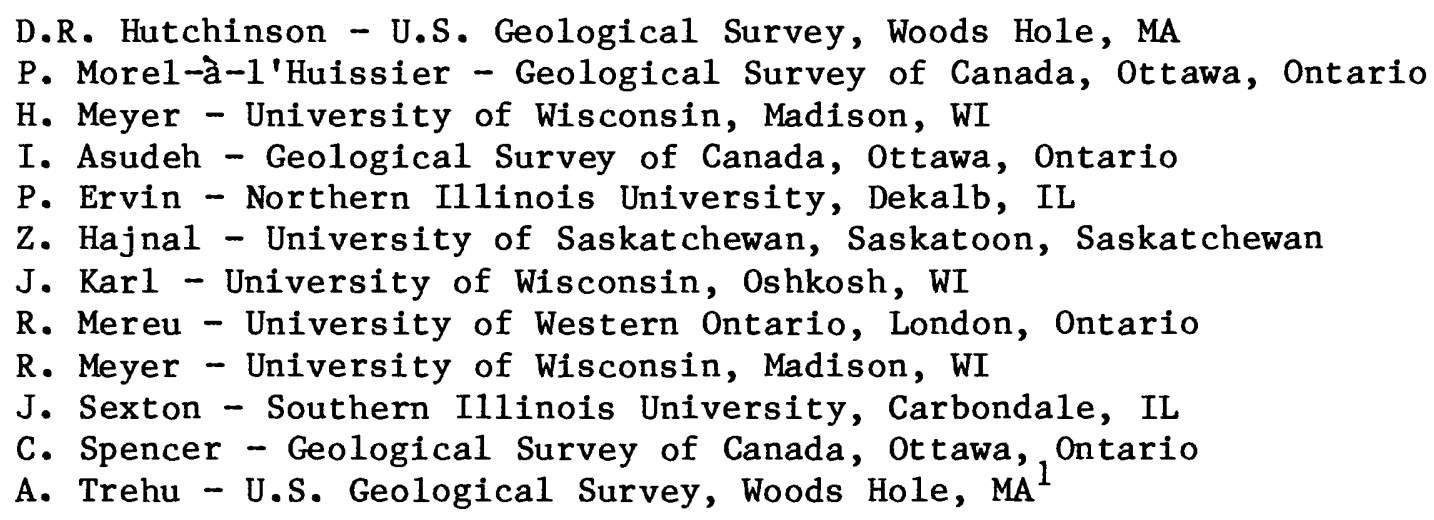

U. S. Geological Survey Open-file Report 88-431

This report is preliminary and has not been reviewed for conformity with U.S. Geological Survey editorial standards and stratigraphic nomenclature. Any use of trade names is for descriptive purposes only and does not imply endorsement by the U. S. Geological Survey, by the Geological Survey of Canada, or by any of the participating universities.

1 Present address: Oregon State University, Corvallis, OR 
List of Tables.........................................

List of Figures........................................

Introduction.........................................

Experiment Overview.......................................

objectives.....................................

Summary.........................................

Marine Seismic Survey.$\ldots \ldots \ldots \ldots \ldots \ldots \ldots \ldots \ldots \ldots \ldots \ldots \ldots \ldots \ldots \ldots \ldots \ldots \ldots \ldots$

Airgun Array $\ldots \ldots \ldots \ldots \ldots \ldots \ldots \ldots \ldots \ldots \ldots \ldots \ldots \ldots \ldots \ldots \ldots \ldots \ldots$

Navigation.......................................

Shot time determination.............................

Bathymetry.....................................

Brief Chronology $\ldots \ldots \ldots \ldots \ldots \ldots \ldots \ldots \ldots \ldots \ldots \ldots \ldots \ldots \ldots \ldots$

Experimental Details.....................................

Line A - refraction (L. Superior) ....................

Line A - refraction (L. Superior) .....................

Line B - (L. Superior) ..............................

Line C - (L. Superior) ............................

Line F - (L. Superior) ............................

Line G - (L. Superior)............................

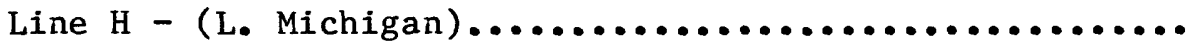

Line I - (L. Huron) $\ldots \ldots \ldots \ldots \ldots \ldots \ldots \ldots \ldots \ldots \ldots \ldots \ldots \ldots \ldots \ldots$

Line J - L. Huron) ................................

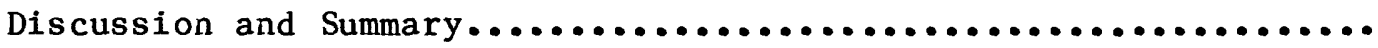

Acknowledgements.......................................

References...............................................

Tables...............................................

Appendix I: Instrument Details and Personnel................. 


\section{List of Tables}

Page No.

Table 1: Summary of Stations occupied in GLIMPCE'86 Experiment.... 11

Table 2: Start and End Information for Marine Seismic Lines...... 12

Table 3: $\quad$ Summary of stations occupied for Line A - refraction..... 13

Table 4: $\quad$ Summary of stations occupied for Line A - reflection..... 14

Table 5: Summary of stations occupied for Line B.............. 15

Table 6: Summary of stations occupied for Line C.............. 16

Table 7: Summary of stations occupied for Line F.............. 17

Table 8: $\quad$ Summary of stations occupied for Line G.............. 18

Table 9: $\quad$ Summary of stations occupied for Line H.............. 19

Table 10: Summary of stations occupied for Line I.............. 20

Table 11: Summary of stations occupied for Line J.............. 21 
Figure 1: Location of GLIMPCE multichannel seismic reflection lines and stations used to record wide-angle and

Figure 2: Source and streamer configuration for GLIMPCE marine multichannel profiles..........................

Figure 3: Bathymetric profiles associated with each GLIMPCE shot line.

Figure 4: Shot and station locations for line A - refraction......

Figure 5: Shot and station locations for line A - reflection.....

Figure 6: Shot and station locations for line B............... 33

Figure 7: Shot and station locations for line c.............. 35

Figure 8: Shot and station locations for line F.............. 37

Figure 9: Shot and station locations for line G.............. 39

Figure 10: Shot and station locations for line H.............. 41

Figure 11: Shot and station locations for line I.............. 43

Figure 12: Shot and station locations for line J............. 45 
In late summer of 1986, eight U.S. and Canadian academic and government groups deployed 137 seismometers and land geophone arrays at 86 locations in and around the upper Great Lakes to passively record airgun shots fired as part of a deep-penetration marine multichannel seismic reflection program of the Great Lakes International Multidisciplinary Program on Crustal Evolution (GLIMPCE). Vertical components were recorded in all locations; horizontal components were recorded in 43 locations. The primary objective of recording the refracted, wide-angle reflected, and fan arrivals was to provide information on crustal velocity structure to supplement images recorded on the eight deep-penetration marine reflection profiles (five in Lake Superior, one in Lake Michigan, and two in Lake Huron). One of the Lake Superior lines was reshot to optimize recording of the large offset data. This report gives a data summary of the field operations related to the large-offset data. 


\section{INTRODUCTION}

The Great Lakes International Multidisciplinary Program on Crustal Evolution (GLIMPCE), comprises United States and Canadian government, academic and industry geoscientists interested in the evolution of the midcontinent region of North America. GLIMPCE was formed in late 1985 to direct and coordinate future research around the Great Lakes. The first major experiment (August-September, 1986) was funded by the U.S. Geological Survey (USGS) and the Geological Survey of Canada (GSC) and utilized a large marine seismic airgun source for simultaneous acquisition of nine normal-incidence multichannel reflection and wide-angle reflection/refraction profiles in Lakes Superior, Michigan, and Huron (fig. 1). Passive recording of large offset information from all lines was done by eight academic and government groups. Together, the multichannel reflection data and the wide-angle reflection/refraction data provide an impressive and unprecedented data set for studying the deep crust and velocity structure of the midcontinent region.

This report describes the details of the field operations in which the large-offset reflection/refraction data were collected. Details of the nearvertical deep-penetration multichannel reflection profiles are included where relevant to the acquisition of the wide-angle data. A summary of the acquisition and processing parameters used for the contract multichannel seismic survey is given in Lee and others (1988) and Milkereit and others (1988). No effort is made to judge data quality or present interpretations.

\section{EXPERIMENT OVERVIEW}

Objectives: This first major seismic experiment was designed to investigate the tectonic framework and regional velocity structure of the crust in the Great Lakes region. Specific targets were the midcontinental geophysical anomaly, the Keweenawan rift, the Grenville Front, the Penokean and Huronian fold belts, and the Hemlo and Michipicoten greenstone belts.

Summary: The experiment is most easily divided into two parts: a normal incidence, deep-penetration multichannel reflection survey and a large-offset refraction/wide-angle reflection survey. The vertical reflection data comprise eight lines that were shot using a state-of-the-art marine multichannel acquisition system (lines A-C, F-I, fig. 1).

The large-offset data, consisting of wide-angle reflection, refraction and fan (i.e., of $f-l i n e$ ) arrivals, were recorded by seismometers located around the lakes during shooting of the eight offshore profiles. A ninth line was shot on equally spaced firing times and recorded by seismometers located within and around Lake Superior. This refraction line, Line A-refraction, essentially overlies line A-reflection, and is not plotted as a separate line on Figure 1.

In total, $1350 \mathrm{~km}$ of multichannel reflection data were collected; shots for the refraction profile covered an additional $214 \mathrm{~km}$. Throughout the survey, large-offset data were recorded at 137 stations in 86 locations (table 1), including five ocean-bottom seismometers within Lake Superior and three multichannel arrays positioned around the lakes. Vertical components were recorded in all locations; horizontal components were recorded in 43 locations. Recording stations for individual lines ranged from 5 (line I) to 31 (line A-Refraction). 
The research groups who provided instruments for acquisition of the large-offset data included two federal surveys (USGS and GSC), two Canadian

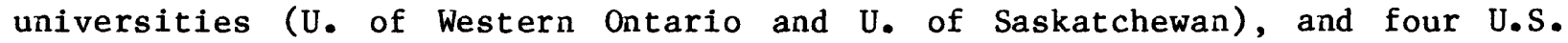
universities ( $U$. of Wisconsin-Madison, $U$. of Wisconsin-0shkosh, Southern Illinois U., and Northern Illinois U.). Additional personnel who participated in the field work were from U.S. Department of Energy, U.S. Coast Guard, Geological Survey of Ontario, University of Toronto, and University of Manitoba. Appendix I gives information about participants and instrumental details not covered elsewhere in the report.

\section{MARINE SEISMIC SURVEY}

All data were shot using M/V Fred J. Agnich, a seismic vessel operated by Geophoto Services, Ltd. (GSI, Calgary, Alberta). Five lines were shot in Lake Superior (lines $A, B, C, F, G$ ), one in Lake Michigan (line $H$ ) and two in Lake Huron (lines I, J). Line $A$ in Lake Superior was also shot separately as a refraction line, utilizing the marine airgun array without the multichannel streamer array. Missing line numbers (D, E) have been reserved for speculation lines shot by GSI in Lake Superior that have not been purchased by GLIMPCE. Table 2 summarizes relevant statistical information about the marine lines. All digital navigation, shot instant, and bathymetry data as well as detailed reports from GSI are archived at GSC (Ottawa, Ont) and USGS (Denver, CO, and Woods Hole, MA).

Airgun Array: The source array (fig. 2) consisted of 76 guns, with 60 guns supplying the operating volume of 7780 in $^{3}(127.49 \mathrm{~L})$ and 16 guns providing spare volume of $2110 \mathrm{in}^{3}(34.58 \mathrm{~L})$. Guns were strung on six linear subarrays, each $9.9 \mathrm{~m}$ long, with a tothal array width of $80 \mathrm{~m}$. Gun sizes ranged from $80 \mathrm{in}^{3}(1.31 \mathrm{~L})$ to $160 \mathrm{in}^{3}(2.62 \mathrm{~L})$. Operating pressure was maintained at $1900-2000 \mathrm{psi}(12.8-13.8 \mathrm{MPa})$. Air gun synchronization was provided by GSI TIGER II controller. Array depths were $12 \pm 1 \mathrm{~m}$ in Lake Superior, and $6 \pm 1 \mathrm{~m}$ in Lakes Michigan and Huron. The shallower array depth was used because of shallow water in northern Lake Michigan and in the channel between Georgian Bay and Lake Huron.

Navigation: Primary navigation for all lines was by GEONAV, which utilized doppler sonar velocities to interpolate fixes between transitsatellite updates.

LORAN C provided secondary navigation and a Global Positioning System receiver provided backup (satellite) navigation. All navigation positions refer to the position of the transit satellite antenna, which was located $74 \mathrm{~m}$ in front of the center of the airgun array (fig. 2). Details of the navigation system are given in Appendix II.

Shot time determination: In order to utilize a common time base between the normal incidence reflection data acquired by the contract vessel and the large-offset reflection/refraction data acquired independently during shooting, all times were synchronized to the time of the eastern Geostationary Operational Environmental Satellite (GOES). The shot instant was calculated by adding known internal system delays to the time recorded for the command to fire the guns which was always initiated on a whole second. System delays totalled $.90796 \mathrm{~s}$ for reflection lines and $1.90796 \mathrm{~s}$ for line A-refraction, with additional delays of $.31062 \mathrm{~s}$ for shots coinciding with the change of 
tape of the DFS V acquisition computer, $24.5 \mathrm{~s}$ for all of line A-reflection, and $23.1 \mathrm{~s}$ for SP $970-1880$ for line C. Determination of these delays is given in Appendix II.

Bathymetry: Digital bathymetry was acquired by a $38-\mathrm{kHz}$ fathometer assuming a water velocity of $1470 \mathrm{~m} / \mathrm{s}$. This assumed velocity is valid for Lakes Michigan and Huron, where the average water temperature during the survey was $12^{\circ} \mathrm{C}$ (corresponding to a theoretical fresh water velocity of 1465 $\mathrm{m} / \mathrm{s})$. Because the colder water in Lake Superior would lower the velocity $\left(5^{\circ} \mathrm{C}\right.$ corresponds to a theoretical fresh water velocity of $1432 \mathrm{~m} / \mathrm{s}$ ), water depths there may be slightly overestimated. The fathometer was located $33.5 \mathrm{~m}$ in front of the ship's antenna, or $107.5 \mathrm{~m}$ in front of the center of the airgun array.

The original digital bathymetry provided by the contractor contained frequent gaps and noise of 10 to $50 \mathrm{~m}$ compared to the fathometer strip-chart profile. Final bathymetry was obtained (fig. 3) by (1) plotting the bathymetry at the same scale as the original fathometer strip-charts, (2) adjusting line segments that were reading a constant offset, (3) redigitizing those parts of lines that were either absent or missed the character of the bottom, and (4) applying a 3-point running average to smooth the noisy signal. Because no fathometer record was kept for line A-refraction (although digital bathymetry were recorded), this line was divided into 50-shot increments and smoothed and redigitized in accordance with its agreement to the relevant portions of line A-reflection. No 3-point running average was used for these relatively widely spaced shots.

The smoothed bathymetry is considered to be accurate to within $5 \mathrm{~m}$ of the depth given on the fathometer strip chart, and should be more than accurate enough for topographic corrections to the large-offset data.

Brief Chronology: The experiment began in Lake Superior with shooting of line A-refraction on 31 August - 1 September 1986. After five days of downtime to resolve a navigation problem, multichannel reflection acquisition began with line B on 6 September. Maintaining the ship's speed so as to fire the guns every $50 \mathrm{~m}$ (about every $23 \mathrm{~s}$ ) while recording long records (every 20 s) and keeping the streamer from sinking in the fresh water of the lake proved to be impossible. The shot spacing was therefore adjusted from $50 \mathrm{~m}$ (30-fold data) to $62.5 \mathrm{~m}$ (24-fold data). The change between $50-\mathrm{m}$ and $62.5-\mathrm{m}$ shots on 1ines F (7-8 September) and A (9-10 September) reflects unsuccessful efforts to reballast the streamer for $50-\mathrm{m}$ (30-fold) data. Line $G$ was shot on 11 September. Line $C$ was shot in 2 parts on 12-13 september because of poor weather conditions and on-board computer problems.

After a port stop in Sault Ste. Marie to exchange personnel, replenish supplies, and reconfigure the source and streamer arrays for shallow water, the reflection shooting resumed in Lake Michigan with line $H$ (18-19 September). Parts of the streamer damaged in the ship's propellor during retrieval were replaced in transit between Lakes Michigan and Huron. The final lines collected were lines I (21 September) and J (22-23 September) in Lake Huron. 
This section provides a line-by-line description of the large offset data, including a brief summary of the stations occupied, type of data recorded, and maximum offsets. (Appendix I gives additional instrumental details, a list of participants for each group that supplied field instruments, and archive information on the field data).

During the field work, coordination between the shooting ship and landbased groups was critical to the success of the operation. A.G. Green and C. Spencer (both with GSC, Ottawa) provided this support out of Sault Ste. Marie (Lake Superior 1ines) and Ottawa (Lakes Michigan and Huron lines).

Line A-Refraction: Line A-Refraction in Lake Superior was shot specifically as a refraction line along the same position as line Areflection. The primary objective of this line was to determine the velocity structure of the crust and upper mantle across the Keweenaw rift where earlier refraction studies yielded crustal thicknesses in excess of $50 \mathrm{~km}$ (Halls, 1982). Figure 4 shows shot and receiver locations, table 3 lists relevant information about the receiving stations.

This line was shot by time, rather than by distance, so that receiving seismographs could be synchronized to record discrete shots. The airgun array was fired every two minutes for a total of 640 shots, which averaged about 333 $m$ apart. This shot spacing was chosen so that, at the longest ranges, arrivals from previous shots would not overlap.

A total of 31 stations recorded data along this line (fig. 4). Although no multichannel streamer array was towed from the ship, three multichannel geophone arrays were positioned on land: WISCORP south of the line, $\mathrm{CH}$ in the Keweenaw Peninsula, and AA north of the line. Five four-component oceanbottom seismometers ${ }^{1}$ (A8, A2, C4, C9, C3 of USGS) were spaced along the line within the lake. Seven vertical component seismometers were located in a linear array north of the line (SUP1, SUP3-SUP8). Five 3-component seismometers ( $\mathrm{C} 1, \mathrm{C} 2, \mathrm{C} 3, \mathrm{C} 4, \mathrm{C} 5, \mathrm{C} 6$ of $\mathrm{UW}$, Madison) and two verticalcomponent seismometers $(2 \mathrm{~N}, 5 \mathrm{~S})$ were located south of the lake. Three 3component seismometers were located slightly offline on the Keweenaw Peninsula

1 A special problem exists regarding the OBS locations. The initial locations were chosen based on LORAN $C$ fixes of the Coast Guard vessel from which the instruments were deployed. These locations were incompatible with locations determined by arrival times of shots from the shooting ship (which used Satellite/Doppler sonar navigation). Hence, either the navigation of the deploying ship or the shooting ship or both was in error. OBS locations were calculated (as described in Appendix I) as though all of the error originated from the deploying ship. (This is reasonable because most commercial LORAN $C$ units fail to include overland-propagation and secondary factor corrections to final latitude/longitude calculations). If, however, the error was in the navigation of the shooting ship, this implies that all ranges calculated for the onshore instruments may be biased. Relative range from shot to shot (and therefore observed apparent velocities) should not be significantly affected. This possible source of error would affect intercept times and may affect correlation of the large-offset data to the near-vertical data. 
(CP1-CP3). Fan recordings were made at five locations: Michipicoten Island (A), Isle Royale (IR1, IR2), Brule River (B1), Bayfield Peninsula (BF1) and Ontanagon (ON1).

For shots along the profile, maximum ranges recorded are $256 \mathrm{~km}$ (SP 109 to station SUP8) and $231 \mathrm{~km}$ (SP 748 to station C4).

Line A-Reflection: Line A-Reflection was shot in two parts with different shot spacings $(50 \mathrm{~m}$ and $62.5 \mathrm{~m}$ ) because of problems in balancing ship's speed against streamer buoyancy. The overlap begins at SP 2290, with SP 2290-2326 (50 m shots) overlapping with SP 2290-2320 (62.5 m shots). As with line A-Refraction, the primary objective of this line was to image the crust and upper mantle structure at the position of the thickest crust associated with the midcontinent rift. Because this line was also shot separately as a refraction profile, collection of large-offset data was not a high priority.

Fourteen stations recorded large offset data (fig. 5; table 4). Two stations (SUP2A, SUP7A) were occupied north of the lake to record data where instruments had failed during the recording of line A-refraction. Two 3component stations recorded data on the Keweenaw Peninsula and south of the line, respectively. Six stations recorded fan arrivals, including one 96channel geophone array (WISCORP).

Line B: Line B, along the northeast shore of Lake Superior (fig. 6), was shot with a $50-\mathrm{m}$ shot interval over a distance of $98 \mathrm{~km}$. The primary objective of this line was to profile the structure of a granite-greenstone belt along the edge of the Keweenaw rift. The offline recorders also received ray paths directly through and beneath the main part of the Keweenaw rift.

A total of 13 stations (fig. 6, table 5) recorded large offset information from shots fired on line $B$. No station was located exactly along the axis of the profile, although BB (a 48-channel geophone array north of the lake) and A (a vertical-component seismometer on Michipicoten Island) are reasonably close to the axis. The remaining 11 stations recorded fan arrivals on 3-component instruments.

Line C: Line C in Lake Superior, $109 \mathrm{~km}$ long, was shot in two parts because of shipboard computer malfunction. Both parts were shot with $62.5 \mathrm{~m}$ shots. The objective of this line was to image the structure of the western 1 imb of the Keweenaw rift. Its location roughly coincides with a refraction 1ine shot in 1967 (Luetgert and Meyer, 1982).

A total of 15 stations recorded data from shots on this line (fig. 7, table 6). One 96-channel geophone array was positioned south of the line (WISCORP). The remaining fourteen stations were 3-component instruments located northwest of the line ( 6 stations, B1-B6), south of the line (4 stations, ON1-0N4) and offline at Isle Royal (2 stations, IR1, IR2), Keeweenaw Peninsula (1 station, CP3) and Big Bay (1 station, C6). Maximum offsets recorded were $131 \mathrm{~km}$ (SP 156 to station ON3 and SP 1880 to station B3).

The overlap between the two parts of line C occurs between SP 741 and SP 771. A special timing problem occurred on the start of the second part of the line. At SP 741, the GSI clock was synchronized to the satellite clock 
for shot instant determination. However, by SP 1057, the two clocks read $23.1 \mathrm{~s}$ apart. When the discrepancy occurred was not logged, and hence the exact shot instants for SP 741-1057 remains uncertain. The 23.1 s correction has been applied to all shots after SP 970.

Line F: Line F, located in Lake Superior, was shot in 6 parts alternating between $50 \mathrm{~m}$ and $62.5 \mathrm{~m}$ shot intervals (see table 2). This variation reflects buoyancy problems with the streamer. A $2.2 \mathrm{~km}$ gap occurs between SP 455 and SP 457; and a major change in the orientation of the line occurs at SP 1579. The primary objective of this line was to image the eastern limb of the Keweenawan rift in a region of relative gravity low and two positive magnetic anomales.

Twelve stations (fig. 8, table 7) recorded data from line F. A verticalcomponent seismometer on Michipicoten Island (A, Fig. 8) is the closest instrument to the axis of the north-northeast segment of the line (SP 1011579); four three-component instruments (C6, ON1-3) and a 96-channel geophone array (WISCORP) are approximately along the axis of the east-north-east segment of the line (SP 1580-1843). The remaining six stations (CP3, IR1, IR2, B1-B3) are three component seismometers that recorded fan arrivals through and beneath the rift basin.

Line G: Line G, $54 \mathrm{~km}$ long in Lake Superior, was shot with 62.5-m shot intervals and is the shortest of all lines. It was positioned to give a line crossing with line $A$ in the region where continental crust was assumed to be thickest.

Eight stations, all three-component seismometers deployed by University of Wisconsin-Madison, recorded fan shots for this line (figure 9, table 8). There were no stations positioned along the axis of the line.

Line $\mathrm{H}$ : Line $\mathrm{H}$, the only line in Lake Michigan, was shot with $62.5-\mathrm{m}$ shot intervals for a total length of $283 \mathrm{~km}$. A major bend in the line occurs at SP 3565. The primary objective of this line was to image the structure of the Penokean fold belt buried beneath Paleozoic sediments of the Michigan Basin.

A total of 21 stations were deployed along line $\mathrm{H}$ (figure 10, table 9). Seventeen stations, containing a combination of fifteen vertical-component instruments ( $\mathrm{MCla}-\mathrm{MC} 5 \mathrm{c})$ and two 3-component instruments ( $\mathrm{MC6}, \mathrm{MC7}$ ), were positioned north of the lake along the axis of the north-northeast trending segment of the line (SP 101-3565). The remaining four stations were verticalcomponent seismometers ( $1 \mathrm{~S}, 2 \mathrm{~N}, 3 \mathrm{~S}, 5 \mathrm{~S}$ ) located northwest of the lake and slighly off the axis of the east-northeast trending segment of the line (SP 3565 - SP 4636). The maximum range recorded for this line was $256 \mathrm{~km}$ (SP 101 to station MC6).

Line I: Line I in Lake Huron, was a north-south line (108-km long) positioned so as to image the structure of Proterozic Huronian platform deposits exposed north of the lake but buried beneath the lake by Phanerozoic sediments. Shots were spaced $62.5 \mathrm{~m}$ apart.

Five stations were occupied during the shooting of line I (figure 11 , table 10). One vertical component seismometer was positioned along the north 
shore of the lake (IRON). A second vertical-component instrument (MAN) was located slightly offline on the western end of Manitoulin Island. The remaining three stations, all south of the line in Michigan, comprised 2 three-component seismometers ( $\mathrm{HE} 1, \mathrm{HE} 2$ ) and a 24-channel geophone array (AL). The largest offsets recorded were $116 \mathrm{~km}$ (SP 102 to station IRON) and $118 \mathrm{~km}$ (SP 1823 to station HE2). No fan arrivals were recorded for this line.

Line J: Line J, located in Georgian Bay and Lake Huron, is the longest of all lines in the GLIMPCE experiment $(323 \mathrm{~km})$. All shots were fired at 62.5-m spacings. Several kinks occur where the vessel adjusted course to stay within the channel separating Georgian Bay and Lake Huron (SP 1800-2300). The primary objective of this line was to profile the Grenville front and the buried igneous terrane to the west.

Eighteen stations were occupied during the acquisition of this line (figure 11, table 10). Three vertical-component seismometers were positioned east of the line on the coast of Georgian Bay (stations C, D, E). A fourth vertical-component instrument was located on the Bruce Peninsula midway down the line (station $B$ ). The rest of the stations were located just west of the end of the line and consisted of one 24-channel geophone array (SH) and thirteen three-component seismometers, ten of which were in a linear array less than $2 \mathrm{~km}$ long. Maximum offsets for this line are $336 \mathrm{~km}$ ( $\mathrm{SP} 101$ to station F11) and $346 \mathrm{~km}$ (SP 5264 to station D).

\section{DISCUSSION AND SUMMARY}

In order to insure consistency in data preparation and distribution, all participants agreed to use the same algorithm for range calculation to display and interpret the large offset data. This algorithm uses the geodetic inverse formula with geodesy by A. R. Clarke (1880) and is listed in Appendix III. Final data exchange format is a superset of SEG-Y, with header definitions for refraction data given in Appendix IV.

In summary, this first GLIMPCE experiment has provided an impressive amount of seismic information for studying crustal structure and tectonics of the mid-continent. Eight academic and government groups "piggybacked" on a major marine multichannel reflection survey and were able to record vertical and three-component data for all seismic lines shot in the Great Lakes. The success of this effort rests with the careful coordination between the shooting ship and the land-based groups. The experiment demonstrates that large offset information can be acquired simultaneously with deep crustal reflection profiling at a fairly modest expenditure of dollars, time and effort. 


\section{ACKNOWLEDGEMENTS}

An experiment of this size and cost would not have been possible without the dedication and cooperation of numerous individuals. Bill Cannon of USGS and Alan Green of GSC provided the driving force behind the organization of GLIMPCE and the 1986 seismic experiment and were instrumental in securing the USGS and GSC funding that made the experiment possible. Alan Green, with help from Carl Spencer, also impressively coordinated efficient communications between the shooting ship and the often remotly located field parties deploying seismometers and geophone arrays. J.C. Behrendt (USGS) and L.D. McGinnis (U.S.-DOE) were GLIMPCE representatives aboard M/V Fred J. Agnich during the Lake Superior lines; A.G. Green (GSC) and D.R. Hutchinson (USGS) were on-board representatives during the Lake Michigan and Lake Huron lines. We thank John Clink (GSI) and the captain and crew of the Fred J. Agnich for their cooperation during the contracting and shooting. We thank the Captain and crew of the U.S. Coast Guard vessel Katmai Bay for their cooperation during deployment and recovery of the OBS's in Lake Superior, and the Geological Survey of Ontario for helicopter logistics into Michipicoten Island. Much of the field logistics would not have been possible without the dedicaton of the many researchers, technicians, and students who operated the field instrumentation, most who are listed in Appendix I. Finally, we thank K. Ruffin, M.C. Mons-Wengler, E. Winget, P. Forreste1, J. Zwinakis and D. Blackwood for technical assistance in preparing the manuscript and $\mathrm{J}$. Luetgert and W. Agena for critical reviews. 


\section{REFERENCES}

Barry, K.M., Cavers, D.A., and Kneale, C.W., 1975, Recommended standards for digital tape formats: Geophysics, v. 40, p. 334-352.

Clarke, A.R., 1880, Geodesy, Oxford, Clarendon Press, 356p.

Creager, K.C., and Dorman, L.M., 1982, Location of instruments on the seafloor by joint adjustment of instrument and ship positions: Journal of Geophysical Research, v. 87, p. 8379-8388.

Halls, H.C., 1982, Crustal thickness in the Lake Superior region, in Wold, R.J., and Hinze, W.J., eds, Geology and tectonics of the Lake Superior Basin: Geological Society of America Memoir 156, p. 239-243.

Lee, M.W., Agena, W.F., and Hutchinson, D.R., 1988, Processing of GLIMPCE multichannel seismic data: U.S. Geological Survey Open-file Report 88$225,46 \mathrm{p}$.

Luetgert, J.H., and Meyer, R.P., 1982, Structure of the western basin of Lake Superior from cross structure refraction profiles, in Wold, R.J., and Hinze, W.J., eds., Geology and tectonics of the Lake Superior basin: geological Society of America Memoir 156, p. 245-255.

Milkereit, B., Green, A.G., Morel'a-1,Huissier, P., Lee, M.W., and Agena, W.F., 1988, 1986 Great Lakes seismic reflection survey-migrated data: Geological Survey of Canada Open file report/Dossiers Publics no. 1592. $35 p$. 


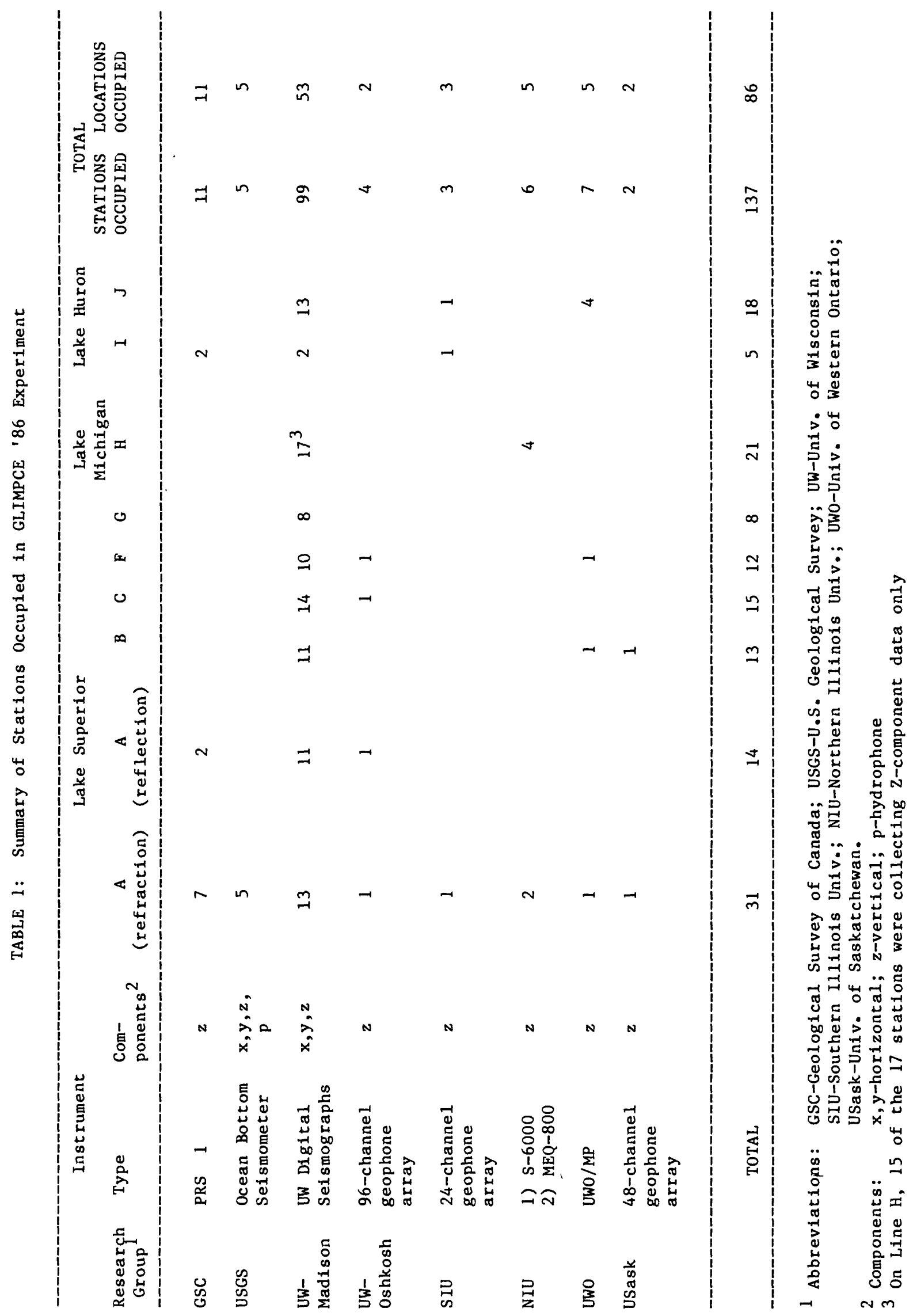




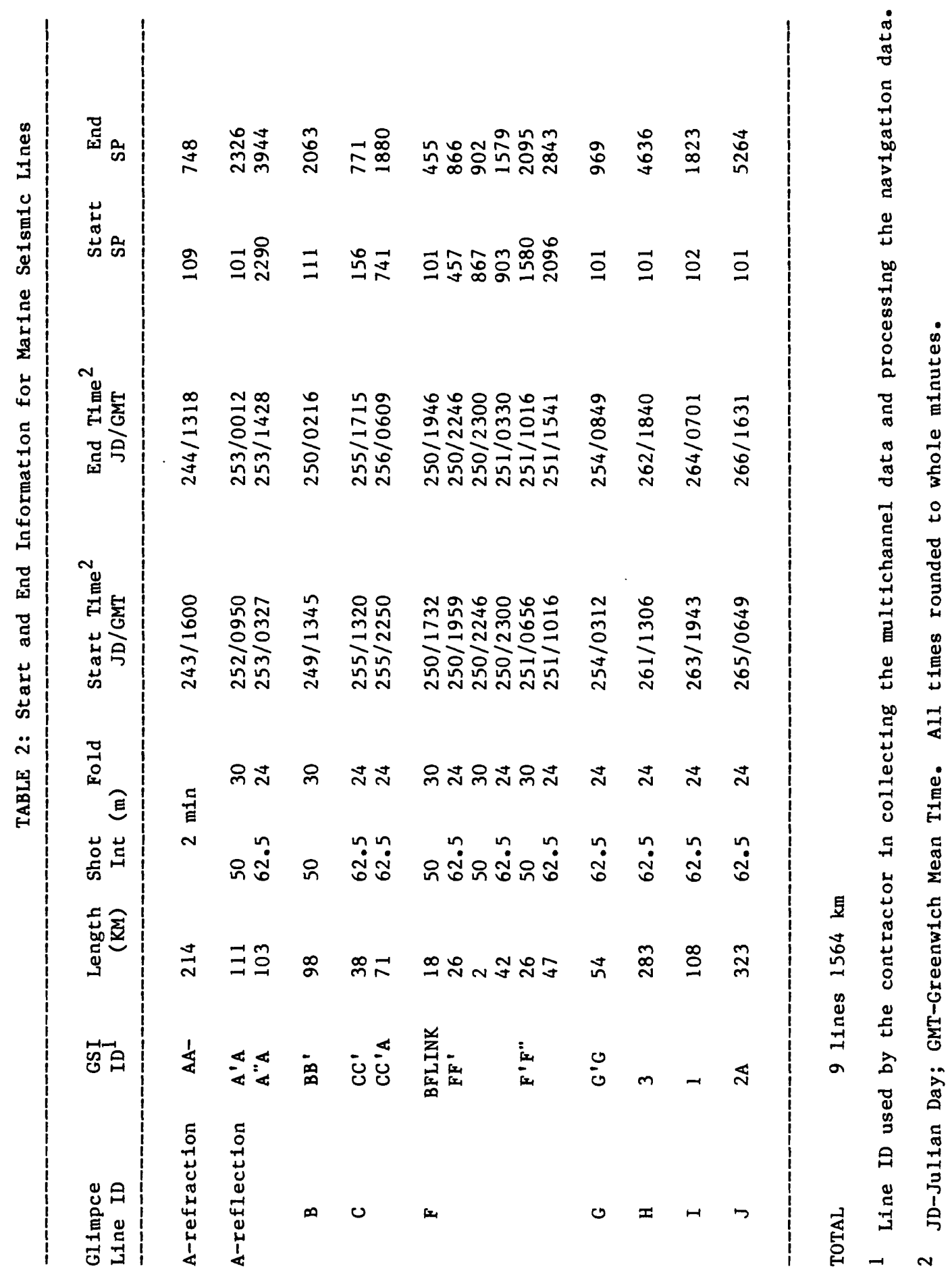




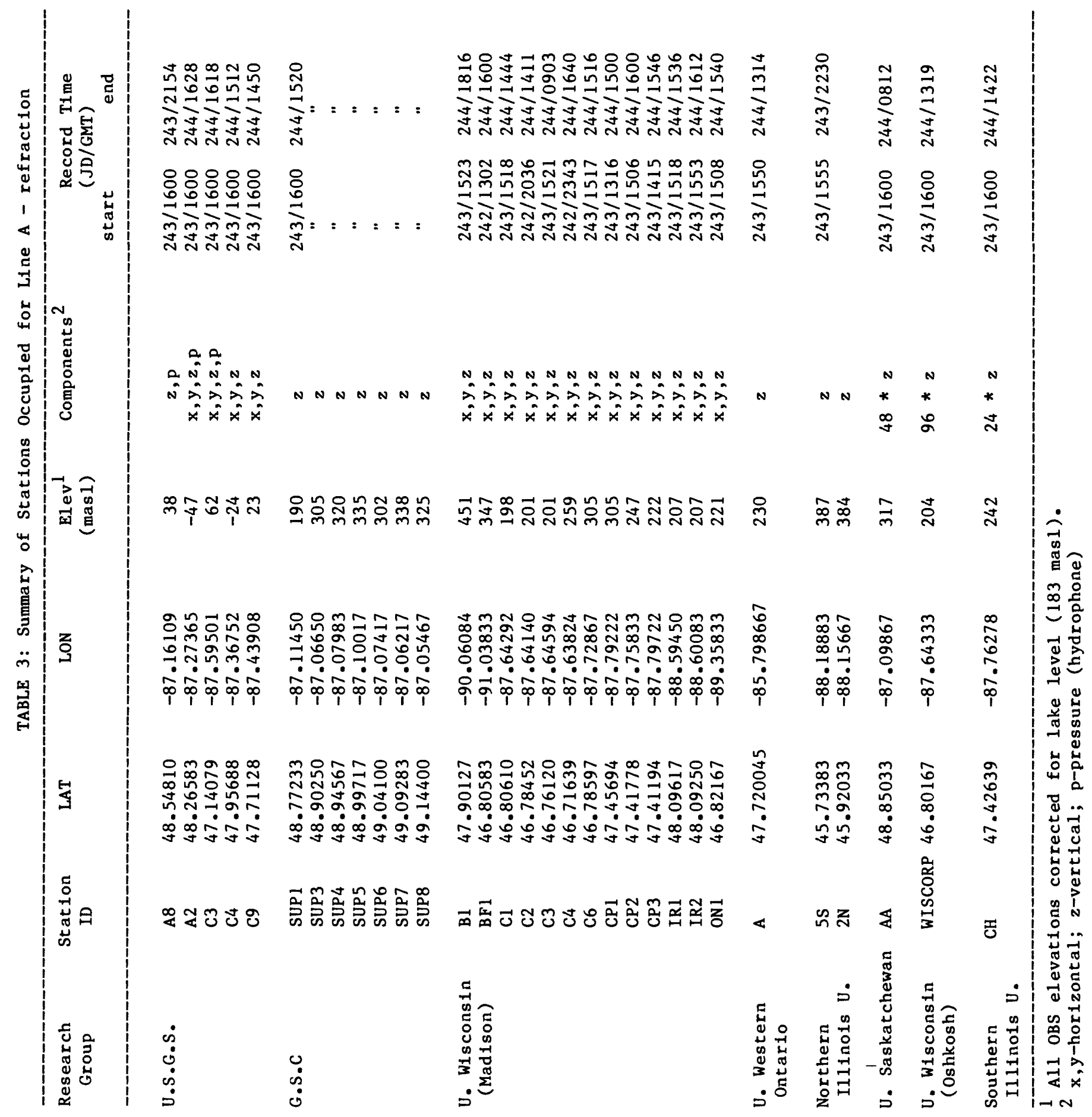




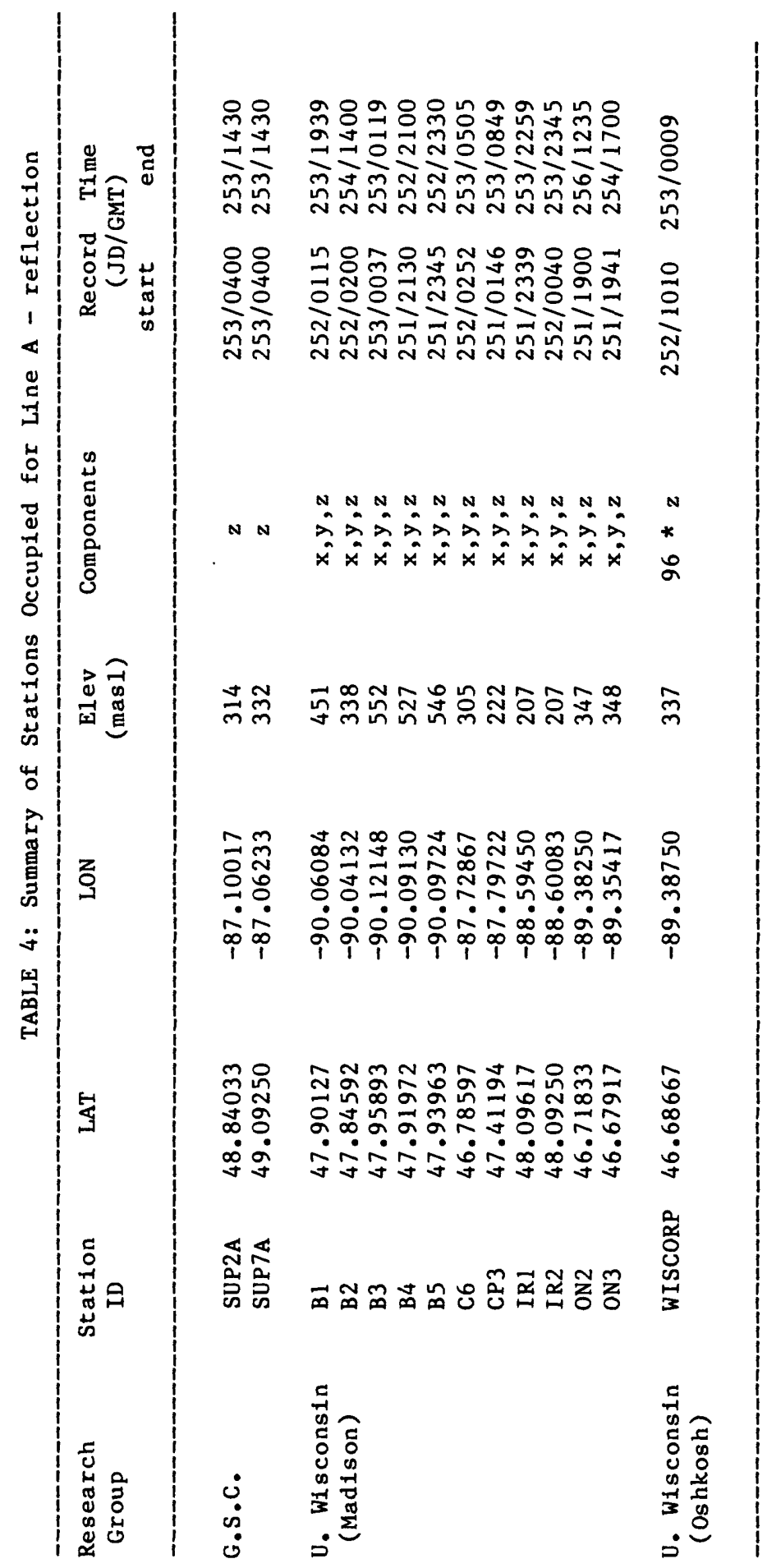




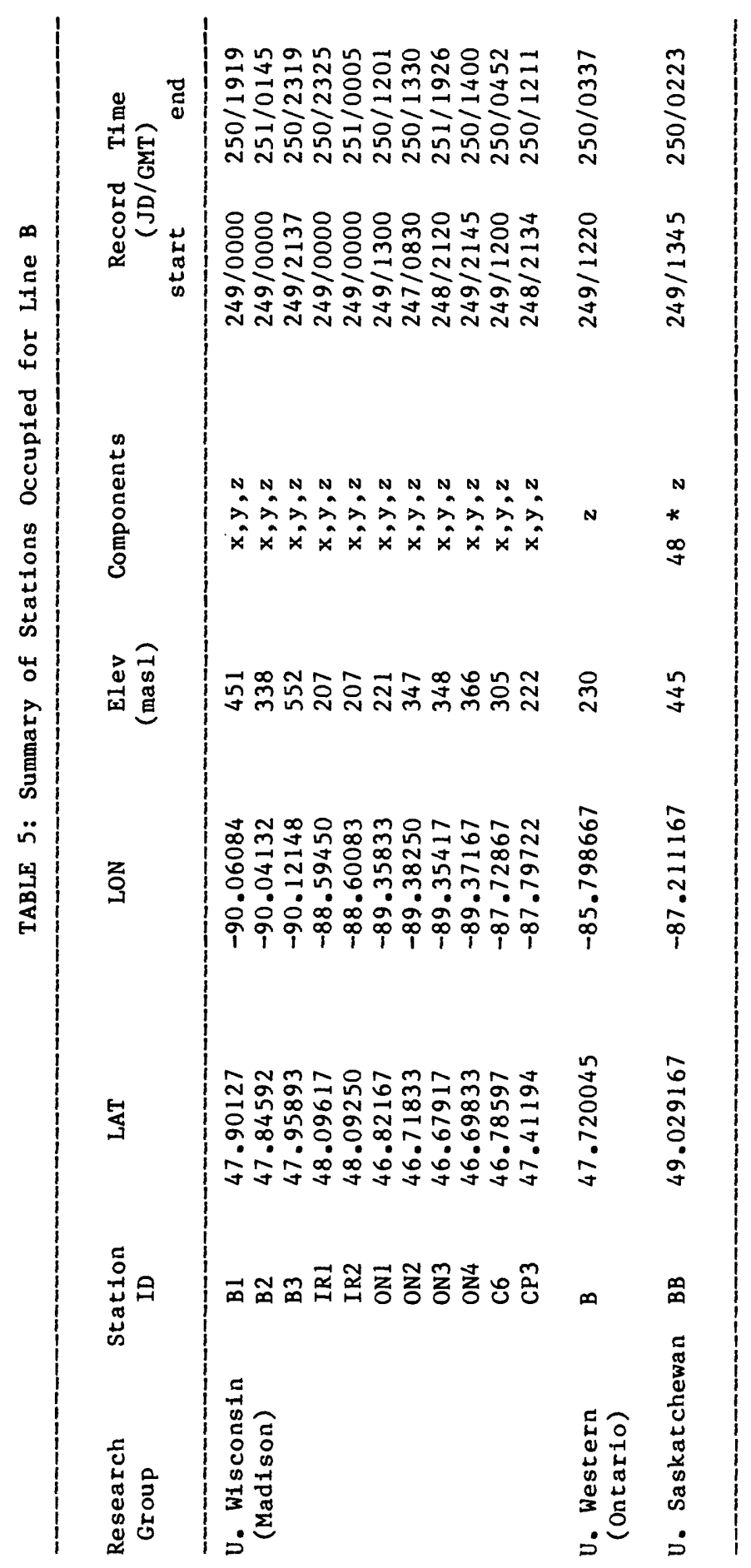




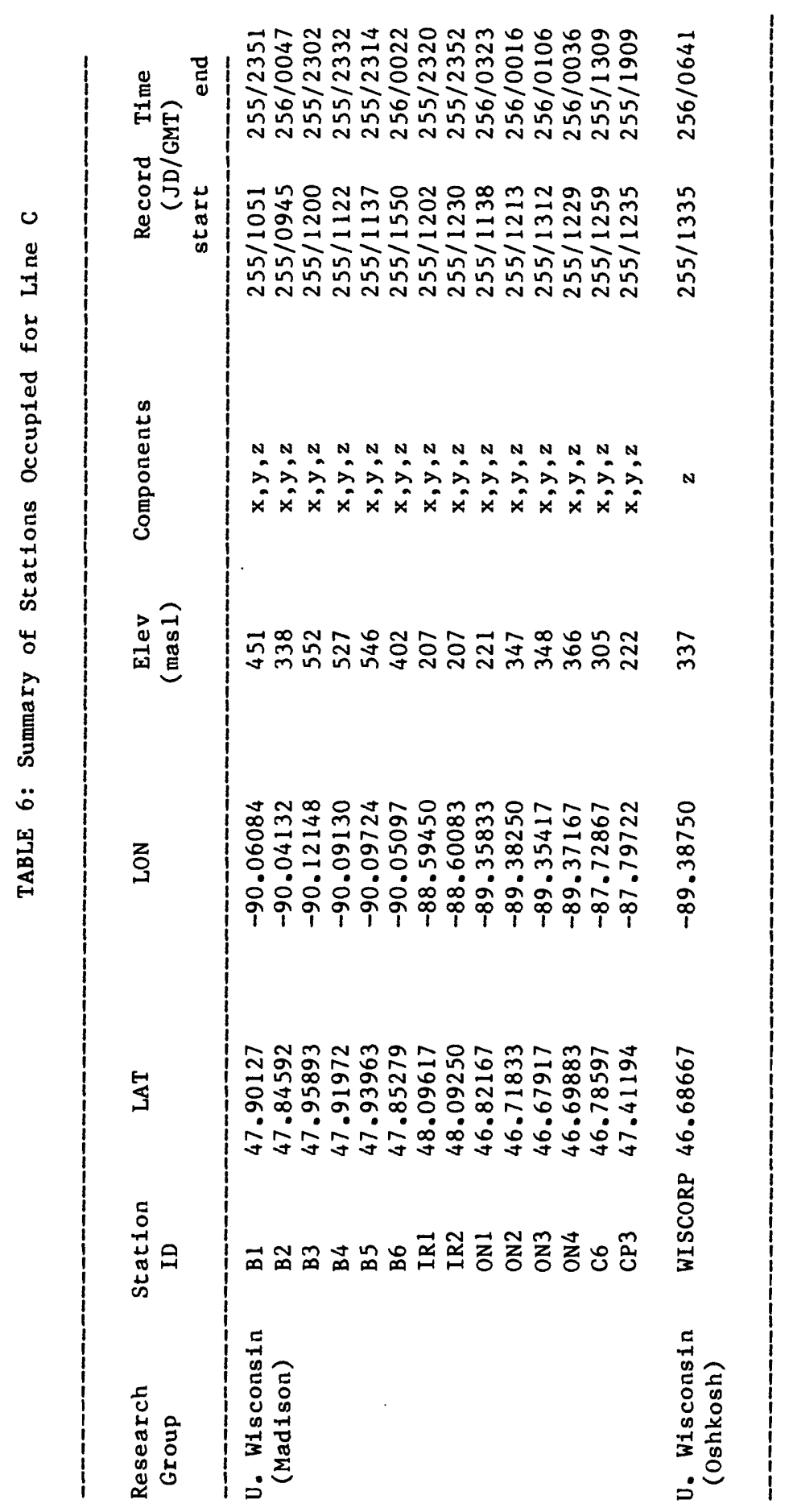




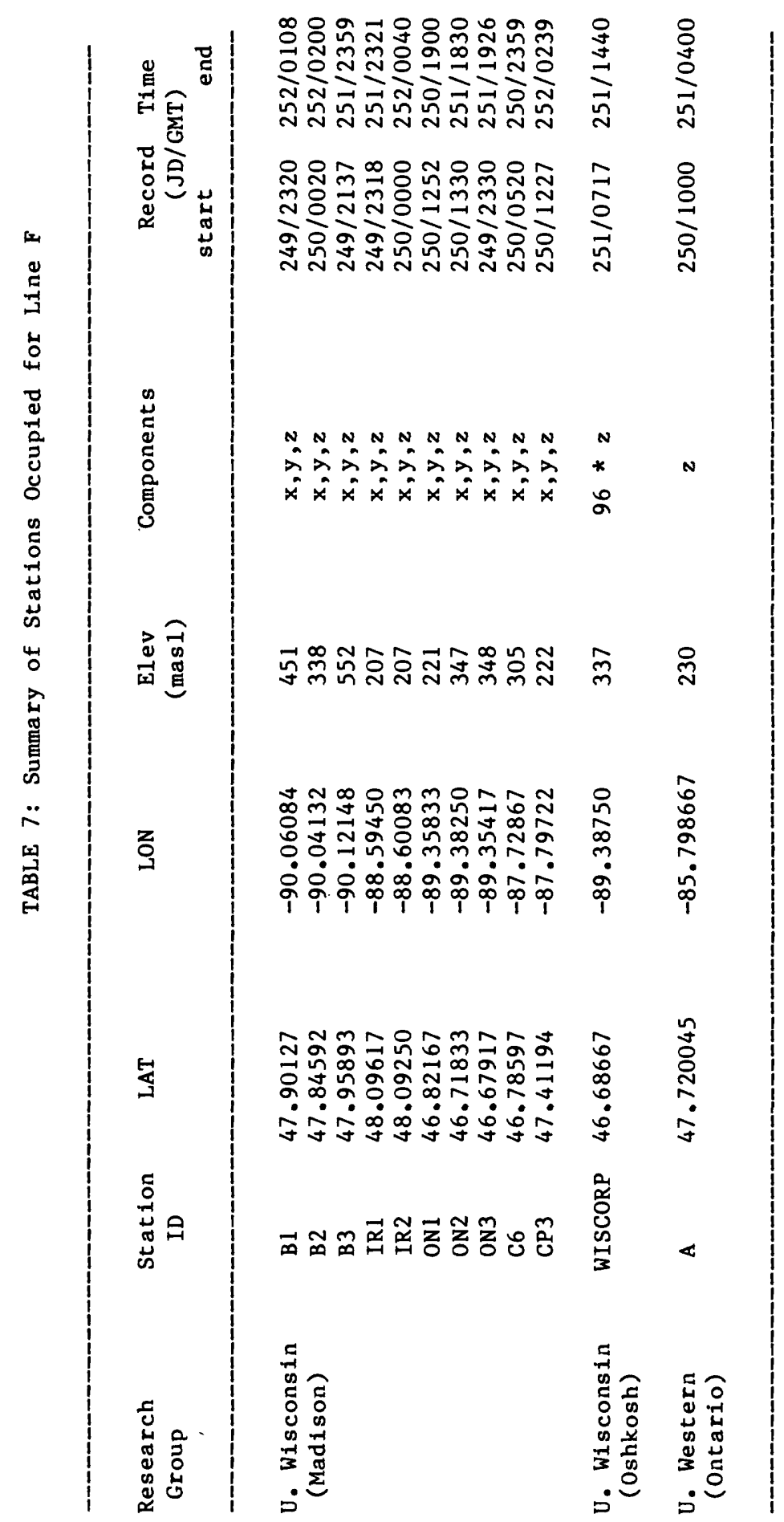




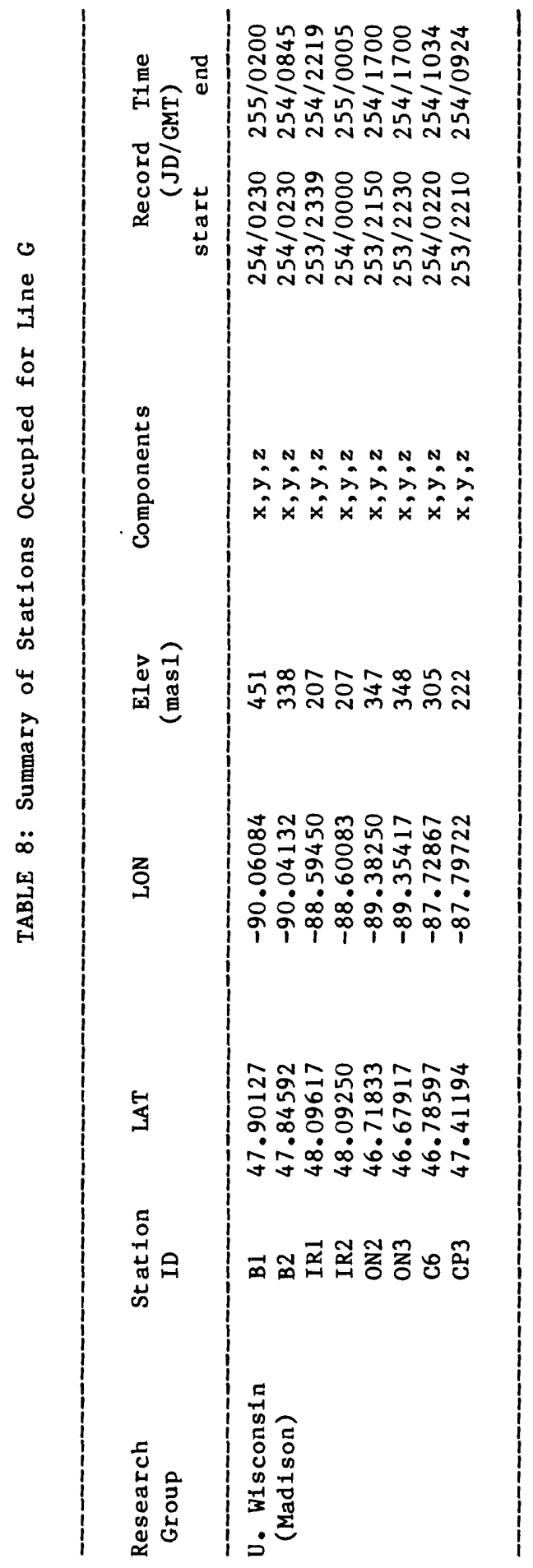




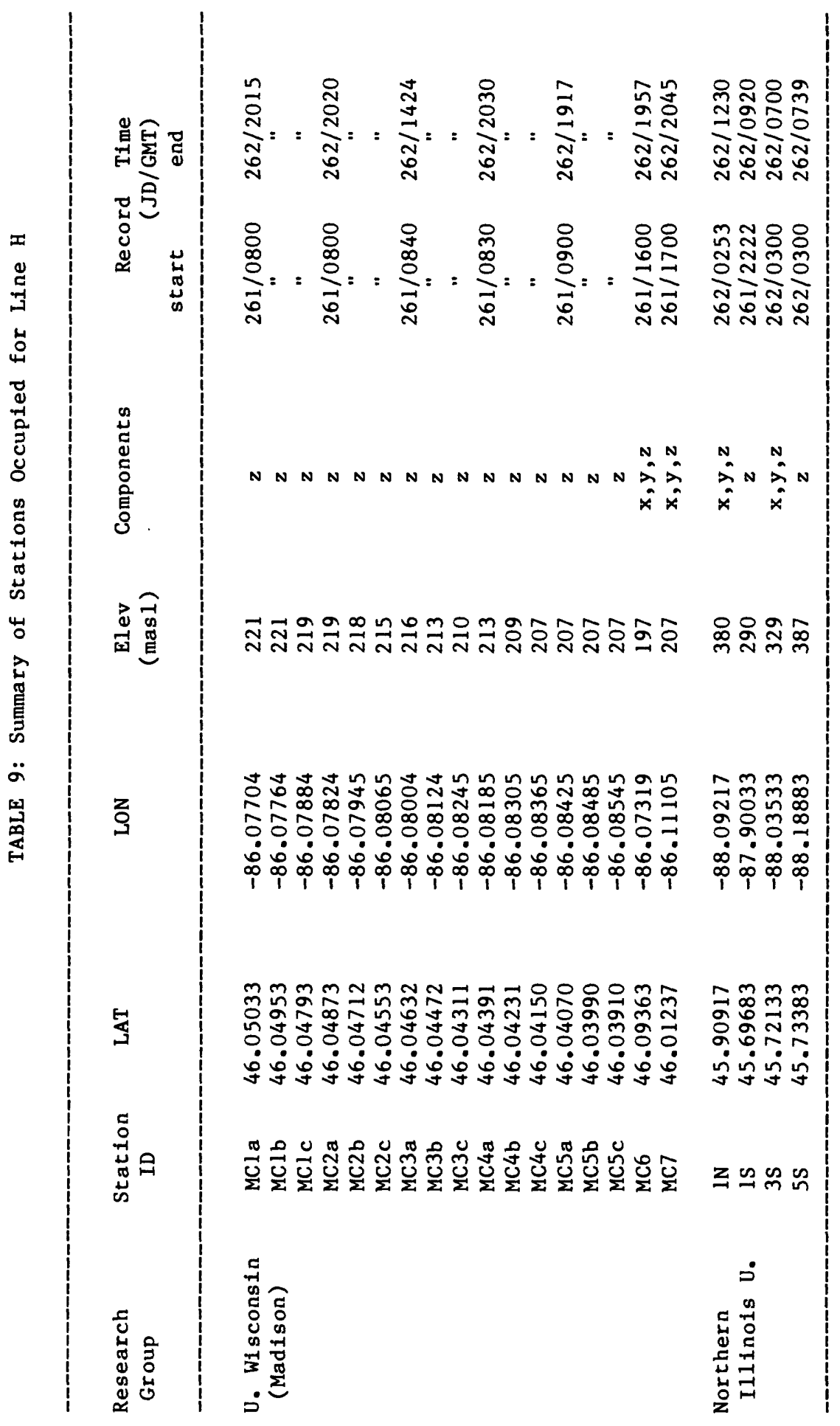




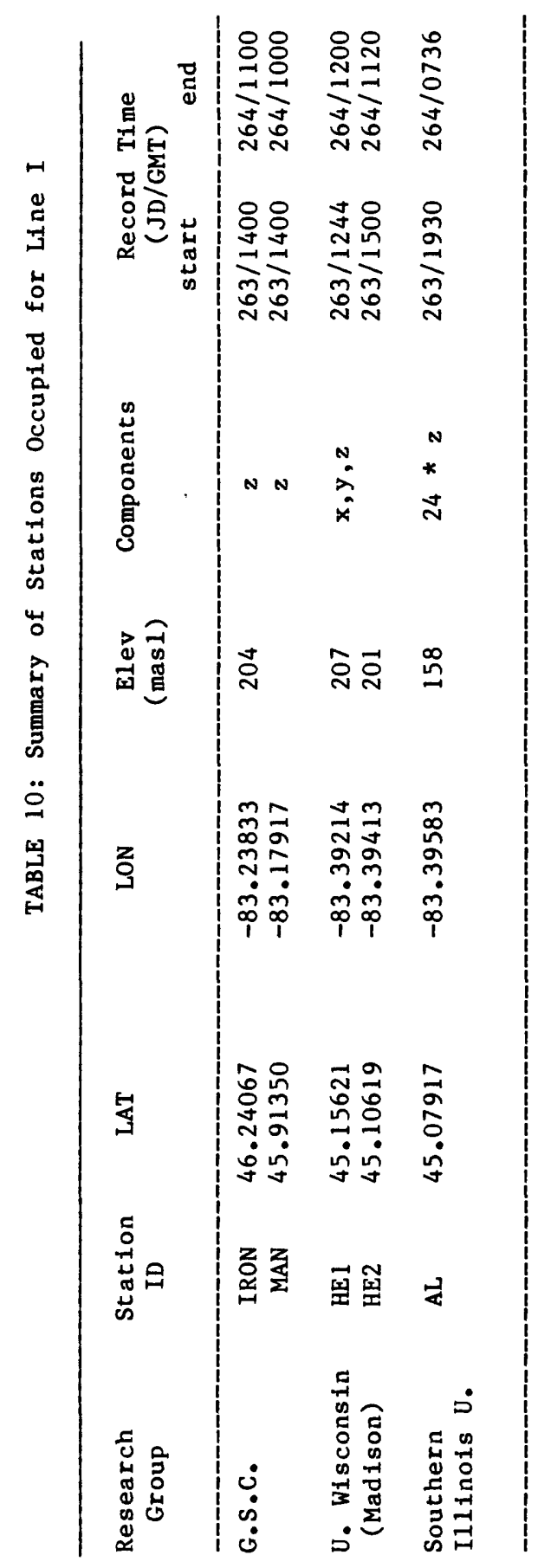




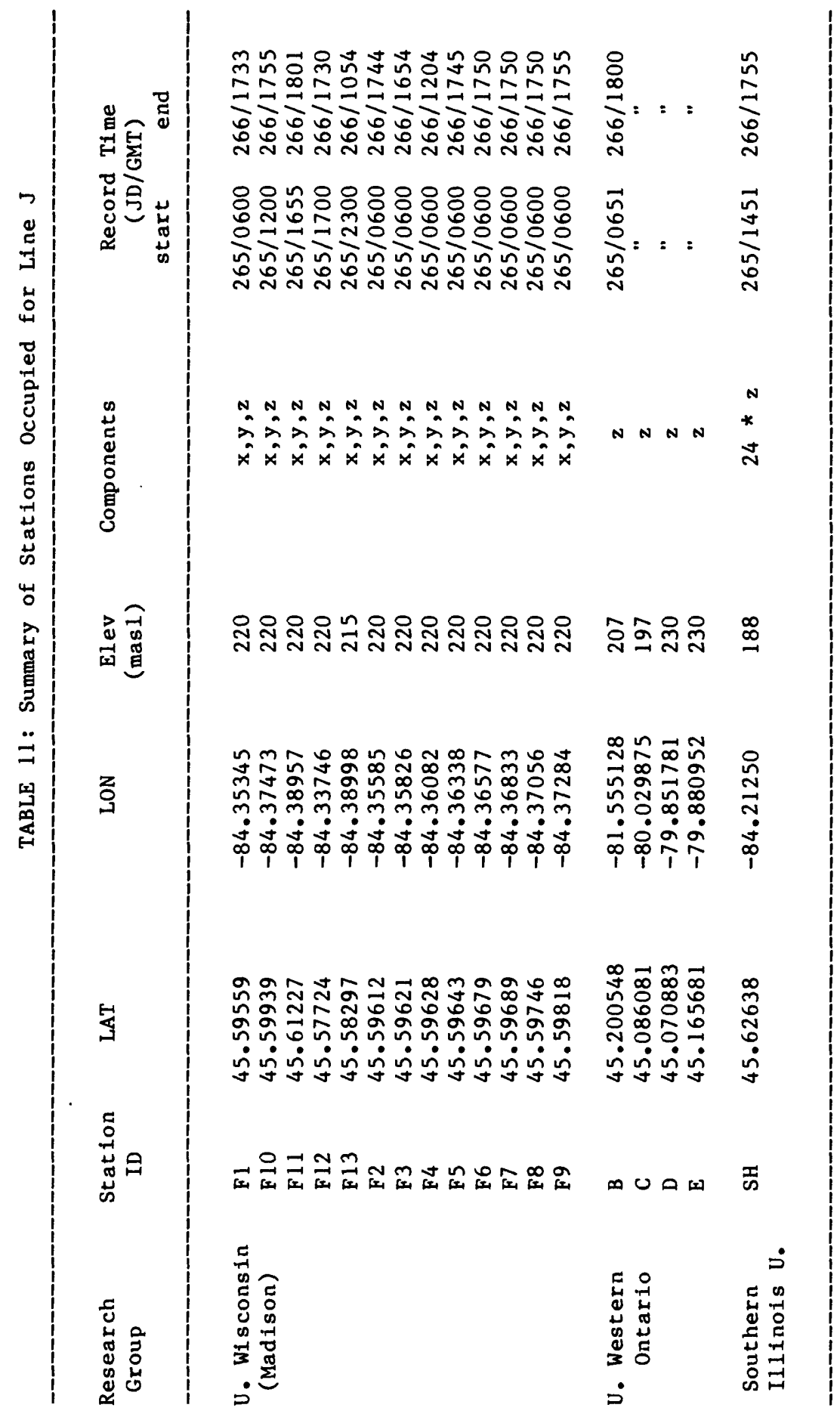


Figure Captions

Figure 1: Location of GLIMPCE multichannel seismic reflection lines and stations used to record wide-angle and large-offset data. Line A-refraction overlies line A-reflection and is not plotted. Individual station names associated with each line are shown in figures 4 to 12 . 


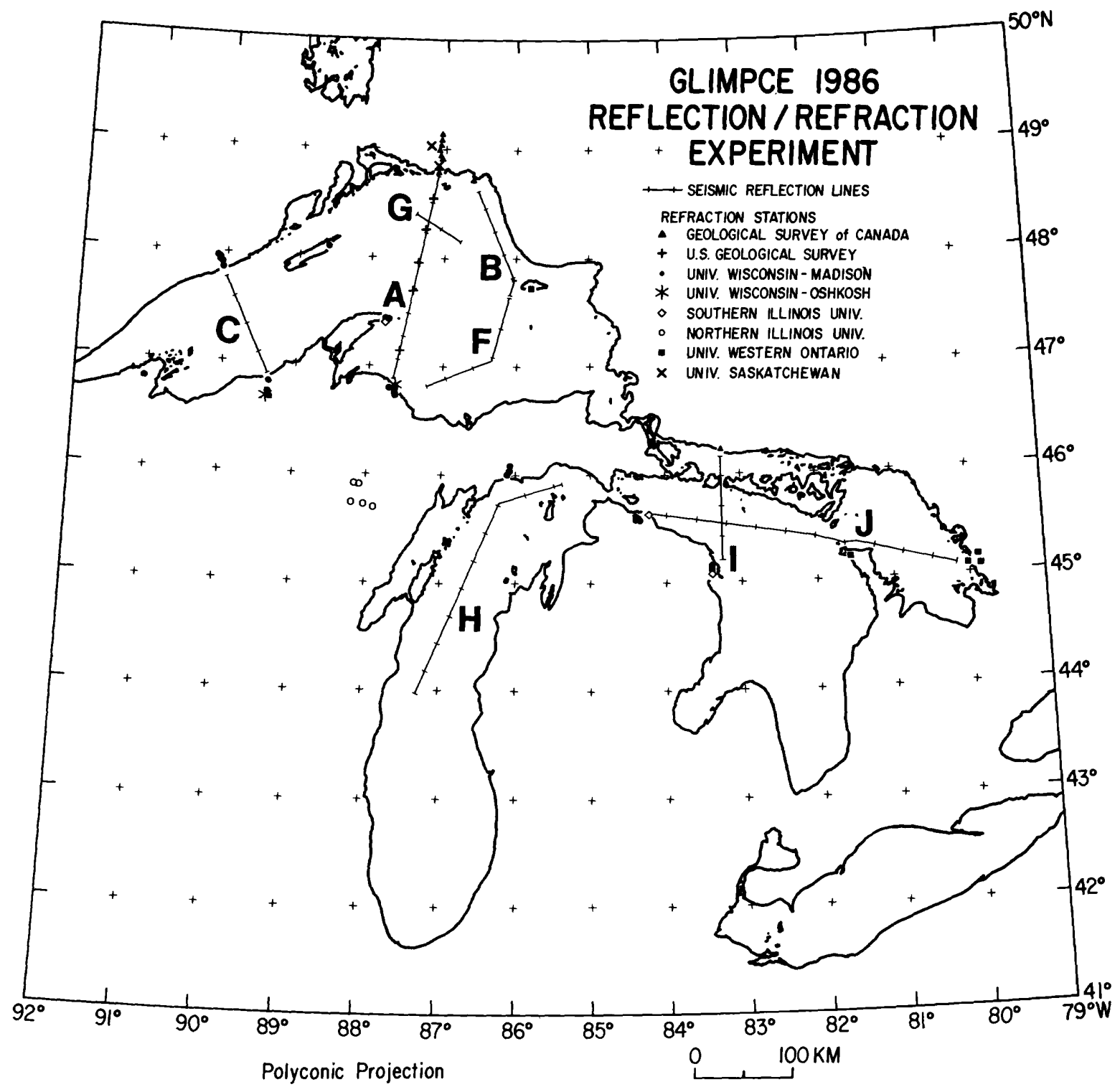


Figure 2: Source and streamer configuration for GLIMPCE marine multichanne1 profiles. A) Streamer geometry and relative positions of fathometer, satellite antenna, airgun array and streamer. B) Geometry and size of the airgun array. Whereas the total array contained 76 guns, only 60 guns were operational at any one time. 


\section{A. GLIMPCE 1986 CONTRACT VESSEL}

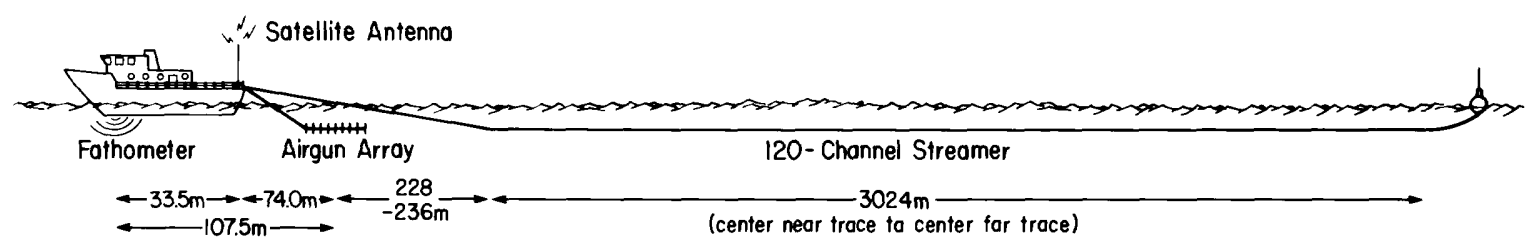

\section{B. AIRGUN ARRAY}

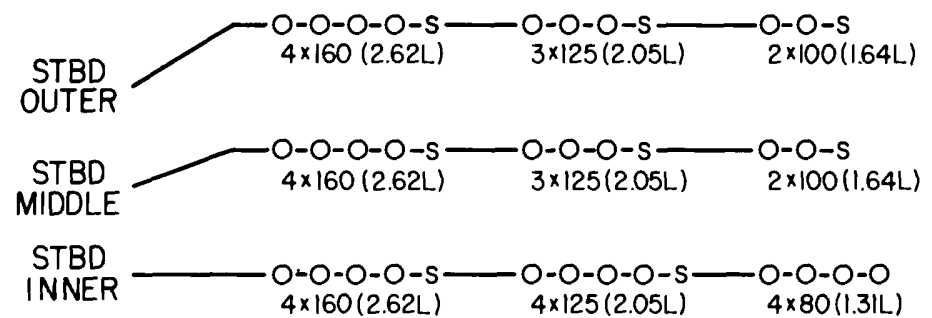

PORT I NNER

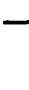

PORT

MIDDLE E

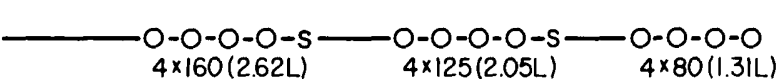
$4 \times 160(2.62 \mathrm{~L}) \quad 4 \times 125(2.05 \mathrm{~L}) \quad 4 \times 80(1.3 \mathrm{~L})$

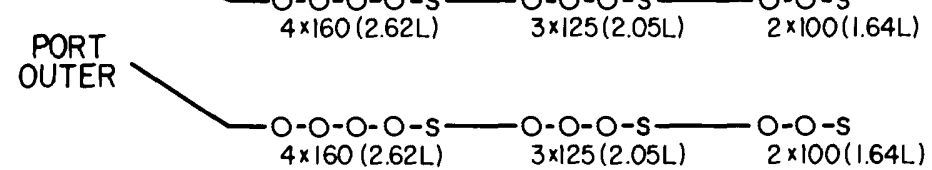

O-OPERATING GUN S-SPARE GUN
ACTIVE GUNS: $24 \times 160$ (2.62L) $20 \times 125(2.05 \mathrm{~L})$ $8 \times 100(1.64 \mathrm{~L})$ $8 \times 80(1.31 \mathrm{~L})$ Total $7780 \mathrm{in}^{3}(127.48 \mathrm{~L})$

SPARE GUNS: $6 \times 160(2.62 \mathrm{~L})$ $6 \times 125(2.05 \mathrm{~L})$ Total $\frac{4 \times 100(1.64 \mathrm{~L})}{2110 \mathrm{in}^{3}(34.58 \mathrm{~L})}$

ARRAY WIDTH : $80 \mathrm{~m}$ STRING LENGTH: $9.9 \mathrm{~m}$ 
Figure 3: Bathymetric profiles associated with each GLIMPCE shot line. See text for a description of processing and smoothing of the digital data. 
GLIMPCE 1986

BATHYMETRY PROFILES

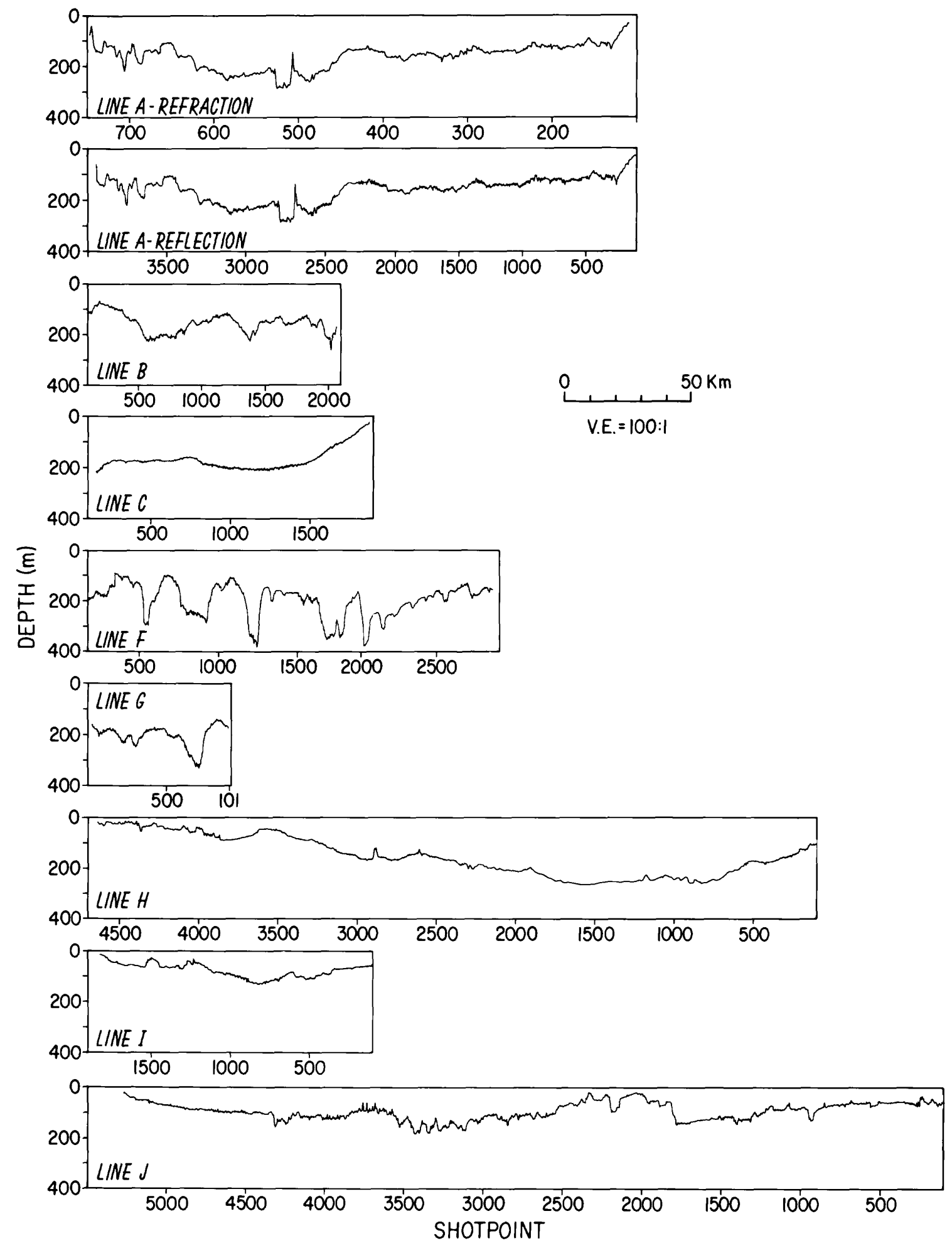


Figure 4: Shot and station locations for line A-refraction. Symbols are the same as those used in Figure 1. Additional information is listed in Table 3 . 


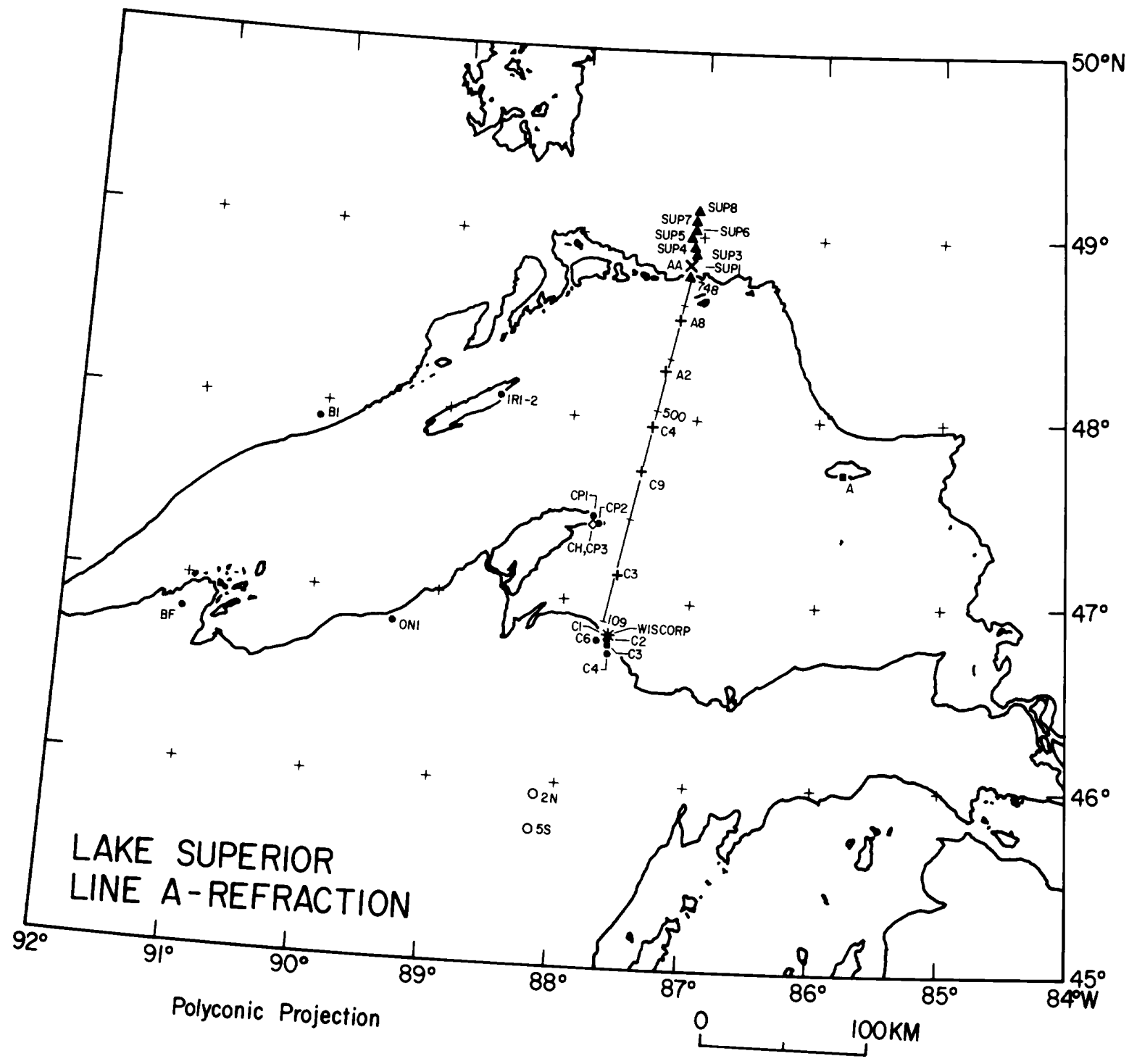


Figure 5: Shot and station locations for line A-reflection. Symbols are the same as those used in Figure 1. Additional information is listed in Table 4. 


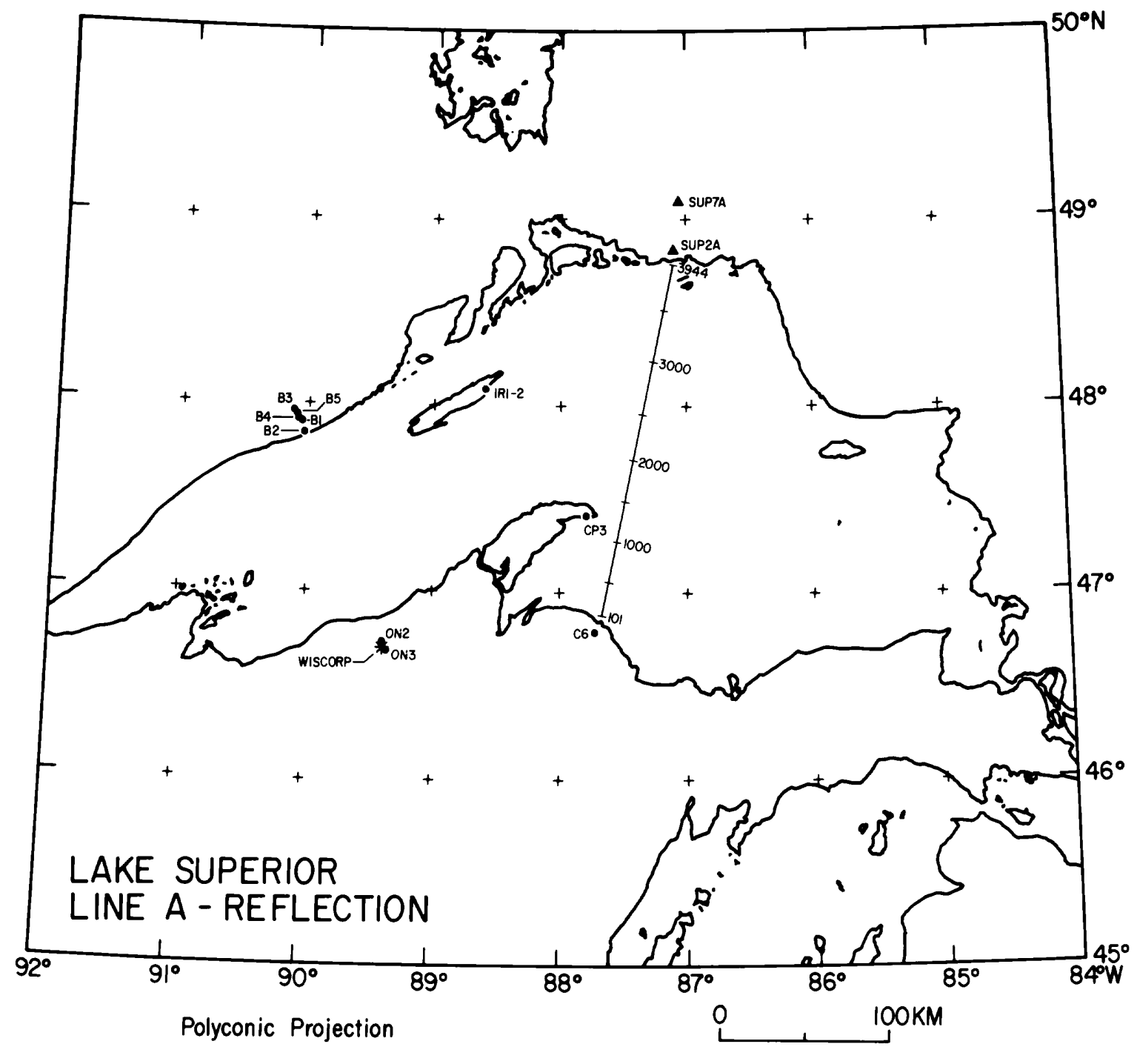


Figure 6: Shot and station locations for line B. Symbols are the same as those used in Figure 1. Additional information is listed in Table 5 . 


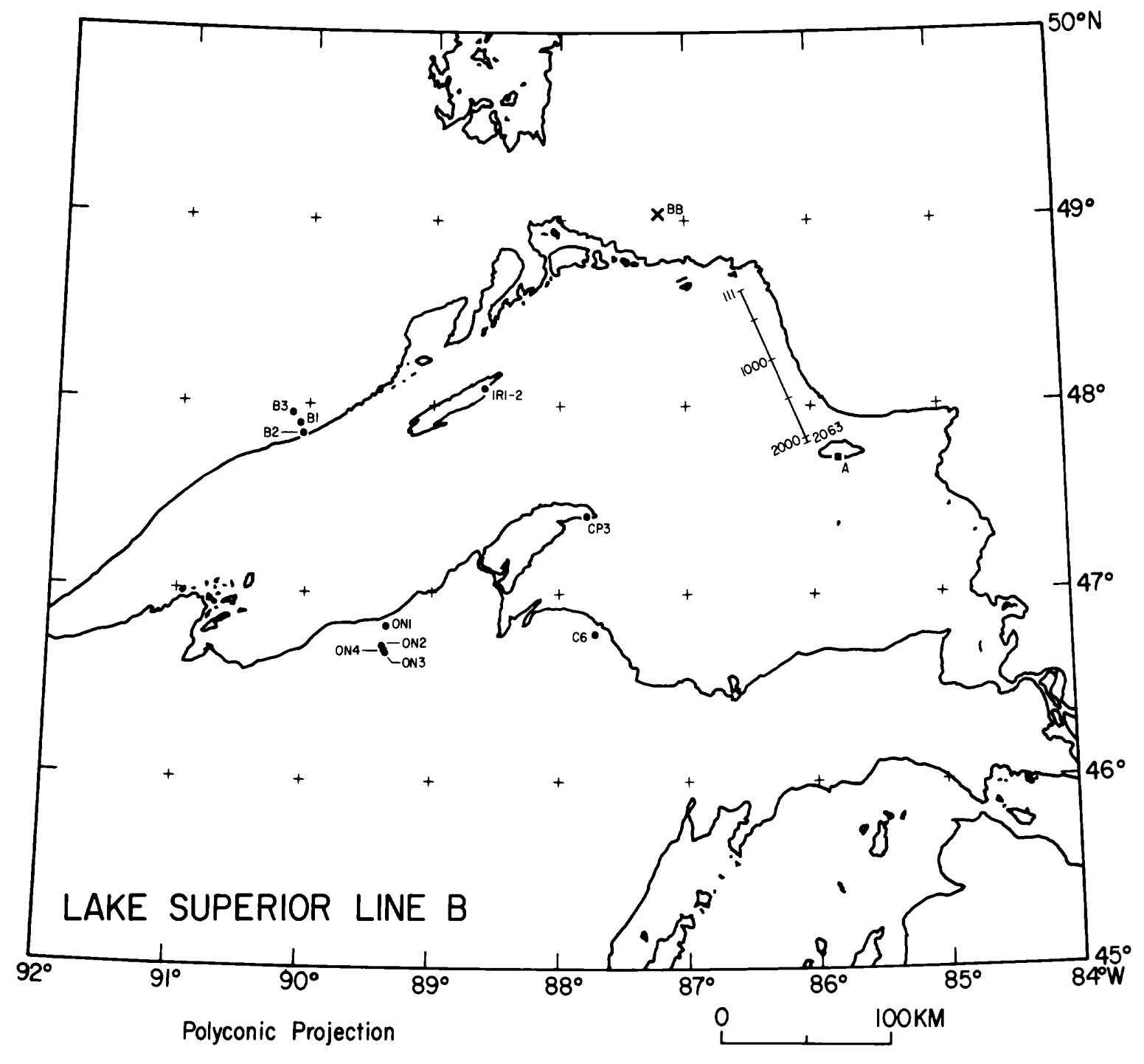


Figure 7: Shot and station locations for line C. Symbols are the same as those used in Figure 1. Additional information is listed in Table 6 . 


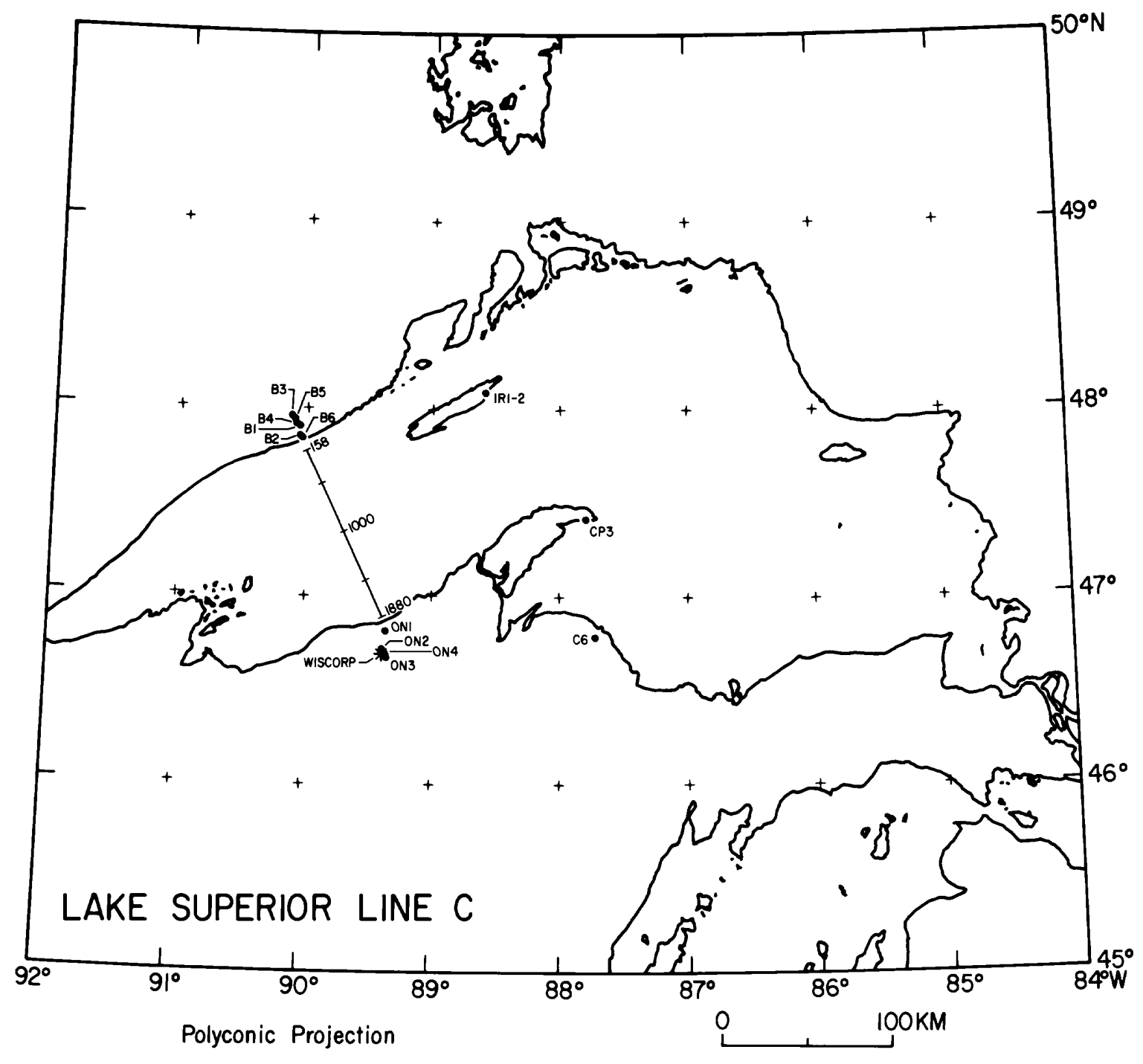


Figure 8: Shot and station locations for line F. Symbols are the same as those used in Figure 1. Additional information is listed in Table 7. 


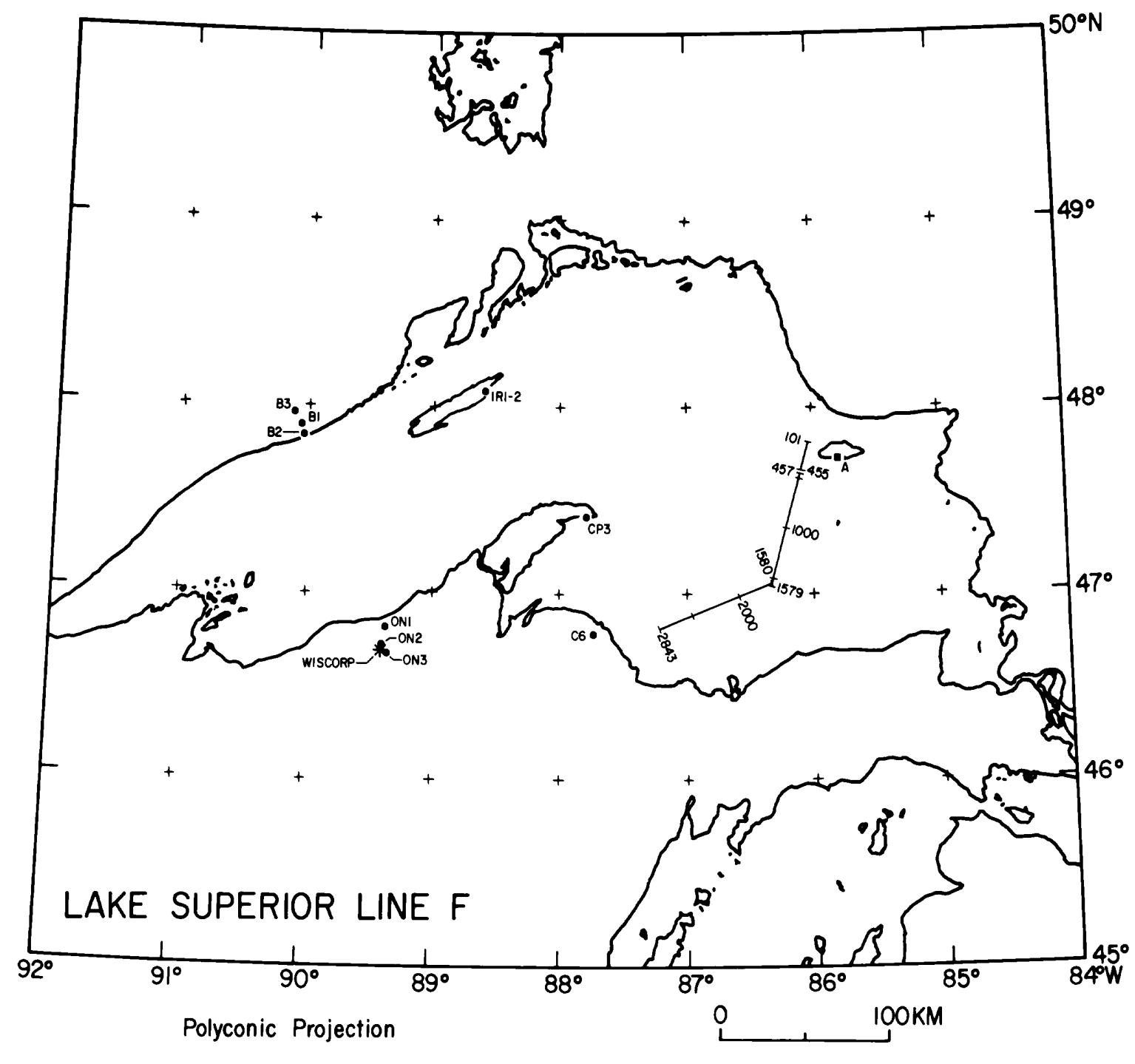


Figure 9: Shot and station locations for line G. Symbols are the same as those used in Figure 1. Additional information is listed in Table 8 . 


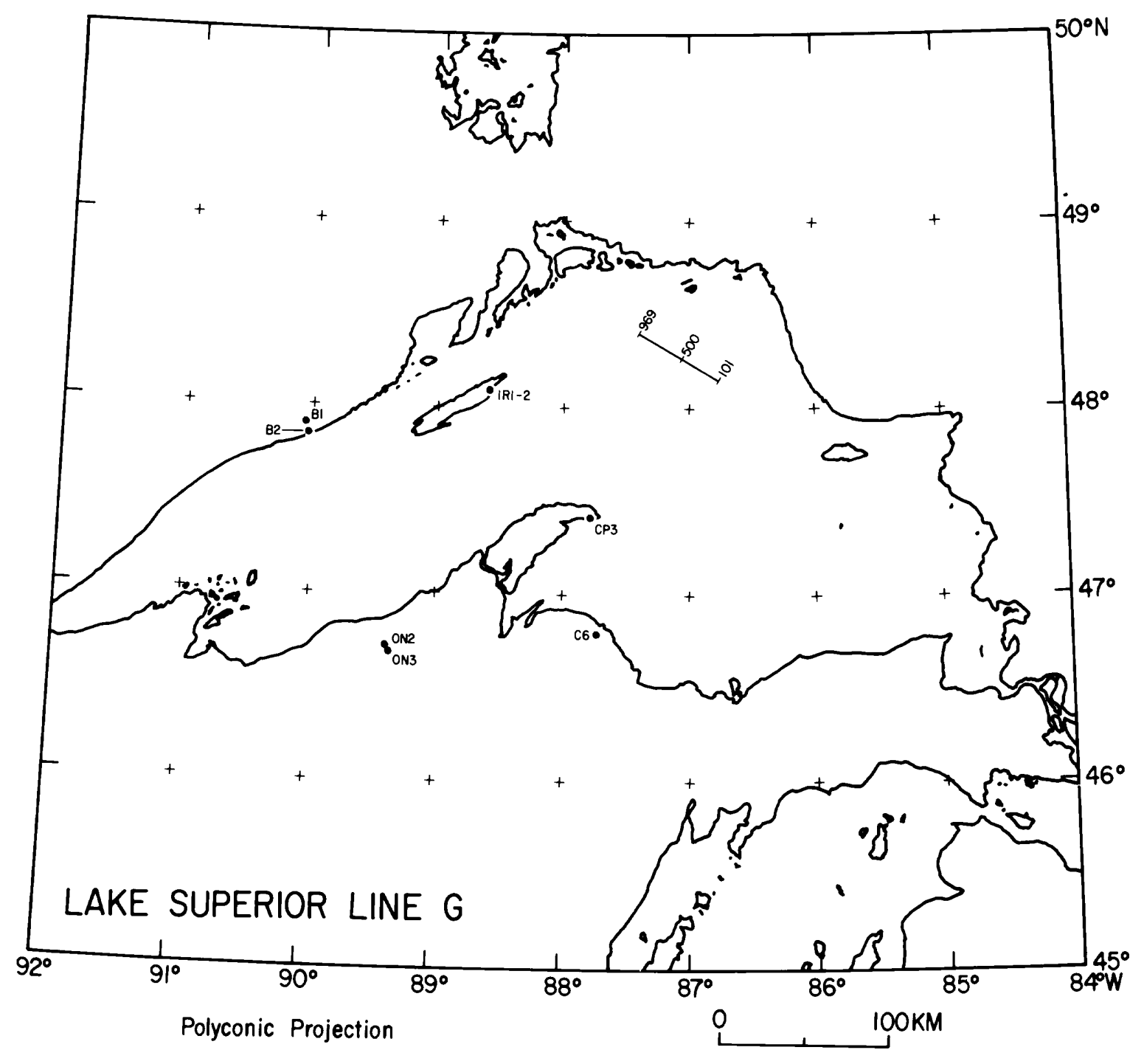


Figure 10: Shot and station locations for line $\mathrm{H}$. Symbols are the same as those used in Figure 1. Additional information is listed in Table 9. 


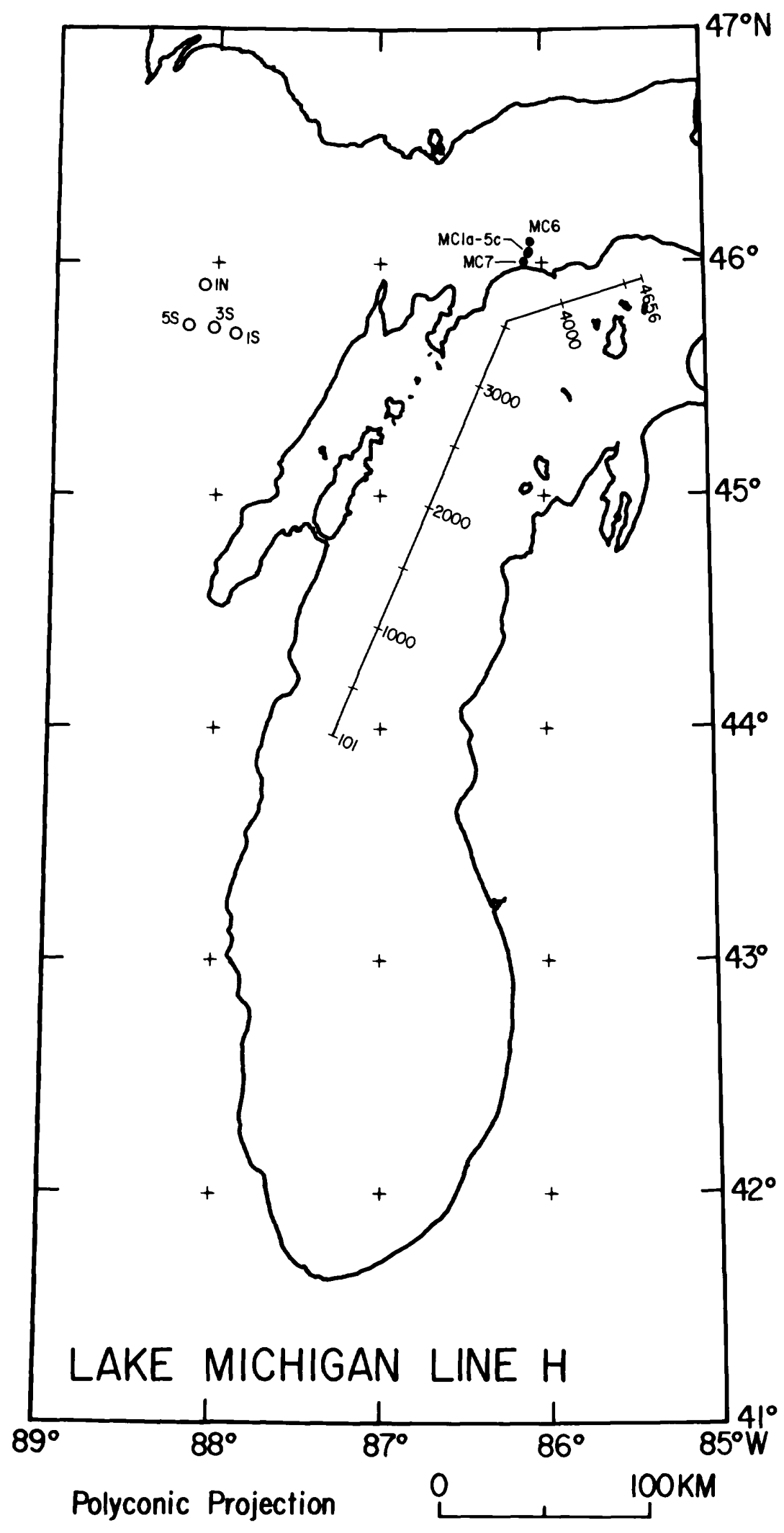


Figure 11: Shot and station locations for line 1 . Symbols are the same as those used in Figure 1. Additional information is listed in Table 10. 


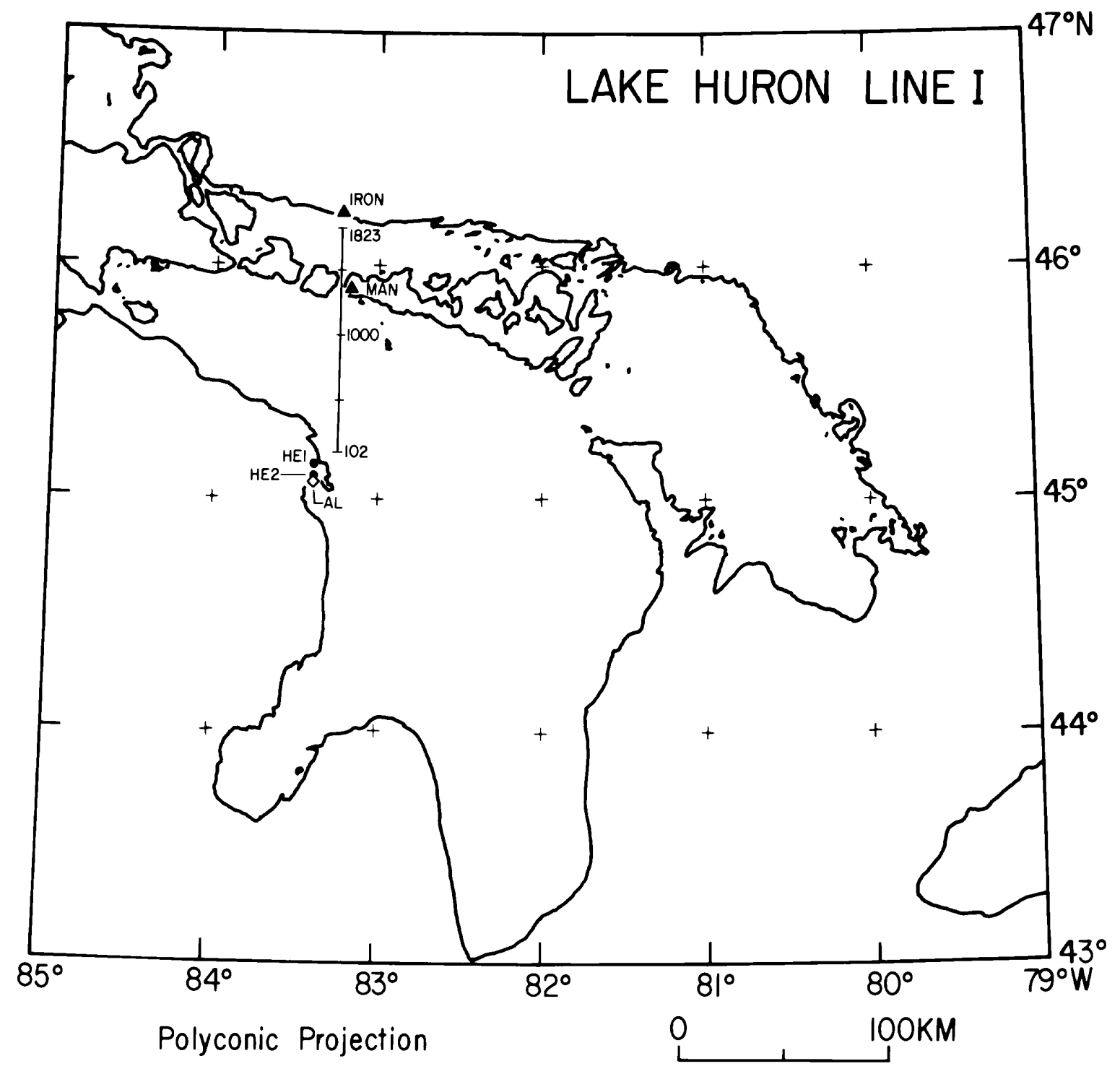


Figure 12: Shot and station locations for line J. Symbols are the same as those used in Figure 1. Additional information is 1isted in Tab1e 11 . 


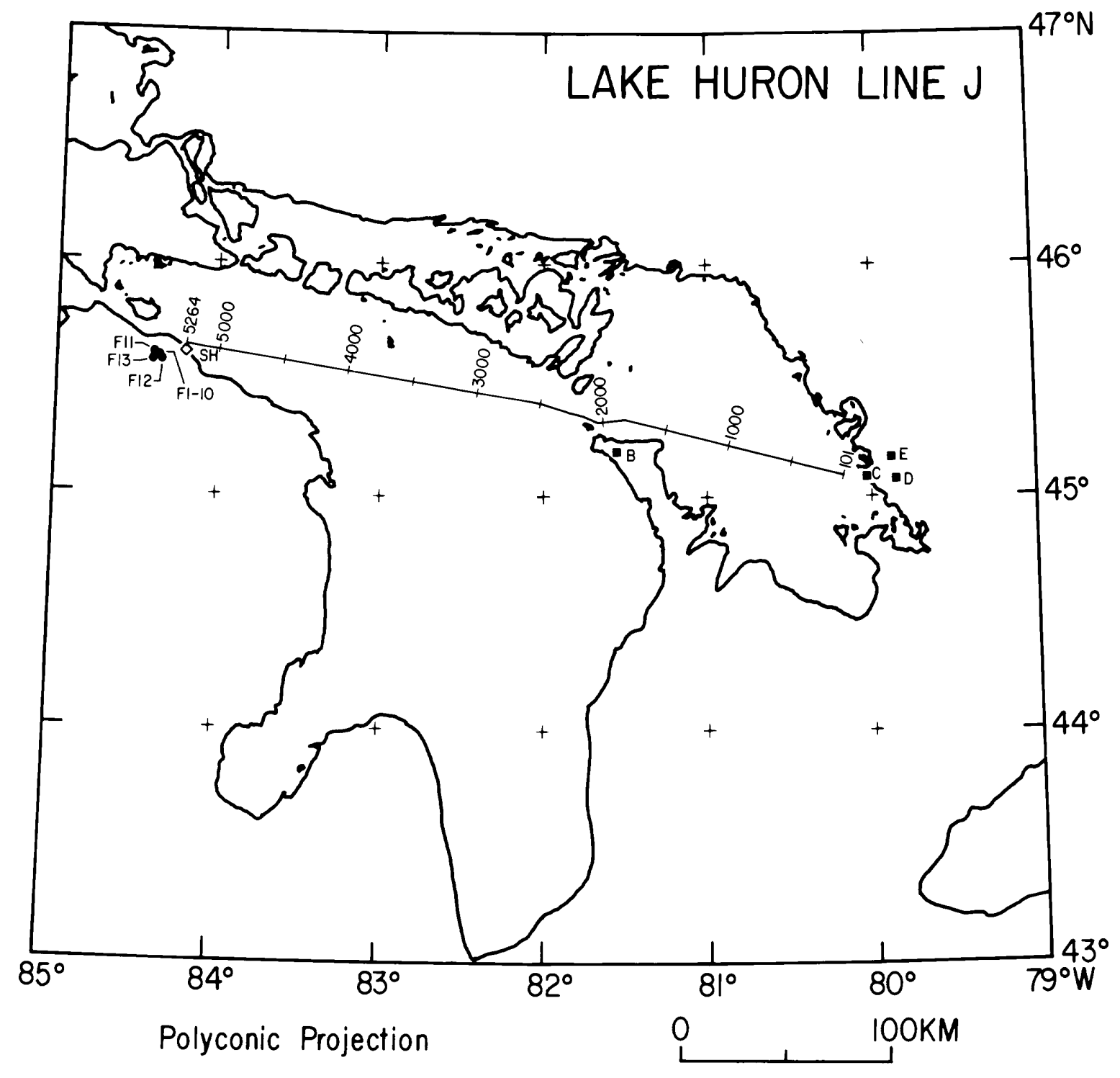


APPENDIX I

INSTRUMENT DETAILS AND PERSONNEL

This Appendix lists the people participating in the field effort and appropriate instrumental details and archive information not covered elsewhere in the report. 
I. U.S. GEOLOGICAL SURVEY (USGS)

Anne M. Trehu: USGS, Principal Investigator

G. Miller: USGS

J.F. Boyd: U.S. Coast Guard, Captain

Crew of vessel U.S.C.G. Katmai Bay

Instrument: USGS Ocean Bottom Seismometer

Sample rate: $7.813 \mathrm{~ms}$, reformatted to $8 \mathrm{~ms}$.

Record length: $32 \mathrm{~s}$

Frequency of recording: $2 \mathrm{~min}$

Filters: $0-30 \mathrm{~Hz}$

Field tape ID: GL86-A2, -A8, -C9, -C4,-C3

Field tape format: TIP (USGS/OBS internal format)

Archived at: U.S. Geological Survey

Data Library

Branch of Atlantic Marine Geology

Woods Hole, MA 02543

Comment: - Instruments C3, C4, C9: no hydrophone data.

- Instrument A8: recorded only far ranges.

- Locations for A2, C3, C4, C9 calculated by water wave inversion technique, as described below.

- Location for A8 taken as the LORAN C position calculated by ranging to the instruments from USCG Katmai Bay.

- Horizontal components recorded for only a portion of the line because of data storage limitations.

Note on Instrument locatons:

Instrument locations in field were determined by acoustically ranging to the OBS on the lake floor from 4-6 surface locatons and inverting the traveltimes thus obtained (Creager and Dorman, 1982). Ranges calculated from these locations were not consistent with the positions of the closest shots plotted on the record sections, indicating that the navigation of the Coast Guard Ship (LORAN C) was incompatible with that of the shooting ship (Satellite and Doppler Sonar).

Instrument locatons for $\mathrm{A} 2, \mathrm{C} 3, \mathrm{C} 4$, and $\mathrm{C} 9$ were recalculated based on the locations of the shots provided by the shooting ship using water-wave inversion solutions, which invert the travel times of the water waves from the closest shots. Because the cross-over distance between the direct water-wave arrival and first refracted arrival occurred within 2-3 shots of the closest approach, locating the instruments with this technique required information on the near-surface sediment velocity in the vicinity of the instrument. This velocity was not well known; however, varying the assumed velocity should yield a solution for both instrument position and velocity that gives minimum travel-time variance. This was not done because of program limitations and the probable poor resolution of the final result. The simplified water-wave inversion solutions were in good agreement with the plotted intersections of allowable range circle drawn for the three closest shots based on direct water wave arrival times and an assumed velocity of $1.45 \mathrm{~km} / \mathrm{s}$. The water-wave inversion technique also calculates water depths (given in Table 3) which were essentially identical to those recorded on the ship's fathometer during OBS deployment. 
Because the water-wave inversion technique utilizes the closest shots, none of which were recorded for instrument A-8, its location is based on inversion of travel-time ranging obtained on the Coast Guard ship

II. GEOLOGICAL SURVEY OF CANADA (GSC)

Patrick More1-a-1'Huissier: GSC, Principal Investigator

C.P. Spencer: GSC

I. Asudeh: GSC

W. Moon: University of Manitoba

P. Burchat: GSC

J. Craven: GSC

F. Larue: GSC

H. Lau: GSC

P. Shyre: GSC

R. St evens: GSC

C. Samson: University of Toronto

D. Epili: University of Western Ontario

T. Shortt: University of Western Ontario

Instrument: PRS 1 digital recorder

Sample rate: $120 \mathrm{~Hz}$ ( $8 \mathrm{~ms}$ )

Record length: 30, 40, $50 \mathrm{~s}, 3 \mathrm{~min}$

Frequency of recording: $2 \mathrm{~min}$ and continuous

Filters: $0.5-60 \mathrm{~Hz}$

Field tapes: floppies and/or cassettes (transcribed to 9T)

Field tape format: SEGY (9T)

Archived at: $\quad$ P. More1-a-1' Huissier

Lithosphere and Canadian Shield Division

Geological Survey of Canada

1 Observatory Crescent

Ot tawa, Ontario KIAOY3

Comment: - SUP1, SUP7: data sets incomplete because of instrument malfunction

- SUP8: hole in middle of section because of instrument malfunction

- SUP2A: completes data that were not recorded by Univ. of Saskatchewan because of poor weather

- SUP7A: completes data not recorded for SUP7.

- Locations and elevations from TOPO sheets 
III. UNIVERSITY OF WISCONSIN - MADISON (UWM)

Robert P. Meyer: UWM, Principal Investigator

H. Meyer: UWM

R. Meyer: UWM

V. Green: UWM

S. Shih: UWM

B. Unger: UWM

Instrument: UW Digital Seismographs

Sample rate: $10 \mathrm{~ms}$

Record length: variable

Frequency of recording: variable

Filters: $0.27-24 \mathrm{~Hz}$

Field tape 10: 275 field tapes

Field tape format: UW Digital Seismograph Standard

Archived at: Dept. of Geology and Geophysics

University of Wisconsin

1215 W. Dayton St.

Madison, Wisconsin 53706

Comment: - Stations MC1, MC2, MC3, MC4, MC5 are 3 vertical geophones in a linear array: all others are 1 vertical, 2 horizontals (north and east).

- Locations and elevations from TOPO sheets

\section{UNIVERSITY OF WESTERN ONTARIO (UWO)}

Robert F. Mereu: UWO, Principal Investigator

T. Cox: UWO

J. Wu: UWO

T. Shortt: UWO

C. Faust: UWO

D. Epili: UWO

R. Secco: UWO

B. Lenson: UWO

C. Spindler: UWO

J. Brunet: UWO

B. Dunn: UWO

B. Price: UWO

Instrument: U. Western Ontario Portable FM recorders

Sample rate: $8 \mathrm{~ms}(125 \mathrm{~Hz})$

Record length: 45 min

Frequency of recording: continuous

Filters: $0.1-35 \mathrm{~Hz}$

Field tapes: analog transcribed to digital

Field tape format: SEGY (digital tapes)

Archived at: R.F. Mereu

Department of Geophysics

University of Western Ontario

London, Ontario N6A 5B7

Comment: - Locations and elevations from TOPO sheets 
V. NORTHERN ILLINOIS UNIVERSITY (NIU)

Patrick Ervin: NIU, Principal Investigator

P. Carpenter: NIU

G. Frantti: Michigan Tech.

B. Morrow: NIU

T. Salihoglu: NIU

M. Thompson: NIU

C.L. Ervin: NIU

Students from Michigan Tech University

Instrument: PDR-2 and MEQ-800

Sample rate: $10 \mathrm{~ms}$

Record length: 6258 bytes

Frequency of recording: continuous

Filters: $0-50 \mathrm{~Hz}$

Field tapes: 20 tapes and paper records

Field tape format: Kinemetrics hi-density, Terra-Tec internal format

Archived at: Department of Geology

Northern Illinois University

Deka1b, Illinois 60115

Comment: - Instrumental problems and large noise made data recovery on all instruments minimal

- Locations and elevations from TOPO sheets

VI. UNIVERSITY OF SASKATCHEWAN (U SASK.)

Zoltan Hajnal: U. Sask, Principal Investigator

W. Chan: U. Sask.

D. Wilkinson: U. Sask.

M. Johnson: U. Sask.

G. Wood: U. Sask.

Instrument: multichannel geophone array

Total groups: 48

Group Interval: $67 \mathrm{~m}$

Array geometry: 1inear $\left(\mathrm{N} 45^{\circ} \mathrm{W}-\mathrm{BB}\right),\left(\mathrm{N} 30^{\circ} \mathrm{E}-\mathrm{AA}\right)$

Recording Instrument: DFS $\mathrm{V}$

Sample rate: $2 \mathrm{~ms}$

Record length: $20 \mathrm{~s}, 30 \mathrm{~s}$

Frequency of recording: $40 \mathrm{~s}, 2 \mathrm{~min}$.

Filters: $0-128 \mathrm{~Hz}$

Field tapes: 2 - 102 (9T, 1600 BPI)

Field tape format: SEG B

Archived at: Department of Geological Sciences

University of Saskatehewan

Saskatoon, Saskatchewan S7N OWO

Comment: - Instrument failure 31 Aug: 1756 - 1916 and no recording because of storm after 1 Sept 0759

- Locations and elevations from TOPO sheets

- Locations are given for the center of the array. Locations written in to the SEG-Y tape header are for the best trace of the array and are slightly different. 
John L. Sexton: SIU, Principal Investigator

S. Wendling: SIU

J. Bowden: SIU

H. Henson: SIU

Instrument: multichannel geophone array

Total Groups: 24

Group Interval: $25 \mathrm{ft}$.

Array Geometry: linear (E/W)

Recording Instrument: DFS $\mathrm{V}$

Sample Rate: $2 \mathrm{~ms}$

Record Length: $60 \mathrm{~s}, 44 \mathrm{~s}$

Frequency of recording: continuous

Filters: $0-64 \mathrm{~Hz}$

Field tapes: 186 (9T, 1600 BPI) tapes

Field tape format: SEG B

Archived at: Department of Geology

Southern Illinois University

Carbondale, Illinois 62901

Comment: - Some $60 \mathrm{~Hz}$ problems on lines I, J

- Locations and elevations from TOPO sheets

VIII. UNIVERSITY OF WISCONSIN - OSHKOSH (UWOSH)

John H. Kar1: UWOSH, Principal Investigator

T. Jefferson: UWOSH

S. Bouc: UWOSH

J. Colletta: UWOSH

D. Kowalkowski : UWOSH

P. Meyer: UWOSH

Instrument: multichannel geophone array

Total Groups: 96

Group Interval: $100 \mathrm{~m}, 50 \mathrm{~m}$

Array Geometry: L-shape, X-shape

Recording Instrument: DFS - IV

Sample Rate: $8 \mathrm{~ms}$

Record length: $295 \mathrm{~s}, 80 \mathrm{~s}$

Frequency of recording: continuous, $2 \mathrm{~min}$

Filters: $0-31 \mathrm{~Hz}$

Field tapes: 87 (9T, $1600 \mathrm{BPI})$ tapes

Field tape format: SEGB

Archived at: Department of Physics and Astronomy

University of Wisconsin, Oshkosh

Oshkosh, Wisconsin 54901

414-424-4432/4431

Comment: - Locations and elevations from TOPO sheets

- Reel changes cause 10-minute gaps in recording, approximately every hour

- Instrument failure on Line A-reflection caused loss of E-W arm of $x$-shaped array on 7 September, 0420-1400 GMT. 
APPENDIX II:

NAVIGATION AND TIMING DETAILS FOR SHOT POINTS

This appendix consists of the final report submitted by the contractor on the navigation and shot instants. Note that the navigation for each shot point is taken to be the position of the satellite antenna, which was located $74 \mathrm{~m}$ in front of the center of the airgun array. These data are archived at USGS (Denver, $\mathrm{CO}$, and Woods Hole, MA) and are available from National Geophysical Data Center, NOAA, Code E64, 325 Broadway, Boulder, C0, 80303 (telephone: 303-497-6338) 
NAVIGATION REPORT

ON

SATELLITE AND TIMING CORRECTIONS

FOR THE 1986 GREAT LAKES REFRACTION AND REFLECTION SEISMIC SURVEY

FOR

THE GEODETIC SURVEY OF CANADA (SIC)

AND

THE UNITED STATES GEOLOGICAL SURVEY

by

GEOPHOTO SERVICES, LTD.

CALGARY, ALBERTA

$1987 \quad 1207$ 
CONTENTS

PAGE

Introduction .................. I

List of Seismic Lines ............ 2

Map of Survey Area .............. 3

Summary of Events During Survey ...... 4

Satellite Antenna Height Error ...... 6

Sketch of Height Effects .......... 8

Height Correction Diagram .......... 9

Errors in the Timing system ........ 10

Recommendations ............... 12

56 


\section{INTRODUCTION}

A marine geophysical survey was conducted for the Geodetic Survey of Canada in conjunction with the United States Geological Survey between 19860829 and 198609 23 in the Great Lakes. The M/V Fred J. Agnich shot two lines of refraction data and $1343 \mathrm{~km}$ of reflection data in Lake Superior, Lake Huron and Lake Michigan.

Geonav was used as the navigation system to shoot the entire Great Lakes prospect. The integrated navigation was a configuration of a Magnavox. 1107 TRANSIT satellite receiver, doppler sonar and a gyrocompass. An Internav 400 LORAN $C$ receiver was available with additional velocity and position information and a TI4100 GPS receiver was on board for most of the survey as backup and an additional QC system and for updates to the LORAN $C$.

For the purposes of the GLIMPCE experiment some special modifications were made to the M/V Agnich's control/navigation system (CMS). These include interfacing to a GOES satellite receiver/chronometer. interfacing to a modified CMS chronometer and modifying the system coordinator to allow predetermined delays to be set into the recording seauence.

The CMS was synchronized to WWV time through the GOES satellite receiver and the CMS chronometer. After the initial passina of time to the CMS chronometer and simultaneous CMS start and WWV synchronization, the chronometer supplied the CMS with a $100 \mathrm{~ms}$ interrupt by which the CMS kept time. If the CMS chronometer missed its interrupt from the WWV chronometer the two would be out of synchronization and a LED indicated the error unless the CMS was stopped and restarted.

During the course of the project several problems affected the data collection. One serious problem was unexplained large satellite updates occurring with otherwise good navigation data. After completion of the first 1 ine on 0901 several days were spent investigating all aspects of the satellite system and on 0905 it was discovered that the update problems were a result of loading an erroneous antenna height into the 
CMS (neglecting to account for 183 metre difference of Lake Superior to sea level). Another problem affecting the data was the time as recorded on tape was not in synchronization with the WWV satellite time. This was due to some delays not being accounted for and interruptions in the system.

The errors introduced by the above incidents were corrected. This report gives an explanation of the corrections and how they were applied.

\section{LIST OF SEISMIC LINES}

\begin{tabular}{|c|c|c|c|c|}
\hline Line & $\begin{array}{l}\text { Julian } \\
\text { Day }\end{array}$ & FSP & $\begin{array}{l}\text { Jul ian } \\
\text { Day }\end{array}$ & LSP \\
\hline AA- & 243 & 109 & 244 & $\overline{748}$ \\
\hline $\mathrm{BB}^{\circ}$ & 249 & 111 & 250 & 2063 \\
\hline BFL INK & 250 & 101 & 250 & 455 \\
\hline$F^{\prime}$ & 250 & 457 & 251 & 1579 \\
\hline$F^{\prime} F^{\prime \prime}$ & 251 & 1580 & 251 & 2843 \\
\hline$A^{\prime} A$ & 252 & 101 & 253 & 2326 \\
\hline$A " A$ & 253 & 2290 & 253 & 3944 \\
\hline$G^{\prime} G$ & 254 & 101 & 254 & 969 \\
\hline $\mathrm{CC}^{\prime}$ & 255 & 156 & 255 & 771 \\
\hline$C C^{\prime} A$ & 255 & 741 & 256 & 1880 \\
\hline 3 & 261 & 101 & 262 & 4636 \\
\hline 1 & 263 & 102 & 264 & 1823 \\
\hline $2 A$ & 265 & 101 & 266 & 5264 \\
\hline
\end{tabular}




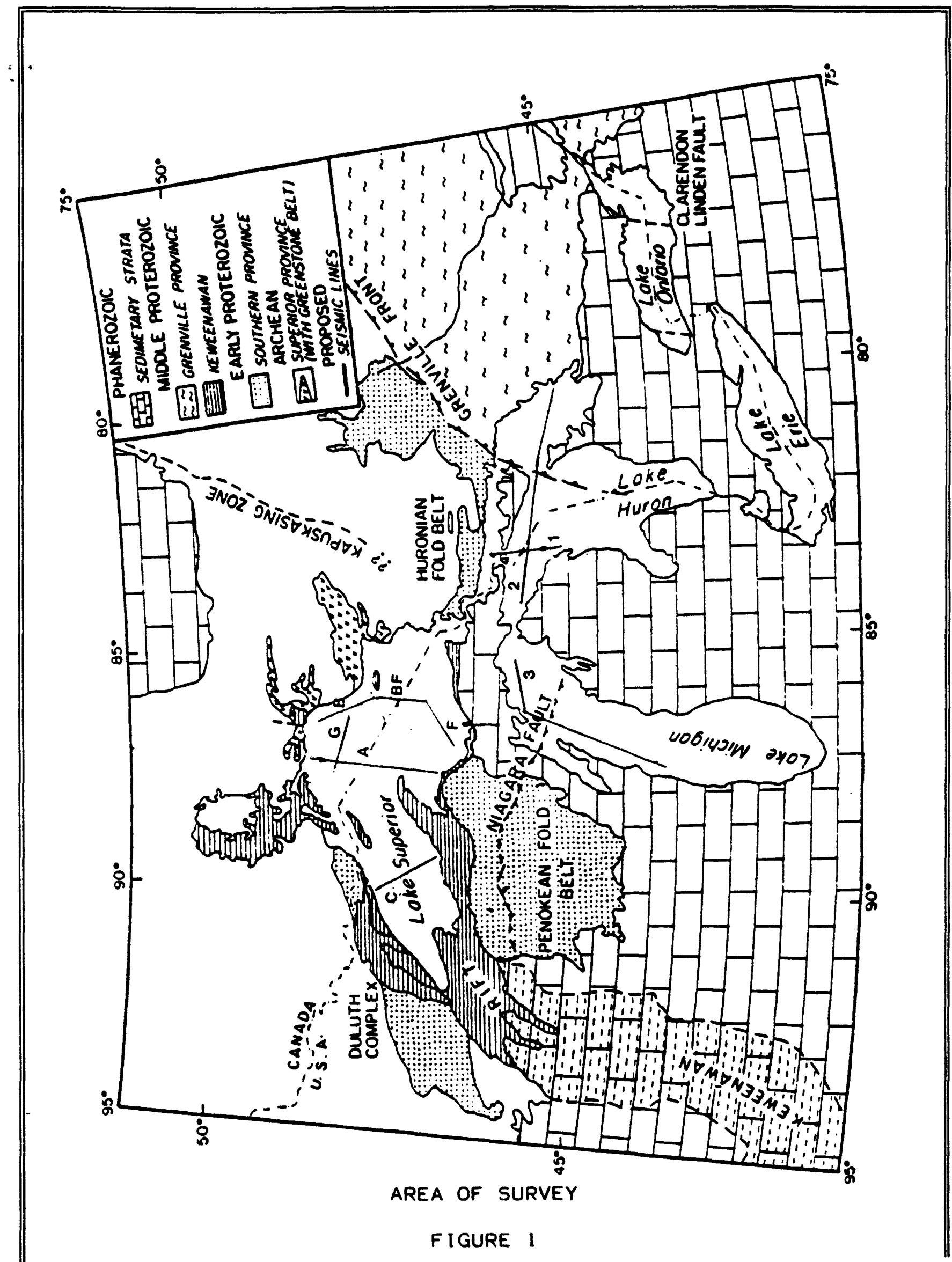




\section{SUMMARY OF EVENTS DURING SURVEY}

\section{LAKE SUPERIOR}

Line $A A-$ was shot in time mode with an external chronometer synchronized to WWV satellite time for control. An external fire command was issued on every even two minute mark. Various stations were set along the shore to collect refraction data in a continuous mode as well as several buoys being placed the U.S.G.S. by the U.S. Coast Guard for collection of reflection data. Problems with large satellite updates began during the shooting of the 1 ine but as it was a one time effort (batteries in the buoys were good for about 24 hours) the production was continued. Line AA- was completed on 0901 . After several days of investigating all aspects of the satellite system, on 0905 it was discovered that the update problems were a result of loading an erroneous antenna height into the system This incident is detailed later in this report.

The first chargeable shotpoint on Iine $\mathrm{BB}^{\prime}$ was 111 and the line proceeded normally to the end with a $50 \mathrm{~m}$ shot spacing.

The end coordinates for BFLINK were the southerly coordinates off line $\mathrm{BB}^{\prime}$ and the the northerly coordinates of $\mathrm{FF}^{\prime}$ and the line was shot as a tie between the two. The shot interval was $50 \mathrm{~m}$ but the cable became uncontrollable and sank due to a change in water temperature. The 1 ine was terminated at shotpoint 456. The client representative on board the vessel approved a decision to increase the shotpoint interval to $62.5 \mathrm{~m}$ to allow an increase in vessel speed.

Line $\mathrm{FF}^{\prime}$ was started with the $62.5 \mathrm{~m}$ shot interval and a speed of $4.3 \mathrm{kn}$ until shotpoint 865 where the interval was reduced to $50 \mathrm{~m}$ and then increased to 62.5 $m$ at shot 902 for the remainder of the line. A dogleg was executed at shotpoint 592 .

$F^{\prime} F^{\prime \prime}$ was started at a $50 \mathrm{~m}$ interval and remained that way until shot 2096 where it was increased to 62.5 $m$ for the remainder of the survey. Velocity information was from sonar and at times LORAN $C$ due to loss of tracking in deep water $(+365 \mathrm{~m})$. 
The $980 B$ NAV computer was halted temporarily to replace a circuit board before the beginning of $L$ ine A'A. The system was restarted before the first chargeable shotpoint. The synchronization between the CMS and WWV time were lost because of this and the CMS time had a 24.5 s offset (slow) that remained until the end of $A$ "A.

On I ine A"A the sonar velocities gave some problems due to a rising and falling water bottom.

Before commencing Line $G^{\prime} G$ the CMS/GOES timing system was resynchronized.

On Line $C^{\prime}$ ' the compasses in the streamer began spiking and were unusable due to a very strong magnetic anomaly in the area. By shotpoint 356 the anomaly was sufficiently far enough away for the Streamer Tracking System (STS) to accept the compass data and they remained settled for the remainder of the 1 ine. There were time loss problems at the end of this line due to a loose connector for the $100 \mathrm{KHz}$ signal thus affecting the count-up for the CMS $0.1 \mathrm{~s}$ clock interrupt and causing it to lose time. It was terminated for this reason and restarted at the last known good $t i m e$.

Line CC'A was started with the CMS synchronized to WWV but a 23.1 s shift occurred was discovered to have occurred sometime after shotpoint 970 .

\section{LAKE MICHIGAN}

The CMS was reinitialized with the new antenna height to include the elevation of Lake Michigan (176.5 $m$ above sea level). Line 3 had a dogleg initiated at shotpoint 3556 .

\section{LAKE HURON}

The elevation of Lake Huron ( \& Georaian Bay) is the same as Lake Michigan so the antenna heights remained unchanged. Line 1 was shot south to North through Mississagi Strait in Lake Huron. The beginning of the I ine was shot at a slower speed to avoid a barge. It was no longer obstructing the path by shot 166. The line was terminated $3.8 \mathrm{~km}$ from the preplotted E.O.L. due to impending shallow water endangering the streamer. 
Line $2 A$ was shot from East to West from Georgian Bay into Lake Huron through the Main Channel via a series of dogleg segments. Deviations of up to $485 \mathrm{~m}$ to the north of the intended line had to be initiated through the channel to avoid rocks, ferry boats and shallow water. The doglegs were executed at shotpoints 1841, 2033 and 2487. At the second dogleg the vessel was steered off line to starboard to avoid a shallow water area. They were back on 1 ine at shot 2281 and performed another dogleg at shot 2487 . The line terminated normally.

\section{SATELLITE ANTENNA HEIGHT ERROR}

It was discovered after completion of Iine AA- that the update problems were due to the wrong satellite antenna elevation being input into the CMS. Lake Superior is $183 \mathrm{~m}$ above mean sea level which was not originally accounted for during system initialization. The errors introduced by this omission are predictable and were corrected in post processing. The magnitude of shift introduced by the error in height initialization ranged from 42 to $392 \mathrm{~m}$ with the greatest movement in a longitudinal direction. The table below summarizes the corrections computed. Figure 2 gives a graphical representation of the situation and Figure 3 shows the magnitudes of the displacement (corrections) versus the satellite elevation angles. 
The following is a list of the corrections applied to the individual satellite fixes on 1 ine AA- in the post processing:

\begin{tabular}{|c|c|c|c|c|c|}
\hline$F I X \#$ & Elev. & $A z$ & CORR (M) & $d N(M)$ & $d E(M)$ \\
\hline 15 & 25 & 85.2 & 85.3 & 85.0 & 6.7 \\
\hline 16 & 65 & 272.6 & 392.5 & -392.1 & 17.8 \\
\hline 17 & 13 & 95.7 & 42.2 & 42.0 & 4.2 \\
\hline 18 & 54 & 285.6 & 251.9 & -242.4 & 67.7 \\
\hline 19 & 11 & 89.7 & 33.0 & 35.6 & 0.2 \\
\hline 20 & 41 & 259.9 & 158.2 & -156.6 & -27.9 \\
\hline 21 & 13 & 101.4 & 42.2 & 41.4 & 8.3 \\
\hline 22 & 55 & 91.7 & 261.4 & 261.2 & 7.8 \\
\hline 23 & 27 & 265.7 & 93.2 & -93.0 & 7.0 \\
\hline 24 & 26 & 75.4 & 89.2 & 86.4 & 22.5 \\
\hline 25 & 26 & 75.4 & 89.2 & 86.4 & 22.5 \\
\hline 26 & 57 & 238.4 & 281.7 & -240.0 & -147.7 \\
\hline 27 & 54 & 87.5 & 251.9 & 251.7 & 11.0 \\
\hline 28 & 56 & 281.2 & 271.3 & -266.1 & 52.7 \\
\hline 29 & 20 & 73.5 & 66.6 & 63.8 & 18.9 \\
\hline
\end{tabular}

Subsequent lines were shot with the proper antenna height applied. 


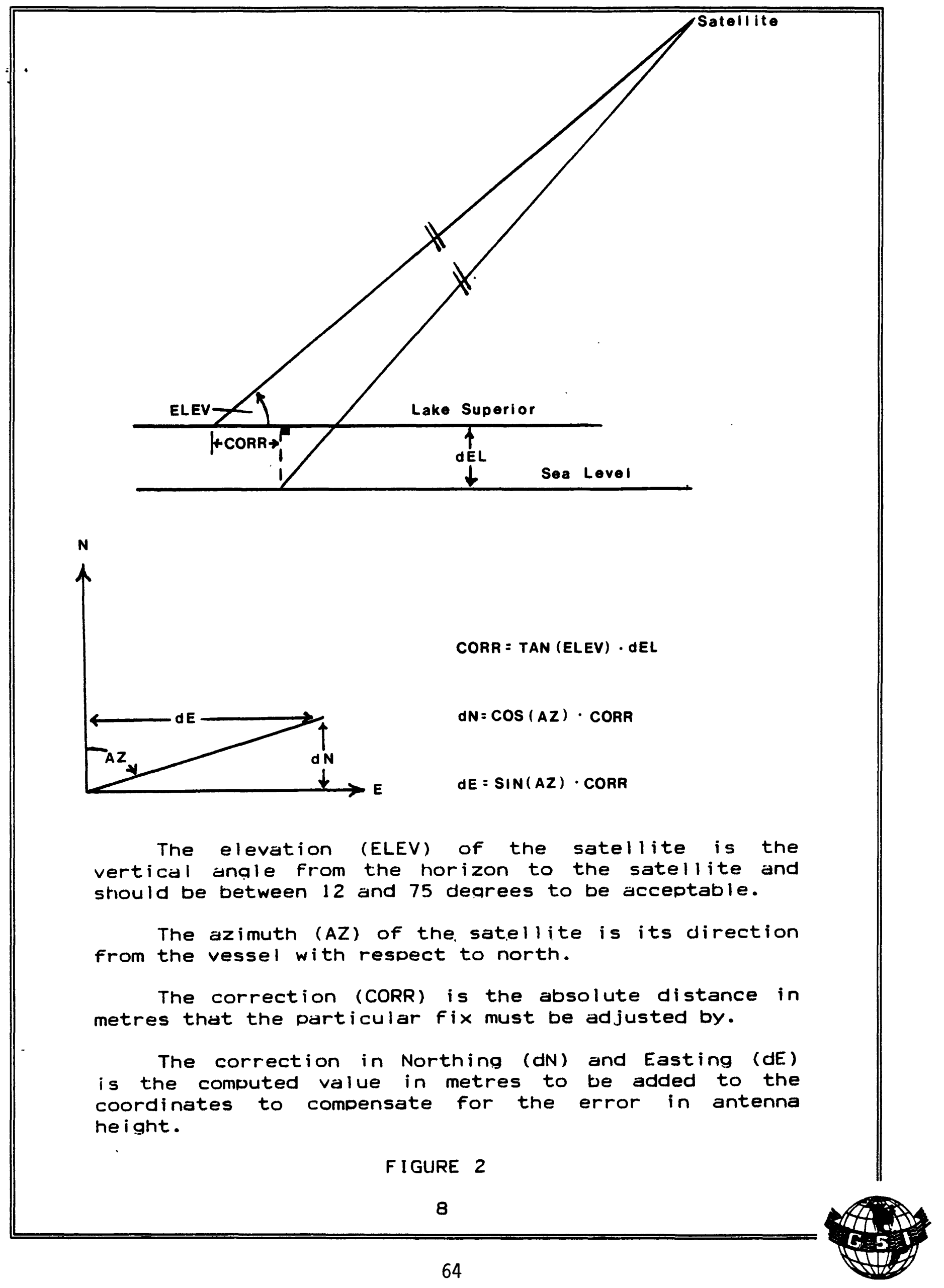




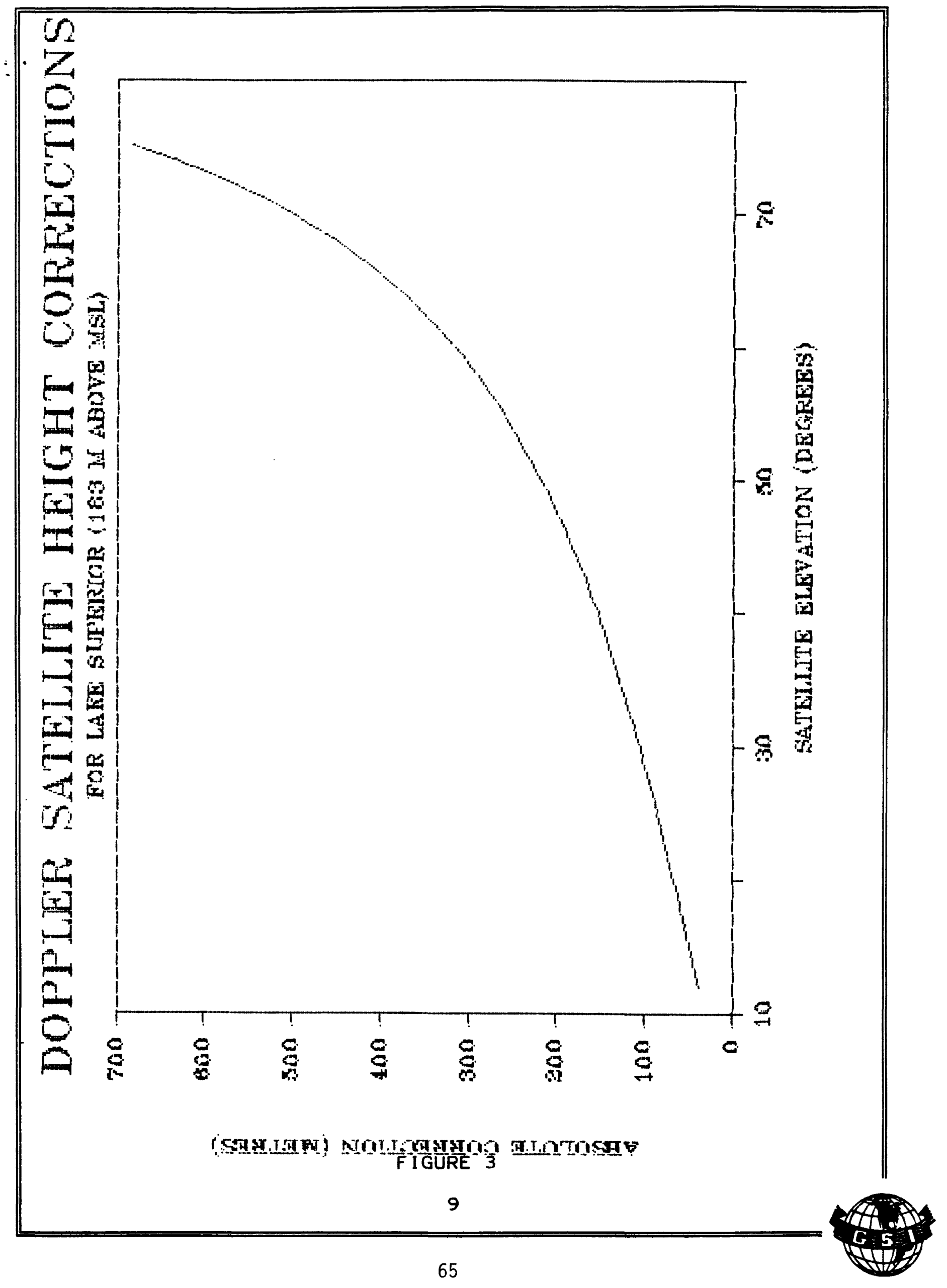




\title{
ERRORS IN THE TIMING SYSTEM
}

\begin{abstract}
A variety of different timing delays affected the the data collected for the prospect.
\end{abstract}

The firing sequence for all lines except the first (AA-) was accomplished with the DFS $V$ in distance mode. The CMS issued the firing command to start the sequence. Additional circuitry to delay the start by $200 \mathrm{~ms}$ was added to avoid CMS shot-to-shot jitter of the start pulse $(1$ - 20 ms $)$. A delay off 0.65536 swas present to allow the DFS tape transports to ramp up to speed and write the header data. A wire blast was issued to the TIGER II which issued a time break (1.4 ms delay). There was a 51.2 ms delay from the issue of the field time break to the firing of the guns. There was a further 1.31072 second delay at the first shot after each DFS tape change due to the DFS taking longer writing its ID burst to tape and detection of the wire blast missing the first normal "window" latch and catching the next rising clock cycle.

Line $A A-$ was shot for refraction data in a time fired mode. The DFS $V$ was fired on a two minute interval controlled by the time from the WWV satellite. To accomplish this additional circuitry was installed in the chronometer to synchronize it with the WWV clock to within $1 \mathrm{~ms}$. The interval was set to fire on even two minute marks with the external start issued from this clock circuitry to the system coordinator which passed it to the CMS and immediately issued a start. All of the above mentioned delays were also present during this mode of shooting except that an additional 1 s delay was introduced into the time as recorded on the CMS (ex: $5 \mathrm{~m}$ $59 \mathrm{~s}$ would be recorded on tape for a shot at $6 \mathrm{~m} 00 \mathrm{~s}$ ) since it used presently latched time to store on tape (gets updated 50 - 150 ms later).

The navigation data were processed without due regard for the original field time and in cases of missed shotpoints and deletions of data anomalies the time was interpolated. Under reflection seismic processing circumstances this would not cause any problems but in the case of the refraction 1 ines it is not acceptable. The time as recorded in the field was stripped from the CMS data and used for the final data. 
The final navigation data with original CMS times were corrected to remove the effects of the delays and time offsets.

The following is a summary of the various system delay corrections (all are positive values) used for the final post processed Navigation Tape:

Distance \& External Mode ....

delay from fire issue to DFS receiving start $0.20000 \mathrm{~s}$

start issue to wire blast to TIGER -------- $0.65536 \mathrm{~s}$

wire blast at TIGER to field time break ---- $0.00140 \mathrm{~s}$

internal gun delay -

TOTAL $\overline{0.90796} \mathrm{~s}$

Total Delay in Distance Mode:

Total of the above delays -- $0.90796 \mathrm{~s}$

First shot at every BOT ---- $2.21868 \mathrm{~s}$

Total delay in External Mode:

Total of the above delays -- $0.90796 \mathrm{~s}$

External Mode delay ------ 1.00000 s 


\section{RECOMMENDATIONS}

On any future jobs of this nature it is recommended that the time from the reference source (WWV satellite receiver in this project) be input from a parallel output into a display with an accuracy of milliseconds. In addition to this a similar output from the CMS clock should be sent to the same display and the time difference computed and displayed as well. These times should be recorded for every shotpoint (to 5 significant digits) in a spare or unused position on the CMS tape. An alarm associated with the display should be in place so that a defined limit could be set and any differences outside the chosen range would be flagged and the alarm tripped. A hardcopy of all times and differences should be recorded in the ADL printer output.

In addition to displaying both CMS start time and WWV clock time we should also log the true firing time of the airguns by using the sum shuttle pulse to load the clock time. This could be output to the line printer and stored to tape at the next $(S P+1)$ shotpoint. We would always have to shoot 1 extra shot at the end of the line but this would be easy to do with existing CMS software. Every shot would have a three-way check ( $t$ ime) with all delays being known. This would also show any wire-blast to time break jitter which exists in the present TIGER II software if the TIGER II is not synchronized to a $1 \mathrm{mill}$ isecond interrupt.

As well as the proper recording and QC display of the timing there should be the opportunity to make corrections to the CMS recorded time for the known delays including those due to BOT headers at DFS tape changes so that the WWV and CMS time difference is zero. The proper time to be recorded on tape is the correct one (no changes or corrections in post processing). If an offset does occur due to a system idle or a loose connection and can't be corrected immediately, then the corrections will have to be made during the post processing. 
Respectfully submitted by Geophoto Services, Ltd.

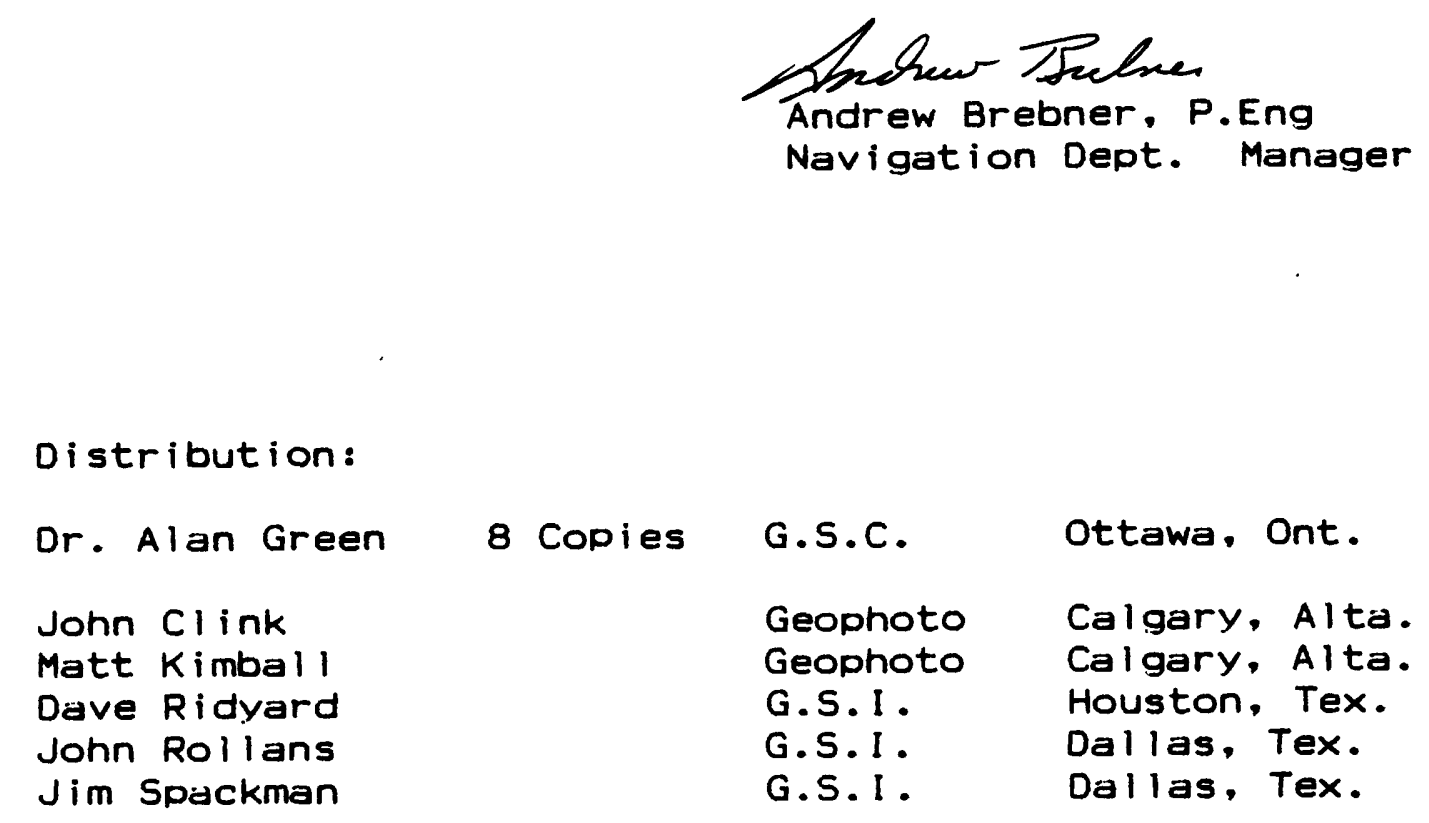


APPENDIX III:

RANGE ALGORITHM

The attached listing gives the FORTRAN code for the algorithm used by all participants in calculating ranges from the shots to the instruments. 


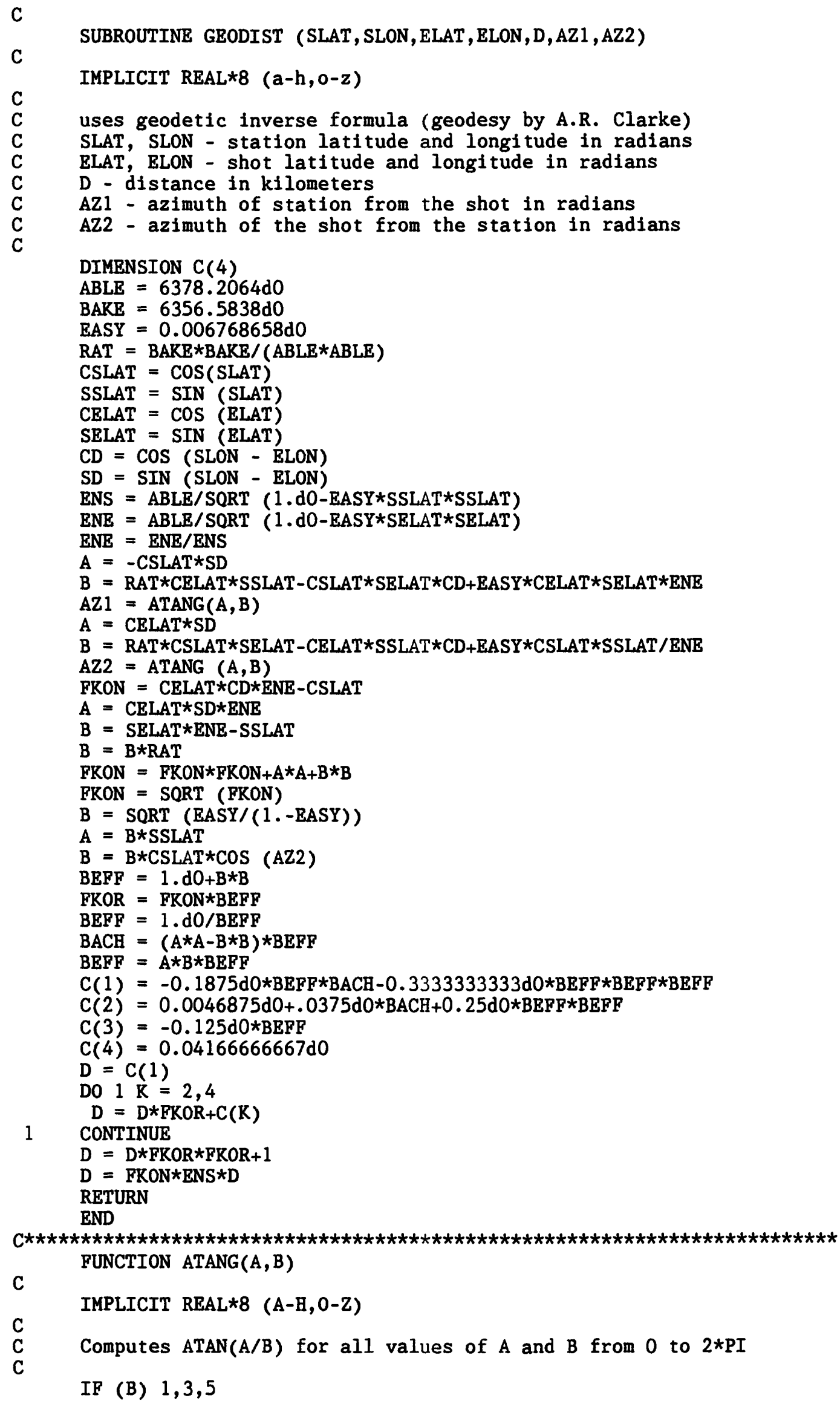




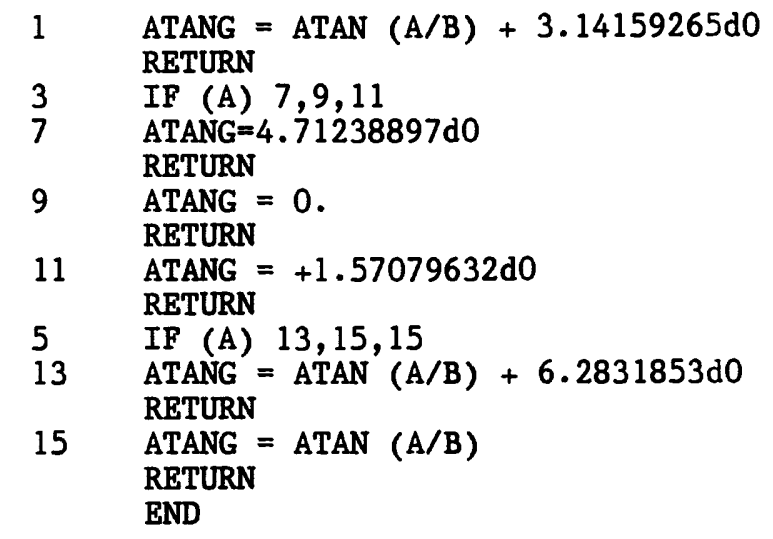

73

paige 75 follow: 


\section{SEG-Y(LDS) EXCHANGE FORMAT}

This appendix lists the FORTRAN code used for the exchange of all refraction and wide-angle data. This code is a series of FORTRAN EQUIVALENCE statements which define file and trace header information for programs used to read the data. This code was developed by C. Spencer and I. Asudeh at GSC for use with lithoprobe refraction data.

The exchange format, called SEG-Y(LDS) (SEG: Society of Exploration Geophysicists; LDS: Lithoprobe data storage), is a superset of SEG-Y format. Whereas SEG-Y provides an industry standard for the exchange of seismicreflection data (Barry et al., 1975), SEG-Y(LDS) provides a suitable format for the storage and exchange of seismic refraction data. Any existing SEG-Y program is capable of reading the data. However, SEG-Y(LDS) goes beyond SEG-Y in three ways: (1) it utilizes unused portions of SEG-Y headers for informaton unique to refraction data; (2) it extends the definition to organization within a disk file; and (3) it allows (but does not require) that data be stored with word formats other than the IBM real and integer formats defined in the industry standard.

Header definition: SEG-Y(LDS) maintains the two part file organization of standard SEG-Y in which a file header ( 3600 bytes long) is followed by seismic trace data blocks, each containing a 240-byte trace header. The last 340 bytes of the file header and the last 60 bytes of the trace header, which were undefined in original SEG-Y standard, are used in SEG-Y(LDS) for information relative to refraction data, such as shot times. The main additions are allowing storage of (1) flexible shot, receiver and line names, (2) more shot and receiver information, (3) more data word formats, and (4) different seismic sttributes. Comments within the code clearly indicate which items are unique to SEG-Y(LDS).

Disk storage: SEG-Y(LDS) has been adapted to disk storage primarily by GSC. The SEG-Y file contains a number of traces, each trace containing a number of data samples. File organizaton, as on tapes, consists of a single line header followed by data blocks containing trace headers. The file is a series of bytes with no logical record structure, and the bytes are defined as for tapes. A file structure without logical record structure allows easy access by most machines (all files must have a machine dependent physical record length, but on most machines this can be transparent to the user). For instance, on the PC, the bytes may easily be read in the C-language. Using the IBM PROFORT compiler the file must be opened for direct access with a chosen record length, then data must be read into a buffer in chunks with that record length. Because most sophisticated processing needs direct access to a particular trace, it is convenient to pad out all traces to the same length (and a minimum of 3600 bytes). When this is done easy direct access to bytes from FORTRAN is possible. Other institutions and users of other languages may ignore this restriction.

Data word formats: SEG-Y defines four data word formats. The actual format used is indicated by the contents of bytes 25-26 in the line header. For SEG-Y(LDS) we have chosen a fifth format to be the gain-ranged LUNCHBOX format utilized by GSC, and a sixth format to be VAX FORTRAN $R * 4$. Note that SEG-Y defines the byte organization within a 2-byte integer on a tape. This is opposite to that on the VAX and the P.C. Yet to be decided is which would 
be the most sensible ordering on disk. Currently, GSC is using the natural way for the VAX and PC, i.e., least significant byte is the first in a two byte integer. 


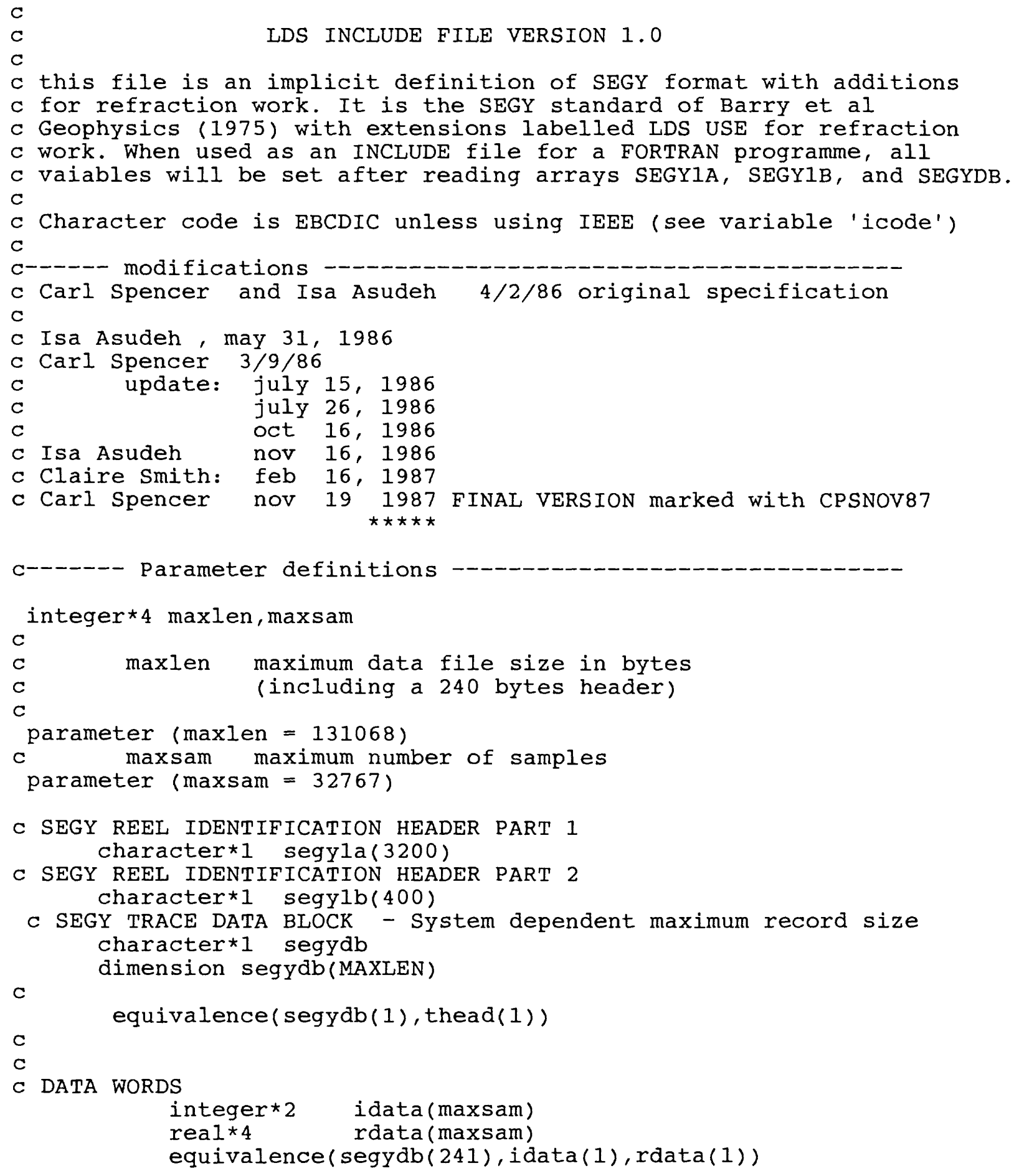




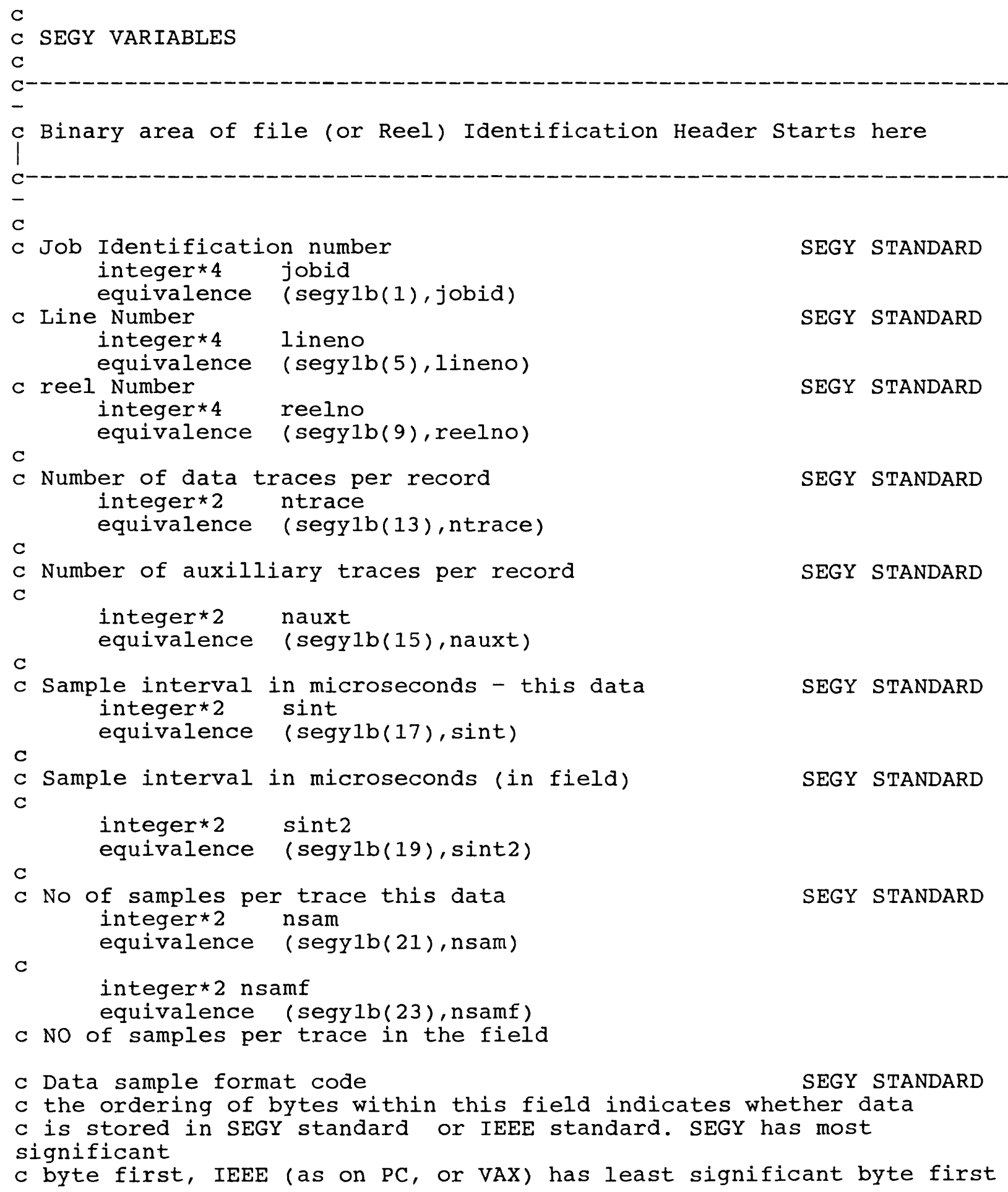

SEGY STANDARD

SEGY STANDARD

SEGY STANDARD

SEGY STANDARD

SEGY STANDARD

SEGY STANDARD 


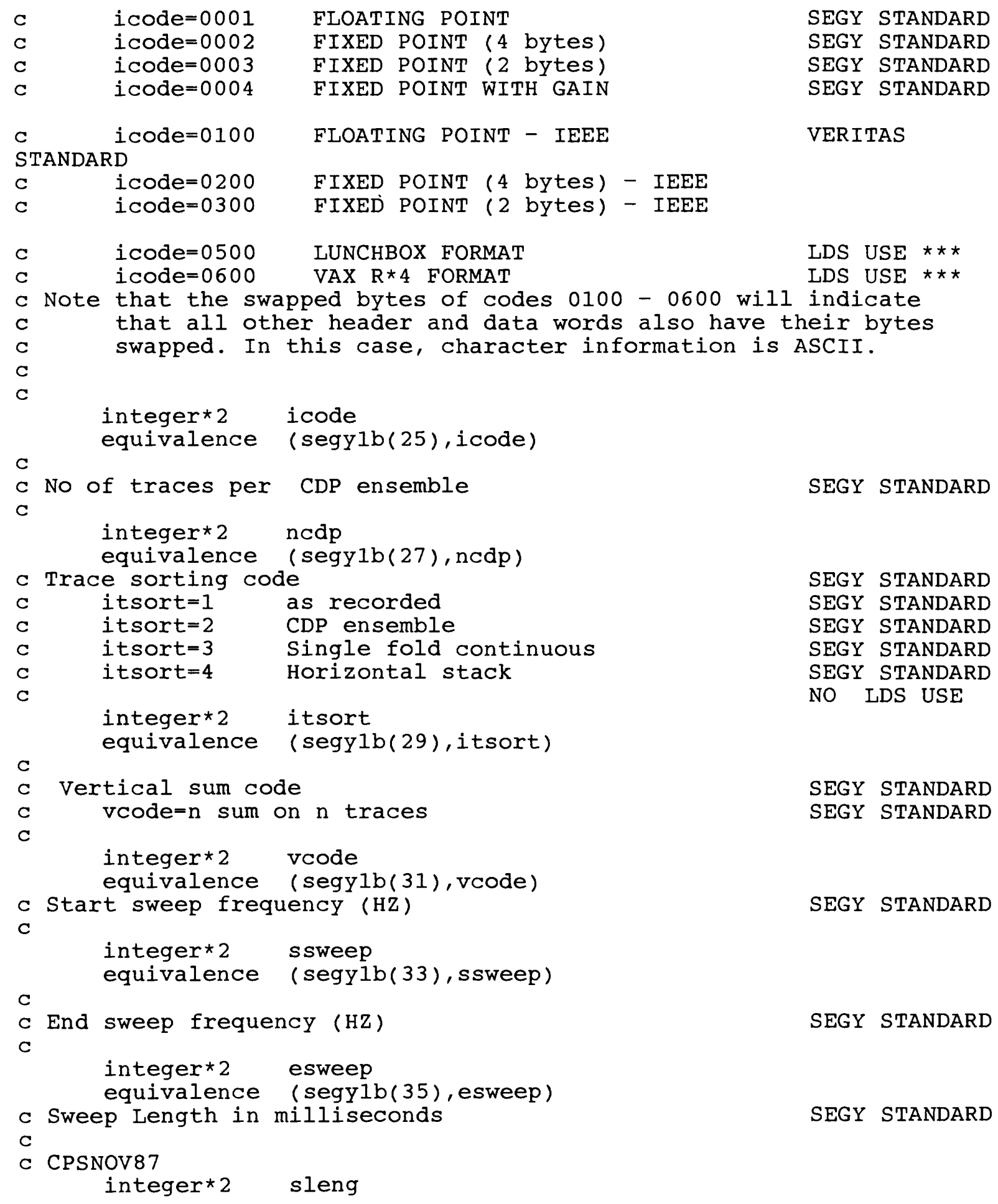




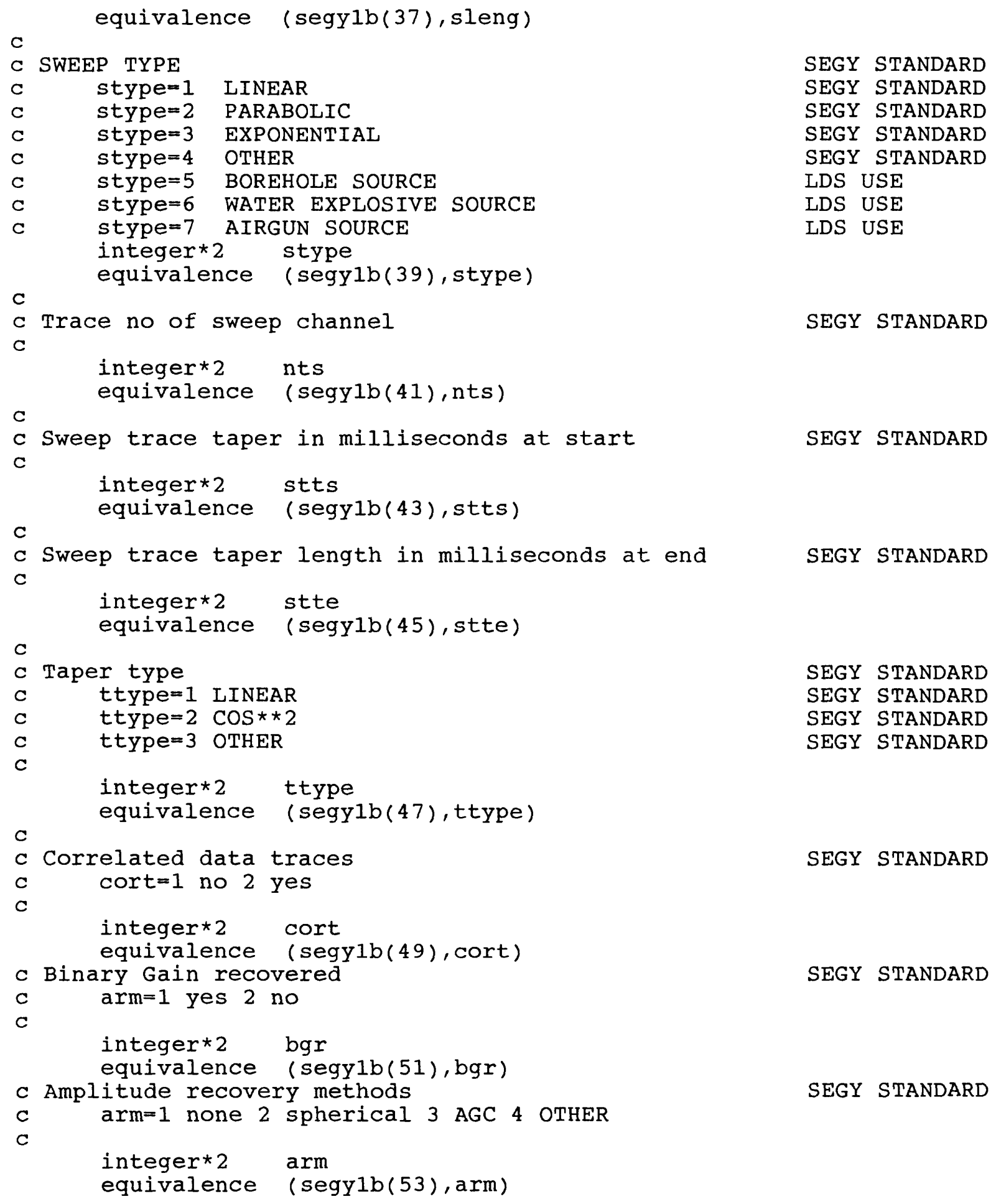




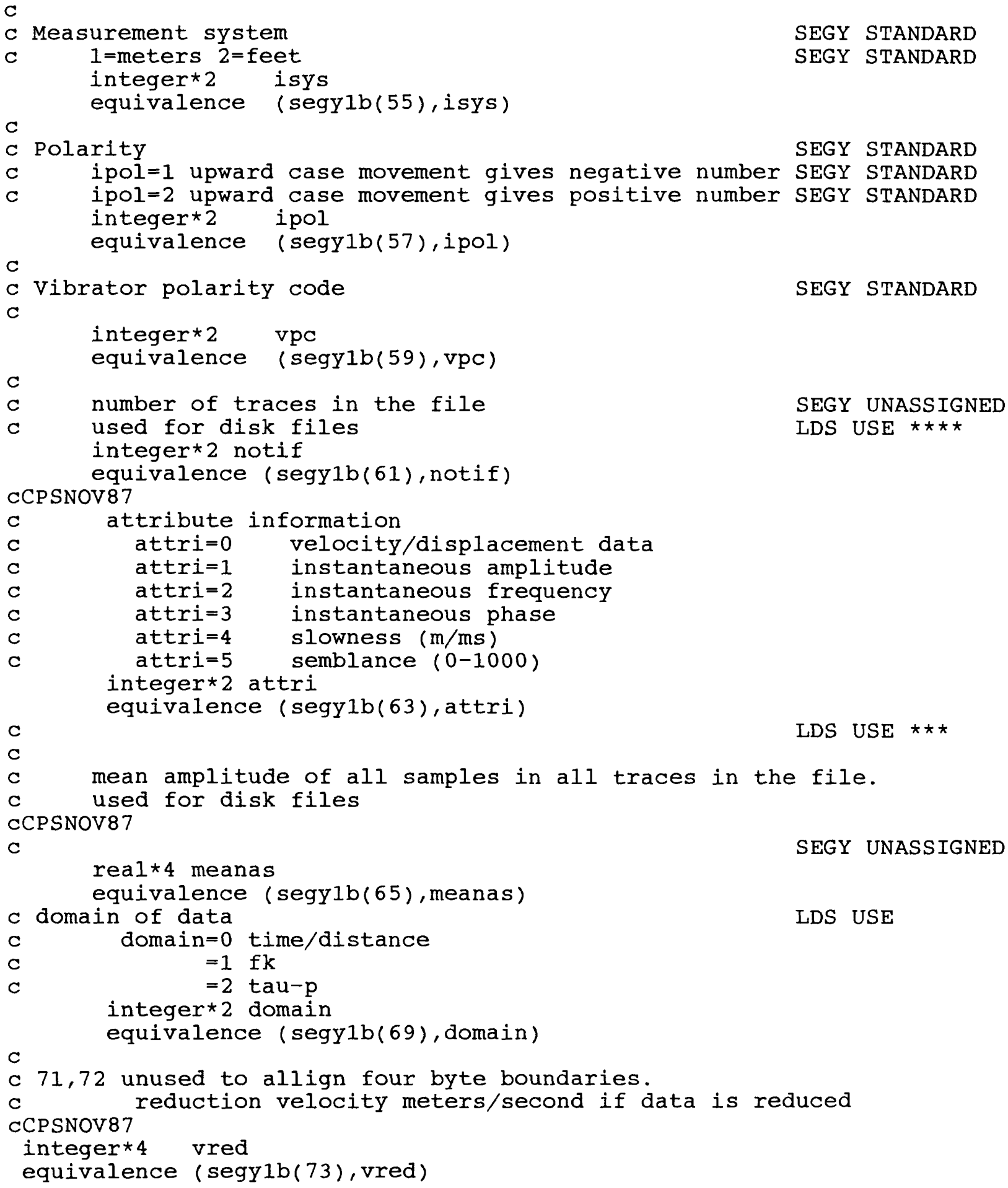




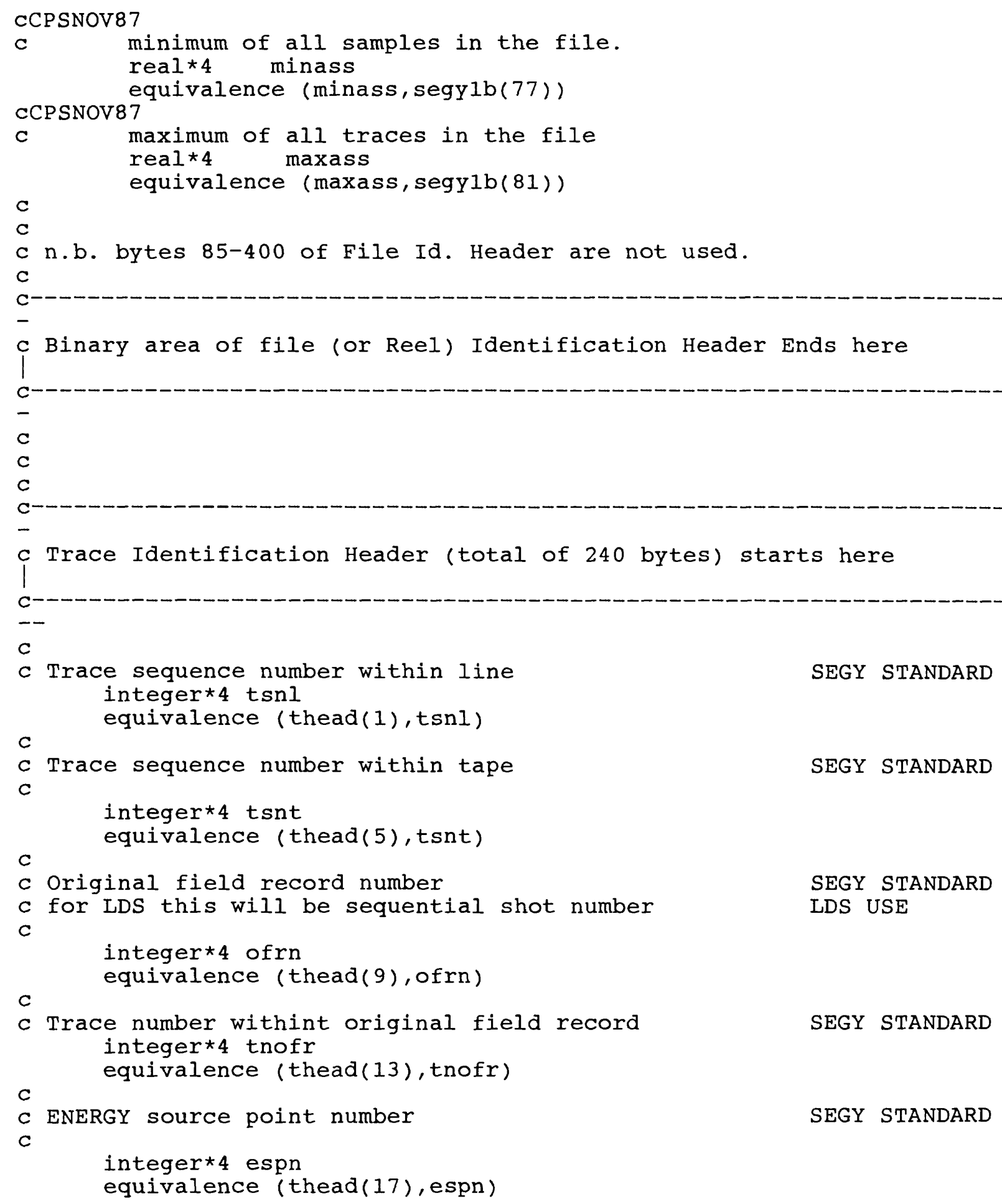

SEGY STANDARD

SEGY STANDARD

SEGY STANDARD

LDS USE

SEGY STANDARD

SEGY STANDARD 


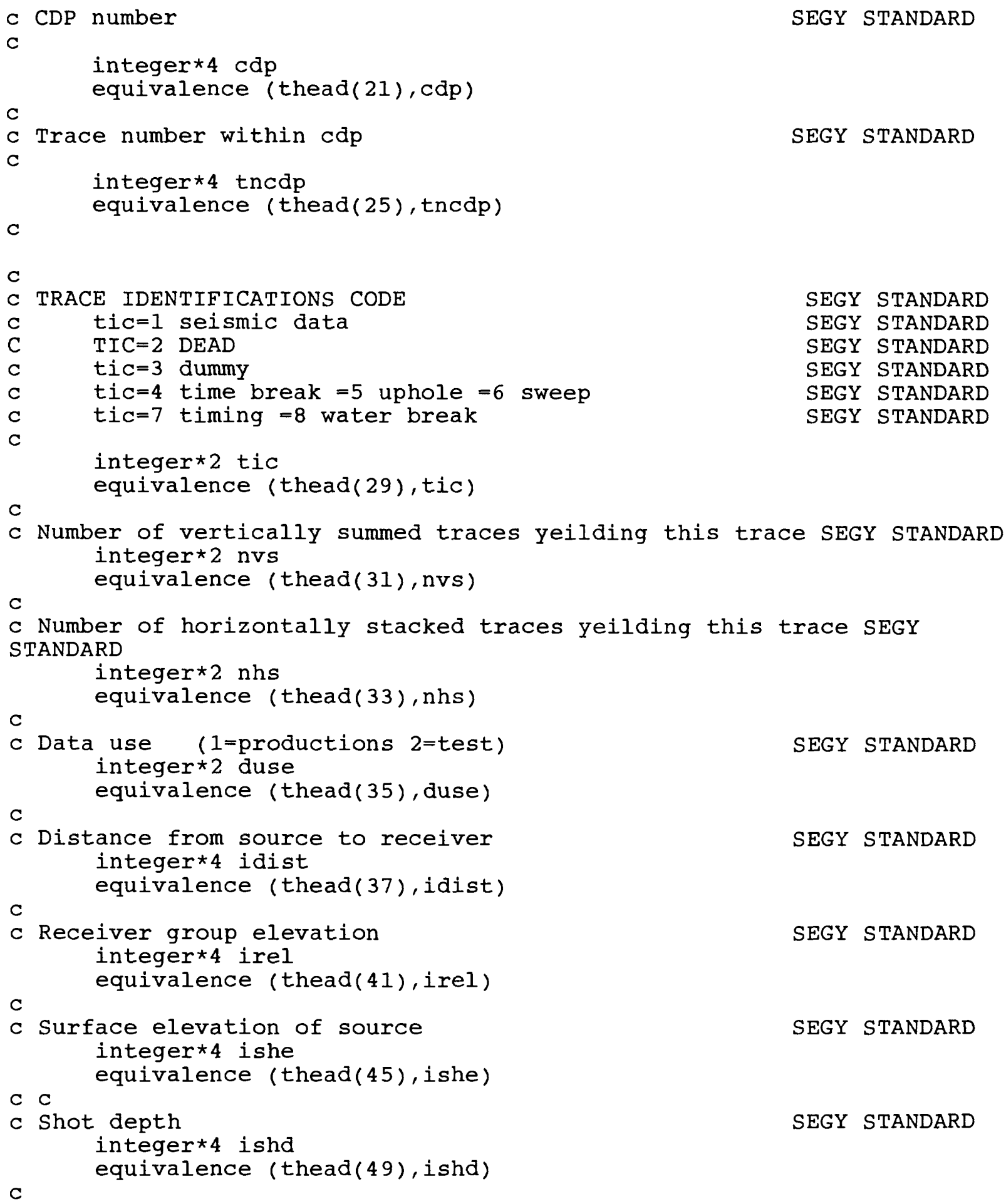


C

c Datum elevation at receiver

SEGY STANDARD

C

integer $* 4$ delr

equivalence (thead (53), delr)

C

Datum elevation at source

SEGY STANDARD

integer* 4 dels

equivalence (thead(57), dels)

C

c water depth at source

integer* 4 wds

equivalence (thead(61), wds)

SEGY STANDARD

C

C water depth at receiver integer $\star 4$ wdr equivalence (thead(65), wdr)

C

C Scalar multiplier/divisor (+/-) for bytes 41-68 integer* 2 smull. equivalence (thead(69), smul1)

C

C

C Scalar multiplier/divisor $(+/-)$ for bytes 73-88

C integer* 2 smul2 equivalence (thead(71), smul2)

C

Source coordinate $\mathrm{X}$ or Longitude (East positive) SEGY STANDARD integer* 4 ishlo equivalence (thead(73), ishlo)

C
Source coordinate $Y$ or Latitude (North positive) SEGY STANDARD integer $\star 4$ ishla equivalence (thead(77), ishla)

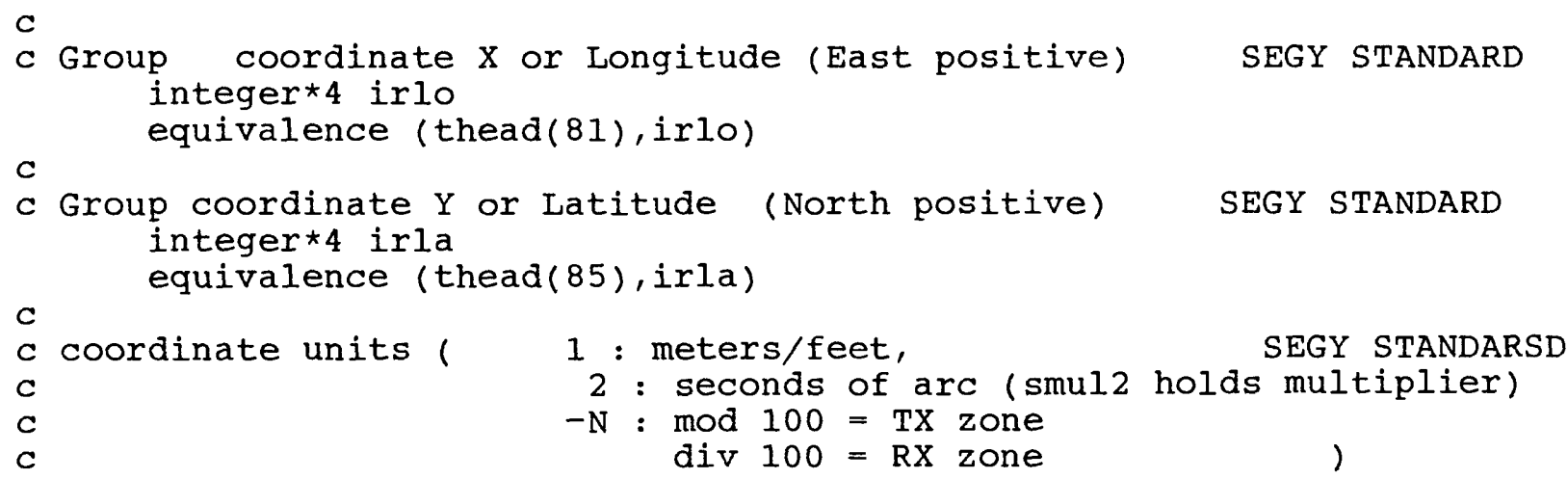




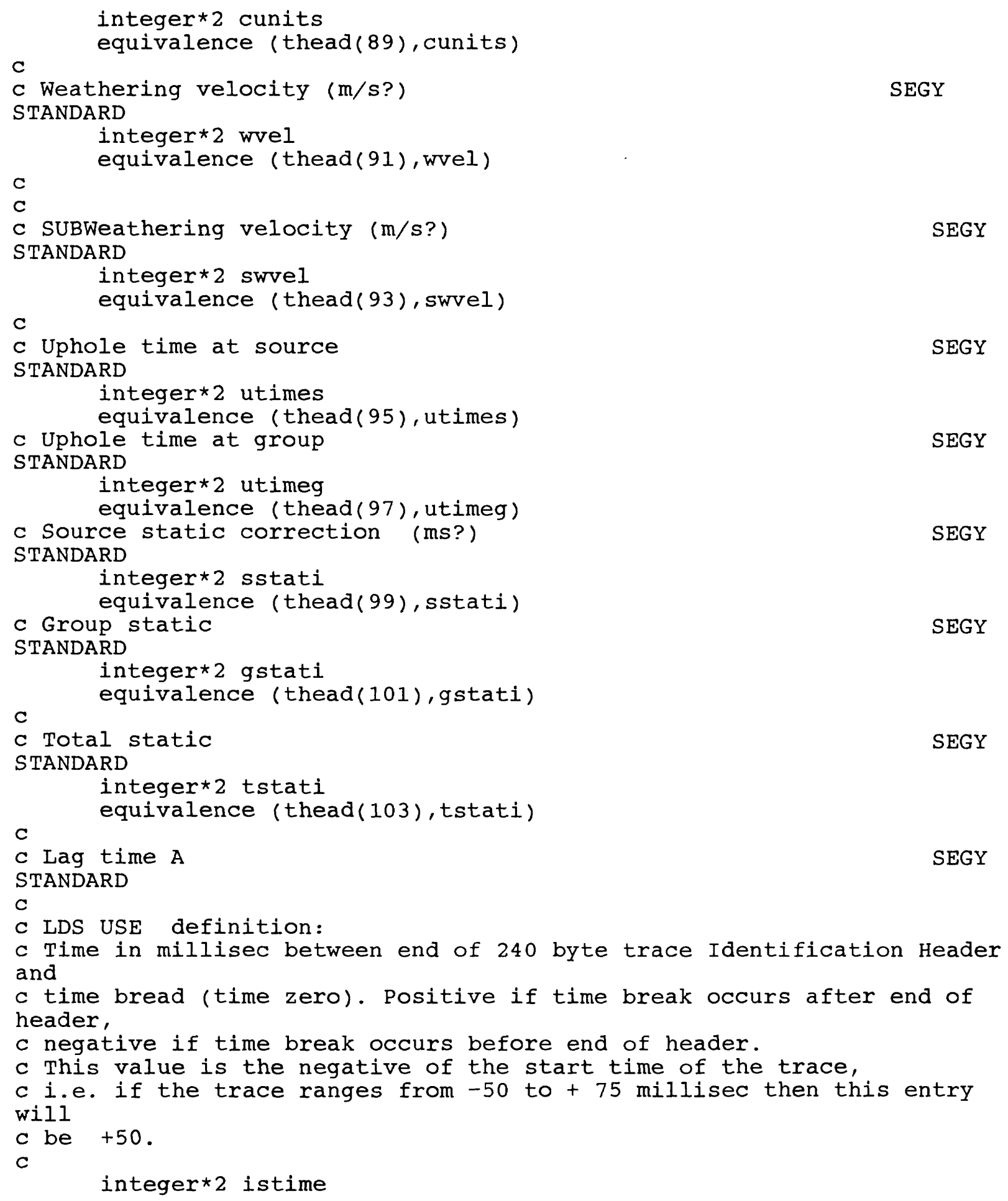




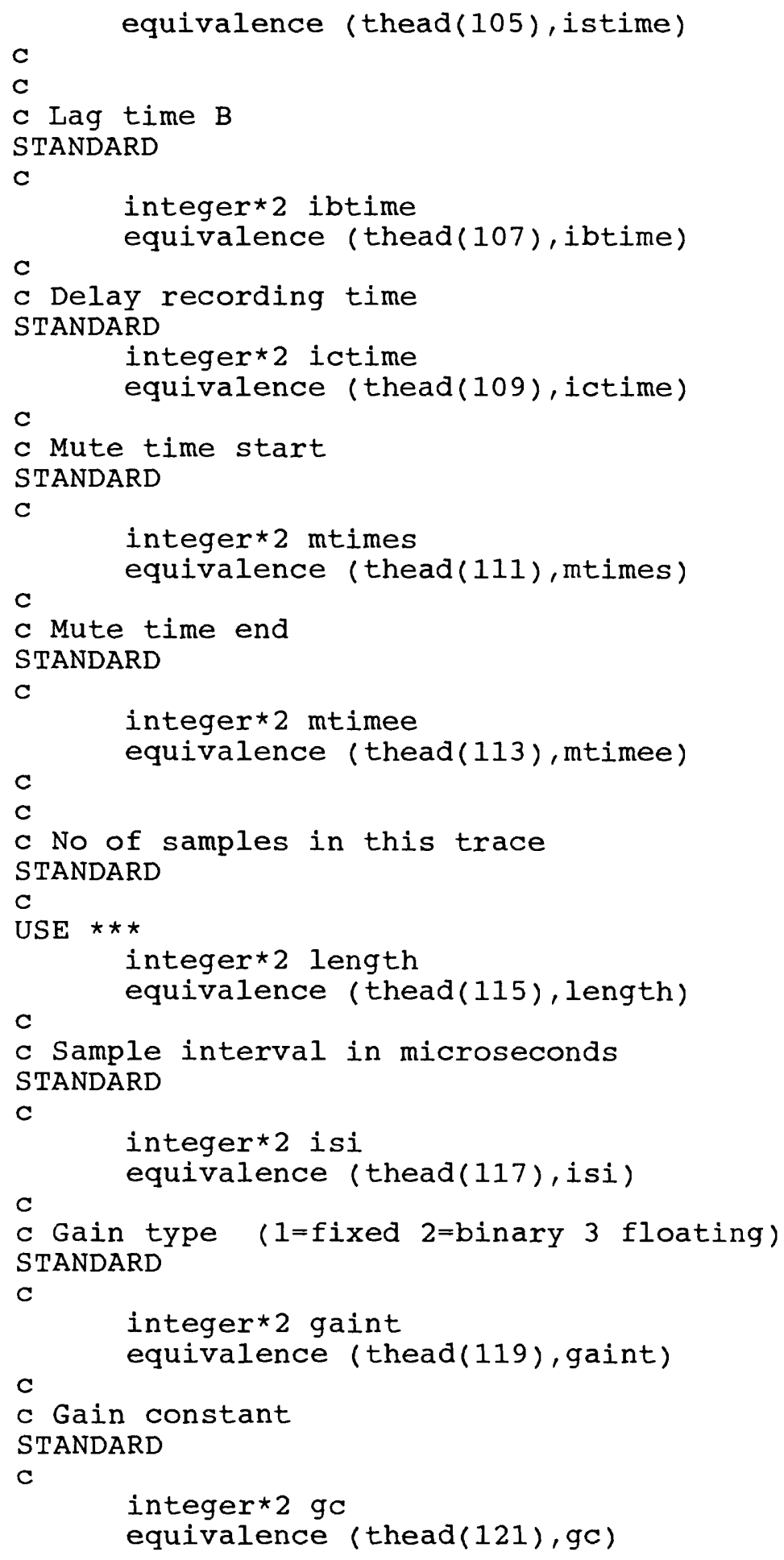


C

C Instrument or initial gain in $\mathrm{dB}$

SEGY

STANDARD

C

integer* 2 gidb

equivalence (thead(123), gidb)

c

c Correlated 1=no 2=yes

SEGY

STANDARD

C

integer* 2 tcorr

equivalence (thead(125), tcorr)

C

c start sweep frequency ( $\mathrm{HZ}$ )

SEGY STANDARD

integer $* 2$ tsswee

equivalence (thead(127), tsswee)

C

C End sweep frequency ( $\mathrm{HZ}$ )

SEGY STANDARD

integer*2 teswee

equivalence (thead(129), teswee)

c Sweep Length in milliseconds

SEGY STANDARD

C

integer* 2 tsleng

equivalence (thead(131), tsleng)

C

C SWEEP TYPE

C stype=1 LINEAR

c stype $=2$ PARABOLIC

c stype=3 EXPONENTIAL

C stype=4 OTHER

C StYpe $=5$ BOREHOLE SOURCE

C Stype=6 WATER EXPLOSIVE SOURCE

C stype=7 AIRGUN SOURCE

integer*2 tstype

equivalence (thead(133), tstype)

C

C

c Sweep trace taper in milliseconds at start

SEGY STANDARD

C

integer $* 2$ tstts

equivalence (thead(135), tstts)

C

C Sweep trace taper length in milliseconds at end

SEGY STANDARD

SEGY STANDARD

SEGY STANDARD

SEGY STANDARD

SEGY STANDARD

LDS USE

LDS USE

LDS USE

$\mathrm{C}$

integer*2 tstte

equivalence (thead(137), tstte)

C

c Taper type

c ttype=1 IINEAR

SEGY STANDARD

SEGY STANDARD 


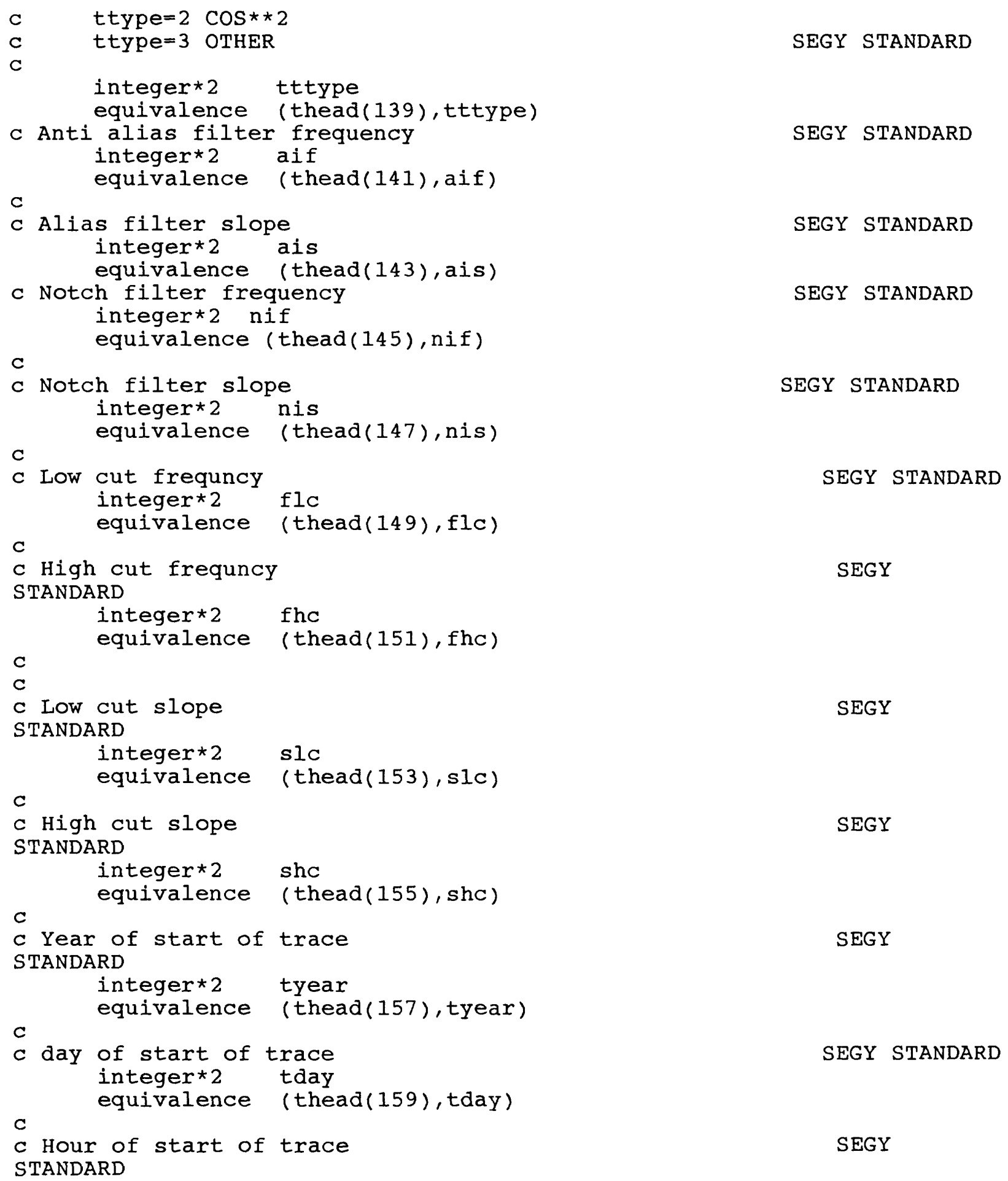




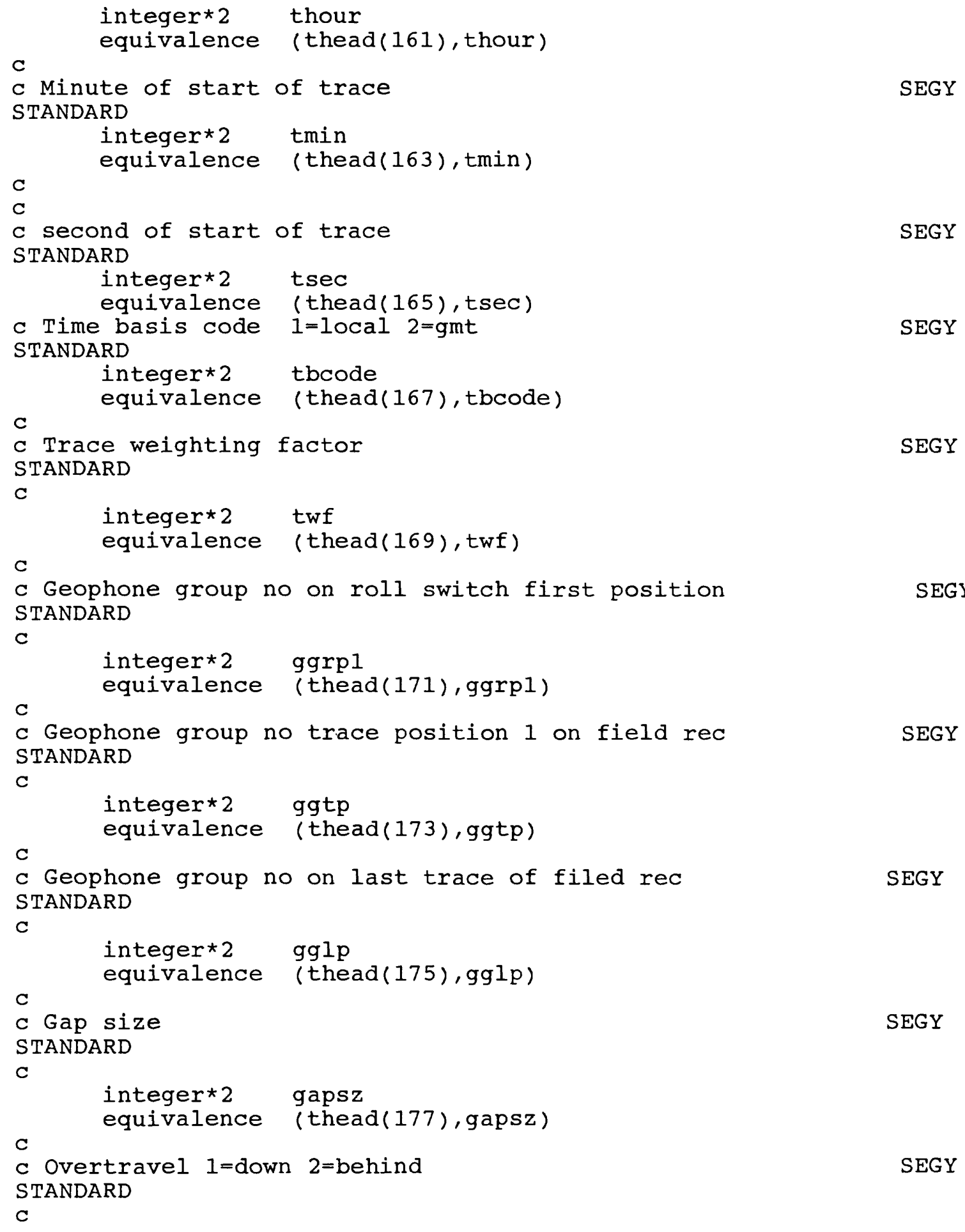




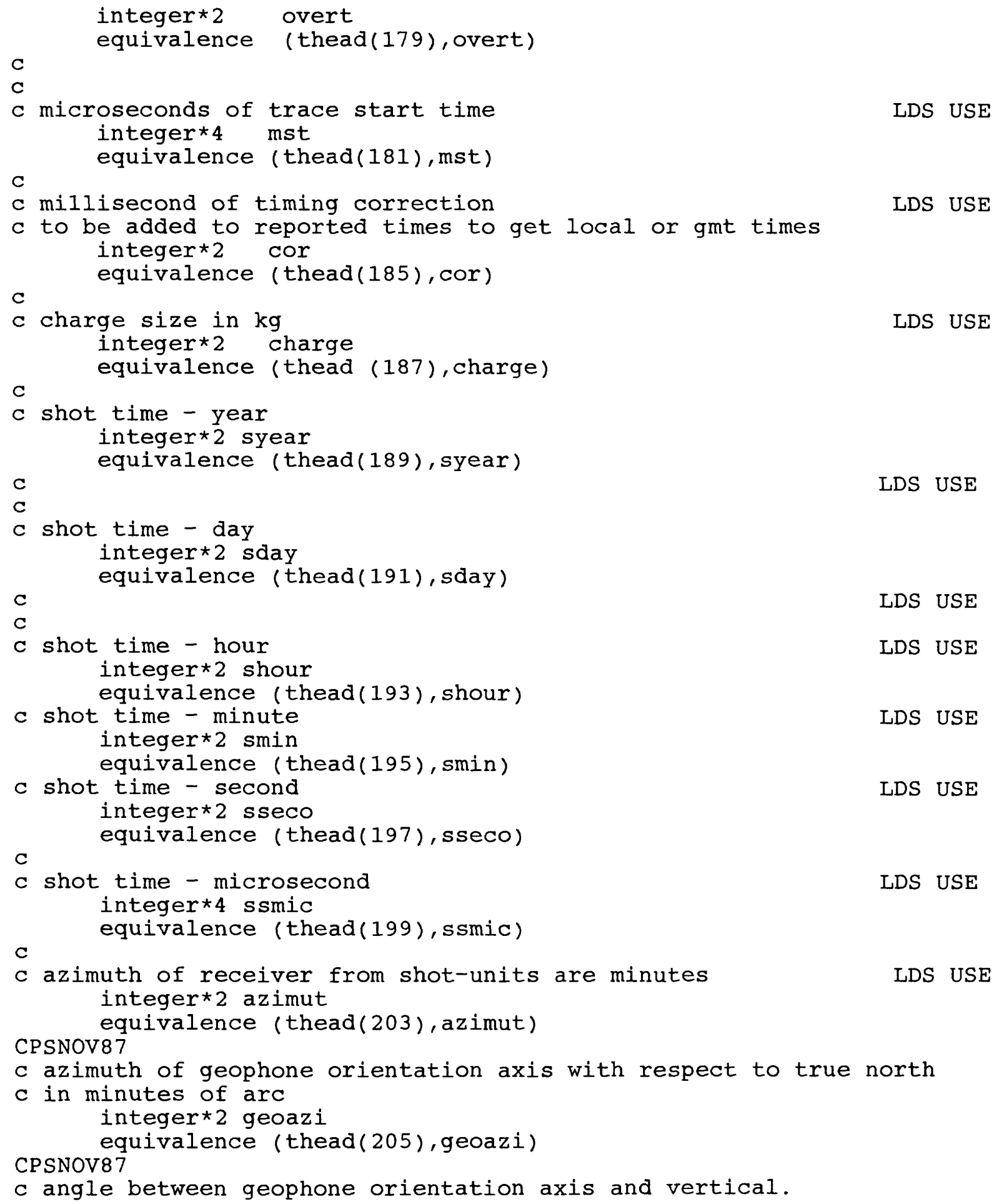




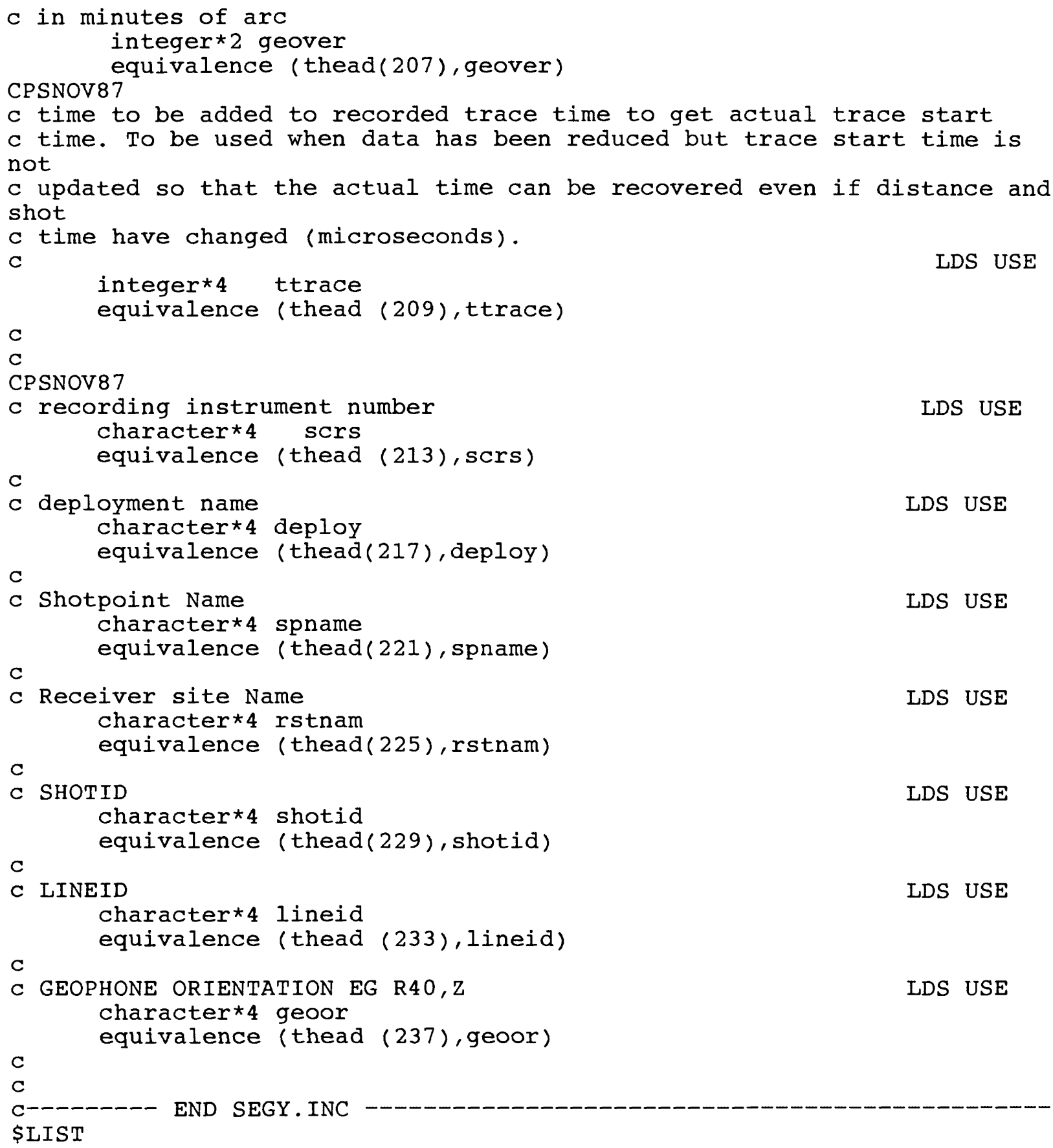

